\title{
Cryomilling as Environmentally Friendly Synthesis Route to Prepare Nanomaterials
}

\author{
Nirmal Kumar Katiyar ${ }^{1,2}$, Krishanu Biswas ${ }^{1 \#,}$ and C.S. Tiwary ${ }^{3}$ \\ ${ }^{1}$ Department of Materials Science \& Engineering, Indian Institute of \\ Technology Kanpur, Kanpur-208016, India \\ ${ }^{2}$ School of Engineering, London South Bank University, 103 Borough Road, \\ London, SE10 AA, UK \\ ${ }^{3}$ Department of Materials \& Metallurgical Engineering, Indian Institute of \\ Technology Kharagpur, Kharagpur-721302, India
}

\begin{abstract}
The milling of materials at cryogenic temperature has gained importance both in academic as well as the industrial community in the last two decades, primarily because of significant advantages this technique as compared to milling at room temperature; environmental friendly nature, cost-effectiveness, rapid grain refinement, less contamination, and large scale production capability of various nanomaterials. Scientifically, milling at cryo-temperature exhibits several distinct material related phenomena; suppression of recovery and recrystallization, predominant fractures over cold welding, significantly low oxidation, and contamination, leading to rapid grain refinement. Cryomilling has extensively been used to obtain finer scale powder of spices for the preservation of aroma, medicines for effective dissolution, or amorphization. It has been considered an environmentally friendly process as it utilizes benign liquid nitrogen or argon without discharging any toxic entity to the environment, making the process attractive and-sustainable. The present review is intended to provide various scientific as well as technological aspects of cryomilling, environmental impact, and future direction.
\end{abstract}


Keywords: Cryomilling Green synthesis, Nanoparticles, Metallic, Ceramic, Polymer, Composite, Spices, High purity, Free standing

\#Corresponding author, email: kbiswas@iitk.ac.in, phone:+91-5122596184, FAX:+915122597505 


\section{Contents}

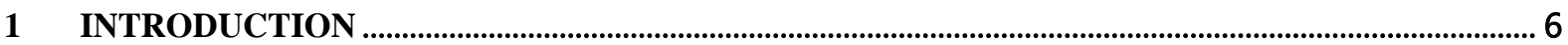

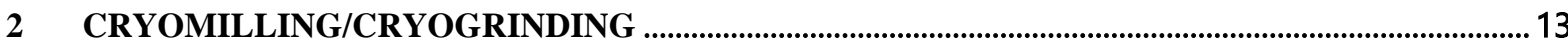

2.1 Mechanical Milling at Room Temperature vs. Cryogenic Temperature in Nanostructure

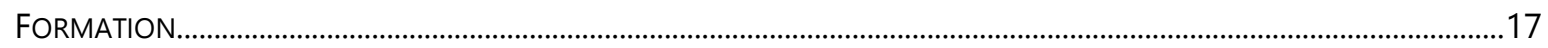

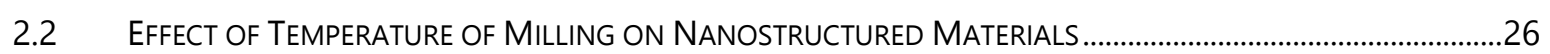

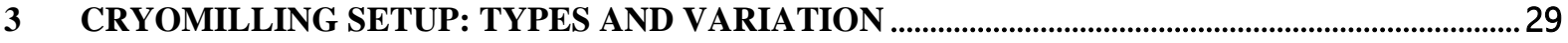

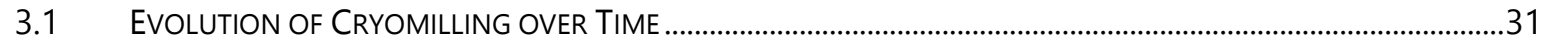

3.2 How to ACHIEVe CRyogenic Temperature With Different CRYO-LIQUIDS ..............................................33

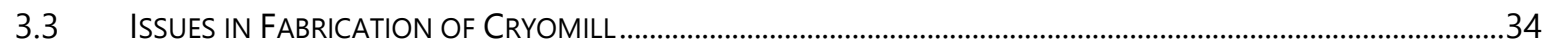

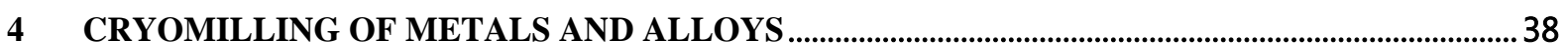

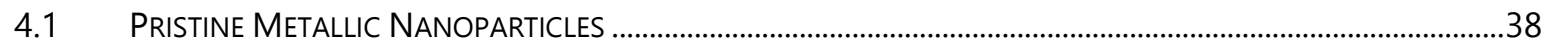

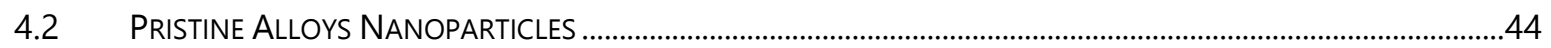

4.2.1 Nanoparticles from Cast and Homogenized Ingot .........................................................................44

N.3 NANOSTRUCTURED ALLOYS AND THEIR CONSOLIDATION................................................................................46

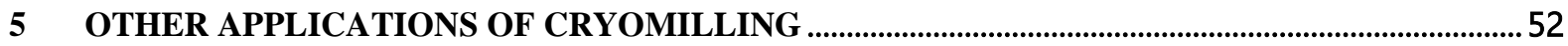

5.1 CRYOMILLING WITH IN-SITU SOLID-STATE REACTIONS...................................................................................5

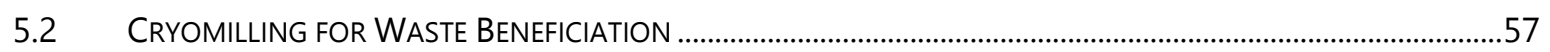

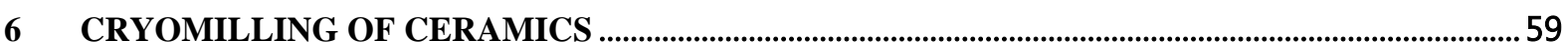

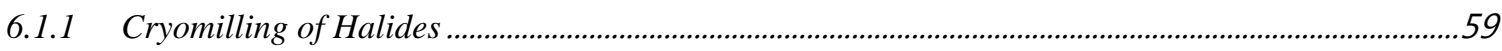

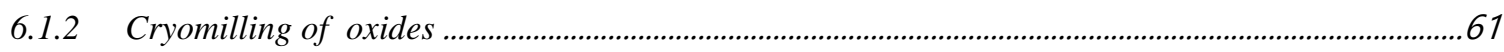

7 CRYOGRINDING OF POLYMER AND POLYMER-BASED COMPOSITES ....................................62

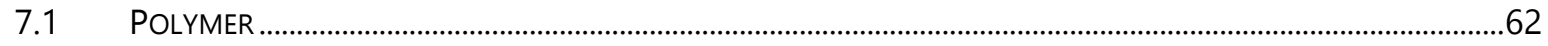

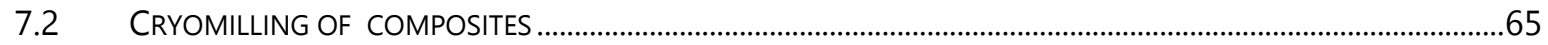

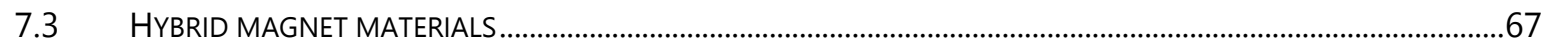

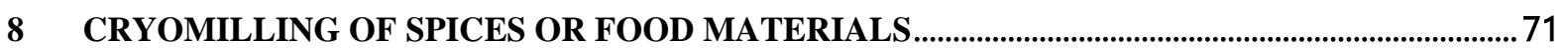

9 CRYOMILLING AS ENVIRONMENTALLY FRIENDLY SYNTHESIS ROUTE TO PREPARE

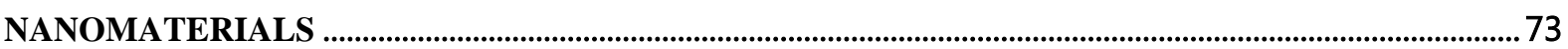

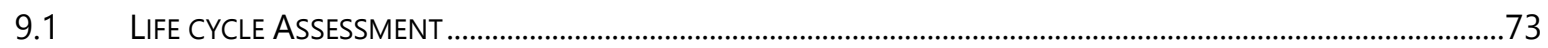

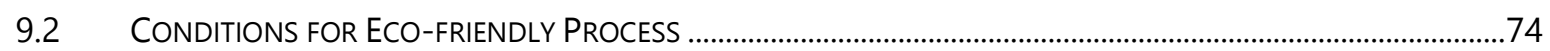

9.3 CRYOMILLING: WASTAGE VS. USE OF ECO-FRIENDLY MATERIALS .....................................................................75

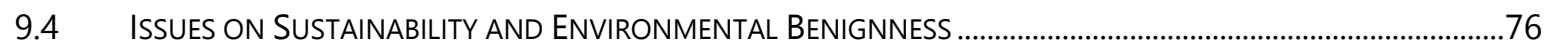

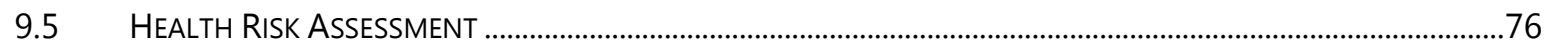

10 SCALE UP AND COST EFFECTIVENESS OF CRYOMILLING IN NANOMATERIAL

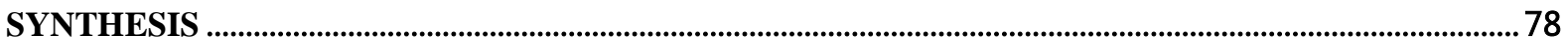

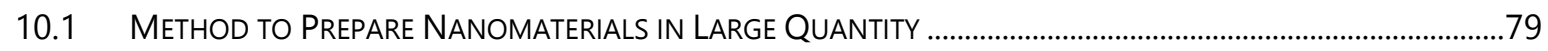

10.2 COST-EFFECTIVENESS OF THIS ROUTE VIS-A-VIA OTHER SPD PROCESSES …….............................................79

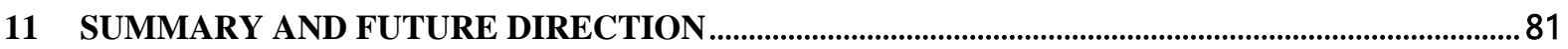




\section{Abbreviation}

DBTT

: Ductile -to-Brittle Transition Temperature

$d_{\min }$

:Minimum grain size

HEA

: High Entropy Alloy

NPs

: Nanoparticles

SAED

: Selected area electron diffraction

TEM

: Transmission electron microscope

SEM

: Scanning electron microscope

$\mathrm{LN}_{2}$

: Liquid Nitrogen

RT

: Room Temperature

MA

: Mechanical Alloying

SFE

: Stacking Fault Energy

SPD

: Severe Plastic Deformation

PCA

: Process Control Agent

CNTs

: Carbon nanotubes

UHMWPE : Ultra-high molecular weight polyethylene

PVC

: Polyvinyl Chloride

BP

: Boiling Point 


\section{List of Symbols}

$\begin{array}{ll}T_{m} & \text { Melting temperature } \\ T_{g} & \text { Glass transition temperature } \\ B & \text { Bulk modulus } \\ b & \text { Burger vector } \\ Q & \text { Self-diffusion activation energy } \\ Q_{p} & \text { Activation energy for pipe diffusion } \\ D_{p o} & \text { Pipe diffusion coefficient } \\ v_{o} & \text { Poisson's ratio } \\ \gamma & \text { Stacking fault energy } \\ y_{l} \text { and } y_{s} & \text { Surface tension of liquid and solid surface } \\ \rho & \text { Dislocation density } \\ G & \text { Shear Modulus } \\ H & \text { Hardness } \\ \Delta H_{m, o} & \text { Melting enthalpy } \\ d & \text { crystallite size } \\ \Omega & \text { Rate of dynamic recovery } \\ \Omega_{c s} & \text { Dynamic recovery cross slip } \\ \Omega_{v c} & \text { Dynamic recovery vacancy climb }\end{array}$




\section{Introduction}

Nanotechnology primarily involves the applications of novel nanomaterials for technological usage [1-5]. It has extensively revolutionized science and technology by combining various fields, including chemistry, physics, materials science and bioscience, and engineering. However, the major driver in the advancement of nanotechnology is the ability to successfully synthesize various nanomaterials in large quantities, so that the growing need for nanotechnology can be fulfilled $[\underline{2}, \underline{6}]$. The synthesis of nanomaterials, in general, is carried out by two broad approaches, viz, bottom-up, and top-down. The former involves the selfassembly of the materials component at the atomic-level to form nanostructures. Typical examples include chemical synthesis routes, laser ablation, atomic layer deposition, etc. [ $\underline{7}$, 8]. The latter approach starts with a large initial structure, which is subsequently processed to obtain nanostructures. Ball milling and other severe plastic deformation (SPD) processes fall under this category. The bottom-up methods, in general, begin with atoms or molecules to build up nanostructures, and thus, fabrication is less expensive. However, most of these involve the usage of hazardous chemicals; the precursors and the reducing/capping agents, making these processes environmentally not sustainable. In addition, the bottom-up approaches, in general, cannot be used for the preparation of nanomaterials in large quantities and hence, cannot satisfy the burgeoning need of nanotechnology. On the other hand, the topdown approaches can effectively be used for large scale production of nanomaterials. In particular, cryomilling is a type of top-down technique in which grinding is carried out at or below $-150^{\circ} \mathrm{C}$ by using liquid nitrogen $\left(\mathrm{LN}_{2}\right)$ or liquid argon (LAr). It is environmentally benign, and can be utilized to prepare all types of nanomaterials in large quantity [9-12]. As mentioned earlier, it also offers many advantages as compared to the conventional ball milling at RT (room temperature) or high temperature. Therefore, it is imperative to understand the basic process involved during cryomilling to make it technologically more 
useful, viable, and robust for the preparation of various nanomaterials, encompassing metals, ceramics, polymers, and composites.

Cryomilling/cryogrinding is a kind of mechanical milling process, carried out at a temperature lower than $123 \mathrm{~K}\left(-150^{\circ} \mathrm{C}\right)$. The cooling of any material before milling has always been considered as effective means to make it brittle and friable. Hence, it is useful to accelerate fracturing and extensively reduce cold welding or agglomeration of the powder. This can be achieved in two ways [13]. In the simple form, the powder to be milled along with the milling media, which is mixed with cryogenic liquid to prepare a cryogenic slurry, and ball milling is further performed. However, this may lead to contamination of the powder due to the direct contact of the cryogenic liquid with powder. Many metallic materials, including $\mathrm{Ti}, \mathrm{Zr}, \mathrm{Al}$ are prone to nitridation in the presence of nitrogen [13-15]. In the second approach, the powder and the milling media are externally cooled by placing a jacket of cryogenic liquid around the vial, so that the powder does not come in contact with the cryogenic liquid. The chance of contamination is thus low. However, it reduces efficiency of cooling of the powder due to poor heat transfer across the thick layer of the vial. In fact, this significantly depends on the nature of vial material. As compared to $\mathrm{WC}$ or $\mathrm{ZrO}_{2}$, the stainless-steel vials will be more useful in achieving faster cooling. Stainless steels being less hard, may lead to contamination of the milled powder. Therefore, the choice of vial and ball will depend on the type of material to be milled and the level of contamination that can be tolerated for a specific application.

Accordingly, different variants of the mills are present in the niche market for the synthesis of nanoparticles. First developed by Exxon Research, cryomills have been designed to cater the need to produce fine powders of metals, polymers, spices, and medicines[16]. The available cryomills include cryomill by RETSCH LTD (UK), cryogenic attritor by UNION PROCESS INC (USA), Goibao group (China), vibratory cryomill by FRITSCH GmbH (Germany), 
Aveka Inc. (USA) and Tau instruments (India). Other variants are also available in the food industry, which are basically cryo-grinders having two separate chambers, typically known as a precooling and grinding stage. The food or species is first cooled to extremely low temperatures in the precooled screw conveyer stage by $\mathrm{LN}_{2}$. The cooled item is then ground using a hammer mill. However, cryomills utilized for materials science and engineering are different as there is no precooling stage.

It is evident that the milling at cryogenic temperatures helps in many ways to obtain highquality nanomaterials, early fracture, rapid grain refinement, the lower oxidation rate of metallic materials, low contamination from the milling media, etc. $[\underline{13}, \underline{17}]$. Low temperature can effectively limit or even suppress the processes like recovery and recrystallization, making early grain refinement. It is evident, the most of the BCC, HCP metals, ceramics and polymers become brittle at the cryogenic temperature due to ductile to brittle transition or glass transition temperature of the materials [18]. Hence, these materials predominantly undergo fracture during cryomilling. For FCC metals (which do not exhibit specific DBTT), the plasticity decreases substantially, making fractures of these metals predominant. The cryo-milling can also suppress the cold welding, which is dominated in conventional room temperature mechanical milling, causing agglomeration [19]. Therefore, the suppression of the cold-welding leads to fracture dominated phenomena with much less agglomeration. Additionally, milling leads to an increase of dislocation density by several-fold as both recovery and recrystallization processes are suppressed at extremely low temperature [14, 20]. The major problem of nano-crystallization of metallic materials via milling is the incorporation of the contamination from the milling media as well as the atmosphere. Atmospheric oxygen can cause oxidation of the metallic nanoparticles at room and elevated temperature. The continuous milling can cause wear and tear of the balls and vials, leading to the incorporation of these materials into the milled powder. Longer milling, in general, 
adopted to obtain nanocrystalline particles for ductile materials, can cause a substantial level of contamination. In cryomilling, rapid nano-crystallization occurs as mentioned earlier, requiring relatively shorter milling time and hence less contamination. Another advantage of cryomilling is related to the fact that it does not need the use of process control agent (PCA), and hence, the chance of contamination is further reduced. In addition, the oxidation rate of metallic materials reduces substantially at an extremely low temperature [21]. Hence, it is evident; the cryomilling can substantially reduce the level of contamination in the milled powder. With these distinct advantages, cryomilling has become a true alternative to synthesize various nanostructured materials, opening vistas to design and development of novel nanostructures.

Cryomilling has extensively been used to prepare various metallic nanoparticles, viz., $\mathrm{Cu}, \mathrm{Fe}$, $\mathrm{Ni}, \mathrm{Al}, \mathrm{Zn}, \mathrm{Ag}$ as well as alloys, including Mg alloys (AZ80), high entropy alloys, etc.[12, 22-29]. It has been observed that quick milling at cryogenic temperature is enough to obtain a finer scale $(<10 \mathrm{~nm})$ nanoparticles of pure metals with narrow size distribution $[\underline{9-12,} \underline{30}]$. It allows achieving finer nanoparticles, which can easily free stand in various organic liquids (ethanol, methanol, benzene, ethylene glycol, etc.) for a sufficiently long time, even several months $[\underline{10}, \underline{30}, \underline{31}]$. Hence, milling at cryogenic temperature has been reported in the literature to be an effective method to synthesize nanoscale free-standing NPs in large quantities without using any PCA or capping agents. Especially $\mathrm{Cu}$ and Ag NPs, are potential candidates for various applications, notably flexible electronics [32], health care, antifouling coating for ship hulls [33], door panels, mattresses in hospitals and nanofluids in heat exchangers [34-37]. Some of these applications have already been realized. There exists sufficient literature on the efficacy of cryomilling on the synthesis of finer nanoparticles either using attritor or vibratory ball milling in dry or wet milling conditions. The detailed study on the dispersion of the metallic nanoparticles reveals the strong Van der Waals 
interaction between the organic molecule and low co-ordinated atoms sitting on the surface of the nanoparticles, overcoming the tendency of agglomeration via collision due to Brownian motion $[\underline{38}, \underline{39}]$. This is significant in a sense it would allow designing various metallic dispersions in liquids by controlling the surface characteristics of the nanoparticles. Unlike, room temperature milling, cryomilling cannot be used to prepare alloy nanoparticles by blending individual powder mixture and milling at cryogenic temperature. Extremely low temperatures can make interdiffusion among powder particles virtually impossible, and hence, alloying among powder particles is not possible at all. However, alloy nanoparticles can be synthesized by crushing the alloy ingots prepared via the melting-casting route at a cryogenic temperature [12]. Extremely low temperatures can be used to reduce ductility to make the cast ingots friable so that nanoparticles can be prepared via cryogenic grinding. This has opened up new vistas to obtain nanoparticles of various alloy with extremely low contamination levels for a large number of applications [11].

The detailed literature survey reveals that the cryomilling is not limited to the metallic materials. It has a wide area of usages, including polymers, ceramics, biomaterials, spices, pharmaceuticals, etc. [40-50]. Cryomilling, in different variants, has widely been utilized to prepare nanostructured polymeric as well as ceramic and composite materials [느, $\underline{48}, \underline{51-53}]$. An important variant, cryogenic grinding, employs cryogenic cooling of polymers to embrittle and grind for obtaining nanoparticles in a wide range of applications. Notable examples include polyvinyl chloride (PVC), nylon, polyethylene, synthetic rubber as adhesive, coating filler, molds, etc. [54, 55]. It effectively avoids excessive temperature enhancement, which degrades the properties of the materials or even leads to the melting of some polymers. Cryogenic grinding has even been used to reduce bulk materials into smallsized particles. Some of the polymeric materials remain plastic and soft at ambient temperature. Hence, cooling down to cryogenic temperature embrittle them and easy to grind 
into fine sizes. As many polymers are amorphous, cooling below glass transition temperature $\left(T_{g}\right)$ also makes them brittle and friable. The cryogenic cooling allows the temperature control to prevent hazardous decomposition in the high energy environment of the mill. The watersensitive polymers can easily be cryomilled because $\mathrm{LN}_{2}$ expands almost 700 times in volume during gasification. It is enough to replace other gases in the chamber, including water vapor quickly. The extremely low-temperature allows the blending of LDPE (lowdensity polyethylene) and UHMWPE (ultra-high molecular weight polyethylene) for the synthesis of nanocomposite coating [56]. The cryomilling has also be used for waste beneficiation for electronics waste (e-waste), plastic rich automotive waste [ $\underline{57}, \underline{58}$. Similarly, cryomilling has extensively been used to synthesize nanoscaled ceramic and

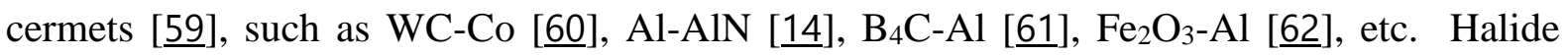
nanocrystals $(\mathrm{NaCl}, \mathrm{KCl}, \mathrm{CsCl})$ can be obtained via cryomilling [63-65]. Cryogenic cooling will restrain the mechanochemical reactions between the metal and ceramic, and hence, the integrity of the interface can be maintained.

The mechano-chemical process at cryogenic temperature has effectively been utilized for the production of nano-sized powders of various important commercial ceramics, as mentioned earlier. Nanostructured ceramics are expected to provide property enhancement for different applications. Cryomilling has also been used to accomplish higher dispersion of carbon nanotubes (CNTs), carbon blacks, graphene, or even particulates in polymeric matrices without modifying their surface properties by using hazardous chemicals [46]. Because of the high aspect ratio, homogeneously dispersion of the second phase particles, which are desired various applications into a matrix, is a major hindrance in accomplishing the full potential of CNT based composites. Dispersion has been reported to increase substantially via cryomilling. 
Additionally, it is important to note that cryomilling has increasingly been used in medical applications. Milling at cryogenic temperature can lead to the amorphization (full or partial)of drugs, enhancing their fast dissolution [66]. Cryo milling using liquid nitrogen $\left(\mathrm{LN}_{2}\right.$ milling) has been reported to grind phenytoin, improving its dissolution rate $[\underline{67}, \underline{68}]$. This drug is considered to be poor water-soluble and needed to be pulverized for the enhancement of the dissolution rate [66]. The pulverization at low temperatures can even reduce the agglomeration of tiny drug particles due to the development of electrostatic charges over surfaces, mechanochemical surface defects, and changes in other physicochemical properties [69]. In the case of food science, the cryogenic grinding is a promising way to tackle damage of the ingredients such as essential oil, lipid, crude protein, starch, non-volatile ether extract, moisture, piperine, etc. and preserve the essential food values [70].

As mentioned earlier, cryomilling is considered as an environmentally friendly (eco-friendly) manufacturing process to prepare NPs of a variety of materials in large quantities. It is worth to mention that the research activities in the last few decades have been dedicated to developing eco-friendly processes (also known as green synthesis processes), for the preparation of NPs, with no usage of the hazardous chemicals [11, 71-76]. Fundamentally, any synthesis process needs to satisfy certain conditions to be called the green synthesis process [77]. These primarily include maximization of output yield and generate products, side products that possess no toxicity to the environment and human health. Hence, the researchers have made significant efforts to develop the green process with high yields and production capability of NPs. In this regard, most of the biologically assisted processes are green synthesis processes $[\underline{72}, \underline{73}, \underline{78}]$. However, these processes suffer from a lack of yield $[\underline{73}, \underline{76}]$. The commonly used chemical synthesis routes for NPs reported in the literature utilizes hazardous chemical with drainage of hazardous wastage and low yield. On the other 
hand, cryomilling utilizes $\mathrm{LN}_{2}$ with no hazardous discharge to prepare metallic, ceramic as well as polymeric nanoparticles. Hence, it can be called a green synthesis technique, sustainable and capable of scaling up.

In this background, the present review intends to provide an in-depth scientific understanding of the process of cryomilling, its environmentally benign nature, and technological applications to obtain various nanomaterials; metallic, ceramic, polymeric, composites, medicinal, food. The process of cryomilling, unlike its room temperature counterpart, has not been discussed in detail in the literature. Starting with basic aspects of cryomilling, design, and development of cryomills, the effectiveness of cryomilling as compared to room temperature milling to obtain better quality (size control, contamination-free) nanomaterials have been dealt with in details. Finally, the cryomilling is an environmentally friendly process, which makes this process unique as compared to other routes to prepare nanomaterials. It is discussed from the perspective of the benign nature of chemical $\left(\mathrm{LN}_{2}\right)$, almost zero discharge of dangerous chemicals, high efficiency, and scale-up. As compared to bottom approaches, the cryomilling process is capable of preparation nanomaterials from laboratory scale to industrial scale $[\underline{11}, \underline{62}, \underline{79}]$.

\section{Cryomilling/Cryogrinding}

"Cryo" is a Greek word, meaning the extremely low temperature. Therefore, the word "cryomilling” indicates mechanical milling or grinding at extremely low temperature, preferably below $123 \mathrm{~K}$ or $-150^{\circ} \mathrm{C}$. It is well known that the process of mechanical milling reduces the particle size, leading to the formation of the nanocrystalline and amorphous materials. Extremely low temperature allows easy and rapid fracture of the particles, significantly reducing the time of milling, oxidation, and contamination. In the following, we shall discuss the process of cryomilling/cryogrinding $\mathrm{s}$ in detail. 
As mentioned earlier, cryomilling/cryogrinding is a kind of mechanical milling process, carried out at a temperature lower than $123 \mathrm{~K}$. Cooling of material has been used effective means to make the materials brittle and friable, accelerating fracture and reducing cold welding as well as an agglomeration of the powder. $[\underline{19}, \underline{80}, \underline{81]}$. In the simplest form, the powder to be milled along with milling media are mixed with cryogenic liquid to prepare a cryogenic slurry, and mechanical milling is subsequently performed. It is widely known as the pulverization process or mechanical grinding at extremely low temperatures. This is termed as wet cryomilling.

However, this may lead to contamination of powder due to direct contact of the cryogenic liquid with powder. Many metallic materials, including $\mathrm{Ti}, \mathrm{Zr}, \mathrm{Al}$, are prone to nitridation in the presence of nitrogen $[\underline{20}, \underline{82}, \underline{83}]$. In the second approach, the powder and the milling media are externally cooled by placing a jacket of cryogenic liquid around the vial so that the powder does not come in contact with the cryogenic liquid, and a chance of contamination is low. This is called dry cryomilling. In principle, various cryogenic liquids, including liquid helium (boiling point $(\mathrm{BP}) \sim 4 \mathrm{~K})$, liquid oxygen $(\mathrm{BP} \sim 90 \mathrm{~K})$, liquid argon $(\mathrm{BP} \sim 87 \mathrm{~K})$, liquid neon $(\mathrm{BP} \sim 27 \mathrm{~K})$ and liquid nitrogen $(\mathrm{BP} \sim 77 \mathrm{~K})$ can be used. However, in practice, both liquid argon (LAr) and liquid nitrogen $\left(\mathrm{LN}_{2}\right)$ are widely used due to availability, benign nature, ease of handling, and cost-effectiveness. $\mathrm{LN}_{2}$ has been utilized as a cryogenic liquid in most of the investigations reported in the literature $[\underline{13}, \underline{17}, \underline{79}]$.

Accordingly, there exist different designs of cryomill to serve varying purposes of a gamut of applications. For spices, in general, a hammer mill is used to pulverize the pre-cooled spices. This allows rapid refinement of the spices, retaining of aroma (volatile etheric oils, providing taste in the spices) as well as maintenance of health and hygiene of the spices [84]. The cryomills in the pharmaceutical industries utilize sophisticated mills such as fluid energy 
impact mills (e.g., fluidized bed jet mills and spiral jet mills) to obtain narrow size distribution nanoparticles. There are many laboratory-scale cryomills available for different materials; metals, alloys, ceramics, and polymer, and composites details. The details are provided in Table 1. Each cryomill has a unique work principle and capacity. Some cryomills also can be assembled or altered to different capacities. More details of different mills are discussed in section 3 .

Table 1: Different types of cryomill in the niche market

\begin{tabular}{|c|c|c|c|}
\hline Company & Model Name & details & Reference \\
\hline $\begin{array}{l}\text { Union process } \\
\text { laboratory (USA) }\end{array}$ & $\begin{array}{l}\text { Cryogenic } \\
\text { grinding system }\end{array}$ & An Attritor type cryomill. & [85] \\
\hline Retsch (UK) & Mixer Cryomill & $\begin{array}{l}\text { Mechanical shaking or radial } \\
\text { oscillations in a horizontal position. }\end{array}$ & {$[\underline{86}]$} \\
\hline SPEX (USA) & $\begin{array}{l}\text { CentiPrep Freezer } \\
\text { Mill }\end{array}$ & $\begin{array}{l}\text { Milling tools:-hardened steel, stainless } \\
\text { steel, zirconium oxide, PTFE with } \\
\text { different size or capacity. }\end{array}$ & [87] \\
\hline $\begin{array}{l}\text { Tau Instrument } \\
\text { (India) }\end{array}$ & Cryomill KC (0) & $\begin{array}{l}\text { Planetary Ball Mill Machine } \\
\text { Milling Tools: hardened steel, } \\
\text { Tungsten carbide with different sizes } \\
\text { of ball and vials. }\end{array}$ & [88] \\
\hline $\begin{array}{l}\text { Fritsch }(\mathrm{GmbH}) \text {, } \\
\text { Germany }\end{array}$ & Cryomill $\mathrm{P}(0)$ & $\begin{array}{l}\text { Vibratory Micro Mill } \\
\text { PULVERISETTE } 0 \\
\text { Milling tools: Agate, sintered } \\
\text { corundum, zirconium oxide, stainless } \\
\text { steel, hardened steel, hard metal } \\
\text { tungsten carbide }\end{array}$ & [89] \\
\hline
\end{tabular}




\begin{tabular}{|l|l|l|l|}
\hline & & & \\
\hline CIPHET & Custom-built & pre-cooling and low-temperature & [84] \\
Ludhiyana (India) & & grinder (two-step cryo-grinder) for & \\
& & spices & \\
& & & \\
\hline
\end{tabular}

Cryomilling has extensive been utilized for medicinal purposes. One of the major advantages of mechanical milling at an extremely low temperature is rapid refinements (canonization), leading to dispersion stability of the drugs due to the enhanced surface area to volume ratio. It is worth mentioning that the dispersion stability of drug molecules in solution is the primary requirement in health applications [90]. Similarly, the mechanical milling enhances the amorphization of the drugs, leading to faster dissolution capability of drugs [66]. Extremely low temperatures can protect them against reverting in the crystallinity form during subsequent milling. The drugs are in a frozen state during cryomilling, protecting them from chemical degradation as compared to room temperature milling. However, the process is reported to lead to many undesirable issues on medicinal ingredients such as agglomeration of tiny particles, development of electrostatic charges over surfaces of the tiny particles, mechano-chemical surface defects, and changes in other physicochemical properties. This significantly affects the physical stability of the medicinal powders. Similarly, the milling of polymeric materials at cryogenic temperature can lead to fine and homogeneous powder formation. The thermosetting/thermoplastic polymer easily can be ground to fine particles utilizing less energy because the low temperature is expected to reduce the clogging and gumming of polymer materials. The pliable and sticky materials are easy to grind to obtain fine powder using efficient milling at cryo-temperature. The explosive materials also can be milled below their ignition temperature. 


\subsection{Mechanical Milling at Room Temperature vs. Cryogenic Temperature in Nanostructure Formation}

The mechanical milling at room temperature has widely been utilized for the synthesis of various nanostructured materials. Extensive literature is available on the formation of nanostructure or amorphous material; metals, alloys, ceramics, etc.[13, 91-94]. The main differences in nanostructures formation associated with the cryomilling are the suppression of cold welding phenomena, predominant fracturing as compared to plastic deformation, and suppression of recovery and recrystallization process, extremely low or no oxidation. Since the invention of mechanical alloying by J. S. Benjamin, in 1968 [91, 92], the mechanical alloying (MA) or mechanical milling (MM) at room temperature has been discussed in details and reader can refer to special reviews on this aspect $[\underline{13}, \underline{79}, \underline{95}, \underline{96}]$. It is evident the friction/collision of balls with milling materials and walls of the vials increases the temperature of the system as well as materials, which has been considered an obstacle in the refinement of materials [97]. This is because various properties of materials, especially mechanical properties, are strongly dependent on the temperature. Takacs et al. have measured the temperature rise of SPEX 8000 and Fritsch P5 Planetary mills during milling, shown in Figure 1(a-b). In the former, the temperature can reach more than $60^{\circ} \mathrm{C}$ within 20 minutes of the milling. Similarly, temperature could increase even $>200^{\circ} \mathrm{C}$ in Fritsch P5 planetary ball mill rotating at $280 \mathrm{rpm}[\underline{97}]$. The temperature rise is sufficient for dynamic recovery, recrystallization, and sintering for some materials during milling. Therefore, the grain refinement can be achieved to a certain size $\left(d_{\min }\right)$ during ball milling, and it is not possible to reduce further due to recovery and sintering dominant phenomena, dependent on temperature and grain size. Fecht et al.[19] have suggested that achieving minimum grain size during mechanical milling is the result of a balance between dislocation structure generated by the severe deformation of mechanical milling and its dynamic recovery by 
thermal processes. It is worth adding that mechanical milling, in general, has been reported to produce nanocrystalline materials via five stages; particles flattening, cold welding, fracture, equiaxed particles formation, and steady-state particles formation to achieve nanocrystalline materials as shown in Figure 2[19, $\underline{\text { 91, }}$ 98].
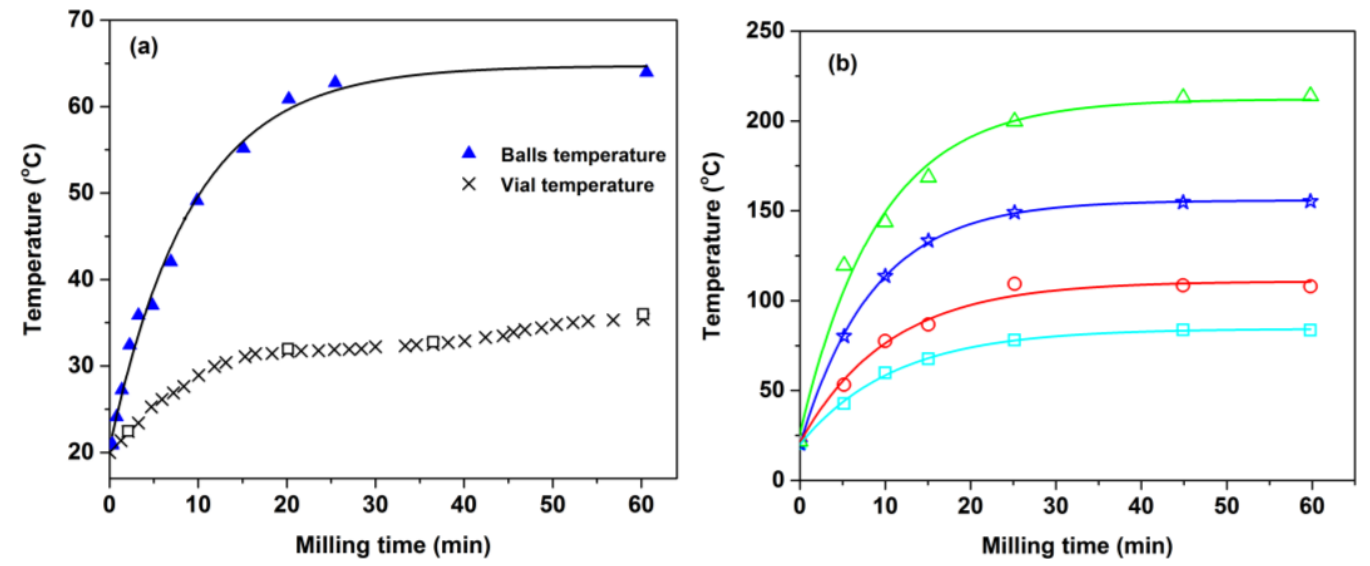

Figure 1:(a) Ball temperature as a function of milling time when using a SPEX mill and flatended vials with five $12.7 \mathrm{~mm}$ balls and no powder $(\Delta)$. The continuous line represents a fitted exponential. The temperature of the vials as measured by a thermocouple $(x)$ and independent calorimetric determination $(\square)$ is shown for comparison(b) Ball temperature milling time curves obtained using a Fritsch P-5 planetary mill. The $(\Delta)$ and (o) symbols represent data with a $10-\mathrm{cm}$ diameter milling bowl, and 100 balls and $280 \mathrm{rpm}(\Delta)$ and 200 rpm (o) speed and the $(*)$ and ( $\square$ ) symbols correspond to a $7.5-\mathrm{cm}$ bowl, 50 balls and $280 \mathrm{rpm}$ $\left.{ }^{*}\right)$ and $200 \mathrm{rpm}(\square)$ speeds [97]. 

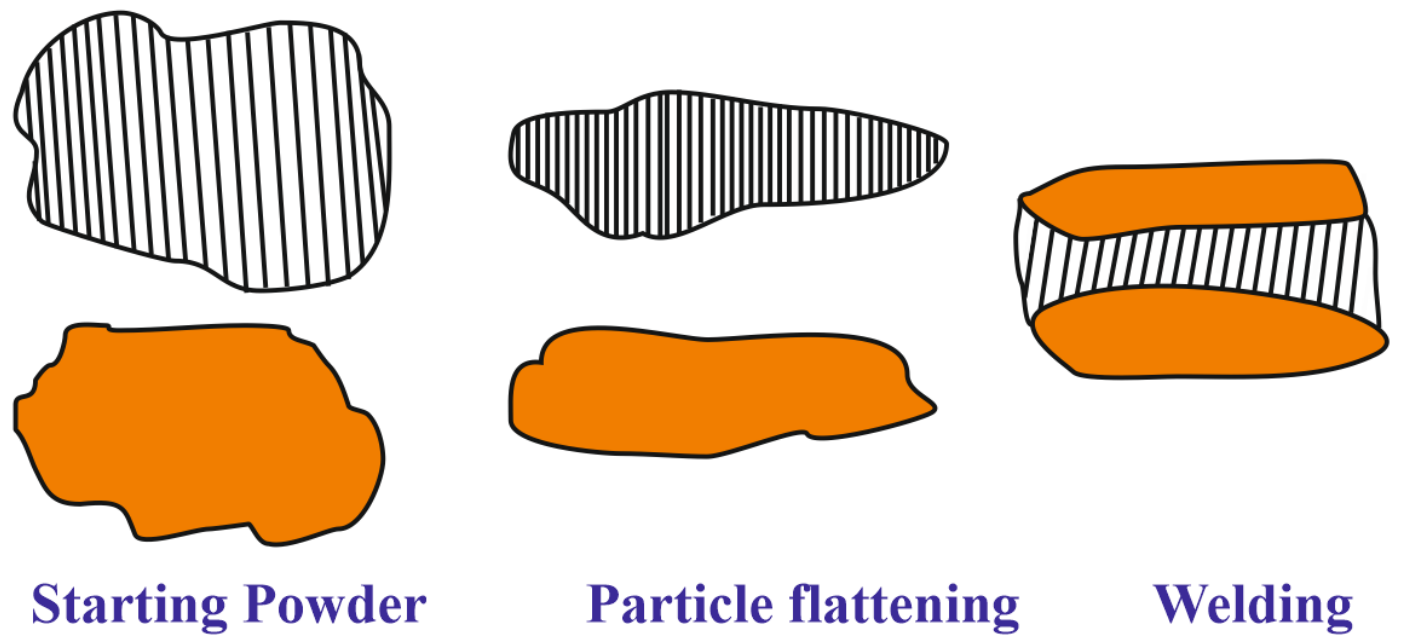

Particle flattening

Welding

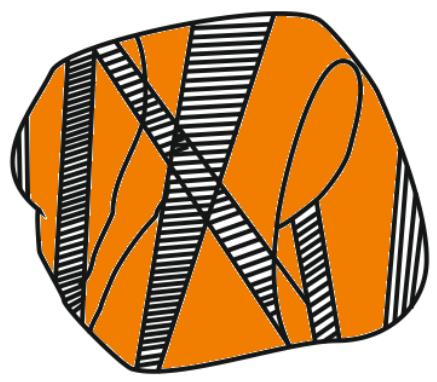

\section{Equiaxed particle} formation

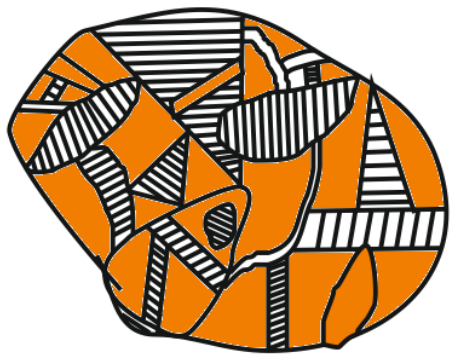

Random welding

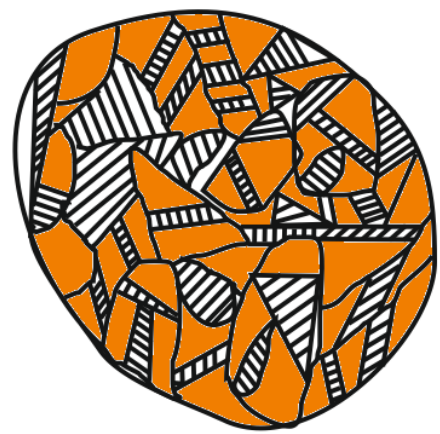

Steady state

Figure 2: Five stage fracture process in room temperature mechanical milling [의]

During the flattening stage, the temperature at the point of collision of the material with balls or vial is likely to increase, depending on the type of material, ball mill. The rise in the temperature promotes both cold welding formation as well as the sintering of particles, leading to the formation of agglomeration having nanocrystallites with increasing particle size. Hence, cold welding phenomena are prevalent in the mechanical milling at room temperature (RT) and the agglomeration of as-synthesized powder. Therefore, the synthesis of fine nanoparticles and rapid refinement is unlikely via ball milling at RT. In contrast, the cryomilling suppresses the cold welding and agglomeration[19]. Modeling of the formation of nanocrystalline materials and the sintering phenomenon can shed new light into the efficacy of cryomilling on the formation of nanostructured materials. In this direction, 
Mohamed et al.[100] have provided a model to predict the minimum grain size $\left(d_{\text {min }}\right)$ achievable via mechanical milling. Similarly, Alymov et al. [101] have developed a model on the sintering temperature of nanoparticles due to the reduction of particles. These models show reasonably good agreement of the experimental findings for the reduction of the size of powder particles. However, the theoretical calculation of $d_{m i n}$ and $T_{S S}$ require material properties, especially defect generation and annihilation. It is indeed, temperature dependent. In the following, this aspect is discussed to elucidate the importance of the temperature of mechanical milling.

Over the past many decades, the characteristics of refinement of particle size and nanostructures formation during ball milling have been studied extensively and guided to many important findings, leading to several models for grain refinement. However, some of the important models require discussion. Let first discuss the conclusions on the experimental findings of the mechanical milling of various materials (concluded by Mohamed et al. [100])

i) grain size decreases and reaches to $d_{\min }$ (minimum grain size) as milling time increases, and $d_{\min }$ is different for different materials.

ii) $d_{\min }$ of any material is inversely proportional to the melting temperature $\left(T_{m}\right)$ and the bulk modulus $(B)$.

iii) for FCC nanocrystalline metals, $d_{\min }$ shows a linear relationship with and critical equilibrium distance between two edge dislocations $(L c)$.

iv) some experimental observations reveal that smaller nanocrystalline grain sizes can be obtained at lower milling temperatures.

Using these experimental findings, Mohamed has derived an equation for $d_{\min }$, as a function of material parameters. In general, grain refinement has been categorized into three steps: 
(a) The localization of high dislocation density in the shear bands;

(b) The annihilation and recombination of dislocations, forming cells and subgrains (recovery);

(c) The transformation of sub boundaries into high-angle grain boundaries.

According to Fecht et al.[19], $d_{\min }$ during mechanical milling is the result of a balance between the generation of dislocation structure by the severe deformation during milling and its recovery and recombination by thermal processes. However, Mohamed et al. have added the recovery can also take place via creep, stating that "steady-state creep represents a balance between competing factors of rate of strain hardening and rate of thermal recovery."

Accordingly, Mohamed et al. has provided an equation as follows

$$
\frac{d_{\min }}{b}=A\left\{\left(\exp \left(\frac{-\beta Q}{R T}\right)\left(\frac{D_{P O} G b^{2}}{v_{o} k T}\right)^{0.25} \times\left(\frac{\gamma}{G b}\right)^{0.5}\left(\frac{G}{H}\right)^{1.25}\right)\right\}
$$

Here, $A$ (dimensionless constant), $b$ is Burger's vector of dislocation, $Q$ the self-diffusion activation energy, $\beta$ is a constant $(0.04) ;, D_{p o}$ pipe diffusion coefficient, $G$ shear modulus, $v_{o}$ Poisson's ratio, $H$ hardness, $\gamma$ the stacking fault energy, $R$ the universal gas constant, $k$ the Boltzmann constant and $T$ is the absolute temperature. According to the equation, $d_{\min }$ is strongly dependent on the milling temperature because $Q, D_{P 0}, G, H$ are dependent on $T$. The term $\left(\frac{D_{P O G b^{2}}}{v_{0} k T}\right)$ is related to the dislocation generation via the thermal process.

The pipe diffusion $\left(D_{p}\right)$ plays a critical role, especially at low homologous temperatures and high stresses. This can be expressed as

$$
D_{\text {eff }}=D_{v}+a_{c} \rho D_{p}
$$


, where $D_{\text {eff }}$ is the effective diffusion coefficient, $a_{c}$ the area of the dislocation core associated with rapid diffusion, $D_{v}$ the self-diffusion (bulk or volume) coefficient, and $\rho$ is the dislocation density.

By taking $a_{c}=5 b^{2}$ and $\rho=10(\sigma / \mathrm{Gb})^{2}$ Eq. (2) becomes:

$$
D_{e f f}=D_{v}+50(\sigma / G)^{2} D_{P}
$$

Here, $D_{p}$ is given by:

$$
D_{P}=D_{P O} e^{-Q P / R T}=D_{P O} \exp -(\alpha Q / R T)
$$

Here, $Q$ is the self-diffusion activation energy, $Q_{p}$ the activation energy for pipe diffusion, $T$ the absolute temperature, $R$ the gas constant, and $\alpha$ is less than unity (about 0.58 for most FCC metals). $D_{P}$ is expected to assume significant value under the conditions associated with milling at low temperatures and severe plastic deformation, which can produce a high dislocation density. This aspect will be important for mechanical milling at cryogenic temperatures.

\section{A model of the initial stage of sintering of ultrafine powders $\left(T_{S S}\right)$}

For the formation and retainment of nanocrystalline particles, the sintering of particles needs to be extensively reduced or even nullified. Temperature plays a critical role in sintering, and hence, sintering temperature vis-a-vis operation temperature of the mechanical milling will have a tremendous role in the formation of the nanoparticles. In this regard, a model has provided by Alymov et al.[101] relates the temperature at which sintering starts $\left(T_{s s}\right)$ and the size of the particles during the initial stage of sintering. The ratio $T_{s} \Omega T_{m}$ (where $T_{m}$ is the melting temperature of the bulk), can be obtained from this model and compared with the milling temperature.

Alymov et al.[101] have provided a relationship for $T_{S S}$ of nanoparticles as following 


$$
T_{S S}=T_{m} \ln \{1+k(e-1)\}
$$

, where,

$$
s=\frac{A}{\left((L+1)-(L+1)^{\frac{2}{3}}\right)}
$$

$$
T_{m}=T_{\circ}\left(1+\frac{y_{s}-y_{I}}{\Delta H_{m_{0}}} \cdot \frac{3}{d}\right)
$$

, where $s$ is the fraction of the sintered region, as defined in equation (6), $A$ is a constant varying from 0.06 to $0.15 ; L$ the number of neighbors of a particle and $T_{m}$ is the melting temperature defined in equation (7). $T_{0}$ is the bulk melting temperature, $y_{l}$ and $y_{s}$ are surface tensions of liquid and solid respectively, $\Delta H_{m, o}$ the melting enthalpy, and $d$ is the crystallite size.

Based on these models, there are few reports available in the literature on the efficacy of cryomilling on the formation of nanoparticles [1이 $\underline{30}, \underline{102}]$. The application of these models suggests that the Zn NPs exhibit strongly sinter-dominated behavior $>170 \mathrm{~K}$. On the other hand, for the Al NPs, the critical temperature at which sintering dominated aspect occurs at $>120 \mathrm{~K}$. This is shown in

Figure 3(a-b). Hence, the successful synthesis of fine nanoparticle and rapid refinement is possible by milling at a temperature lower than the critical temperature below which sintering dominates. Hence, one needs to select the milling temperature in the plastic-deformation 
dominated region instead of the sintered dominated region for the rapid refinement of nanoparticles.
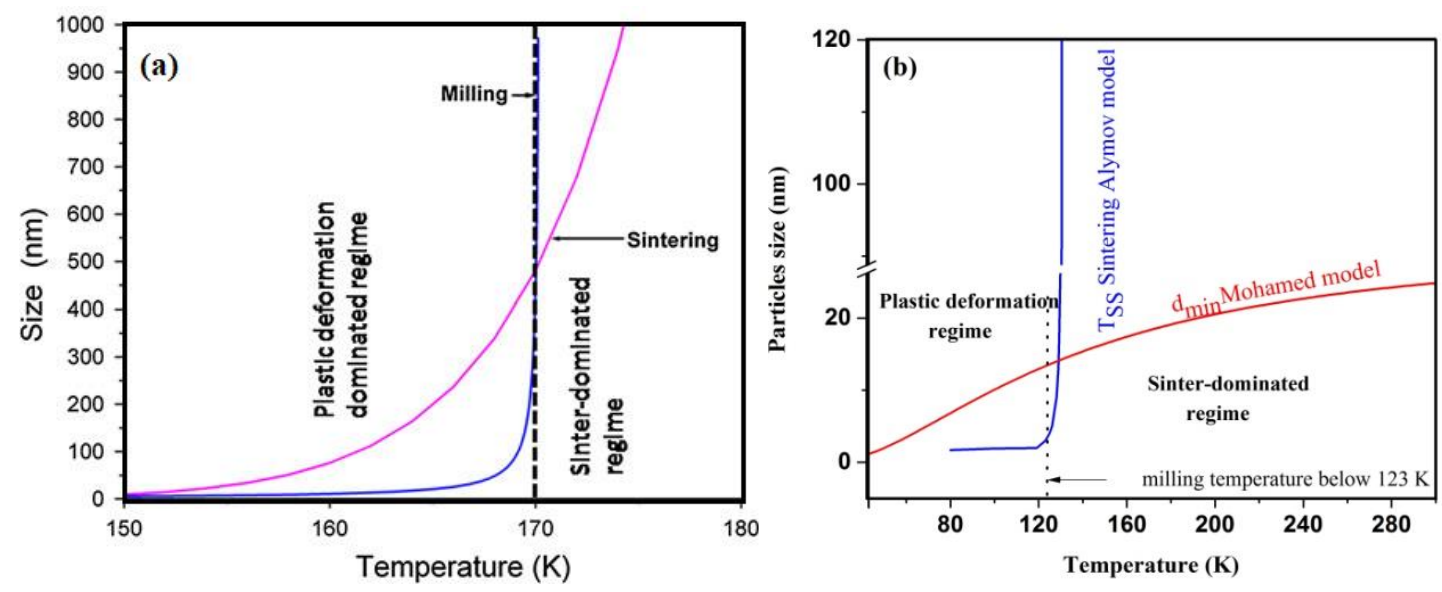

Figure 3: Crystallite size predicted by the model of Mohamed[100](milling) and Alymov etal. [101](sintering) showing distinct regimes (a) Zn nanoparticles[102] (b) Aluminium nanoparticles[10].

Cryomilling can effectively reduce cold welding phenomena because many available materials undergo a ductile-to-brittle transition (DBTT) at or below $123 \mathrm{~K}$, causing predominant fracture over plastic deformation. For the ductile materials, the plastic deformation will be limited at extremely low temperature and hence, even if cold-welded particles forms, these joints are likely to be broken during the subsequent milling operation. This has been reported recently by Katiyar et al.[103] upon investigating the formation of cold-welds of some important materials at different temperatures. Some comparison is shown in Figure 4(a). In these experiments, the two metallic strips of the pure metal were degreased using methanol, scratched for removing the oxide layer, and then riveted together to avoid any deflection between both strips during the deformation. Subsequently, the riveted strips were deformed by different amount $(30,40,50,60,70,80 \%)$ at various temperatures $\left(27,0\right.$ and $\left.-196^{\circ} \mathrm{C}\right)$ for cold weld formation [Schematics diagram shown in Figure 4(b)]. It is evident that the cold-welded joints of both $\mathrm{Al}$ and $\mathrm{Cu}$ exhibit higher bond strength at room temperature as well as after $70 \%$ and $80 \%$ deformation, respectively. However, similar 
deformation at cryogenic temperature leads to a substantial reduction of the strength of the weld (40\% of $\mathrm{Al}$ and $60 \%$ of $\mathrm{Cu}$ ), shown in Figure 4(c). Interestingly, the Fe has not been found to form a cold bond at any temperature, possibly due to BCC crystal structure and high melting temperature. Therefore, it is evident, cold welding and sintering of nanoparticles can severely be reduced by ball milling at cryogenic temperature. This is expected to promote the rapid refinement of the particle size during cryomilling and refinement of the size of the nanoparticles during milling. Subsequently, one needs to look at the mechanical properties of various materials (metals, ceramics, polymer, etc.) at cryogenic temperature to understand the plastic deformation vis-à-vis fracturing phenomena at low temperatures.
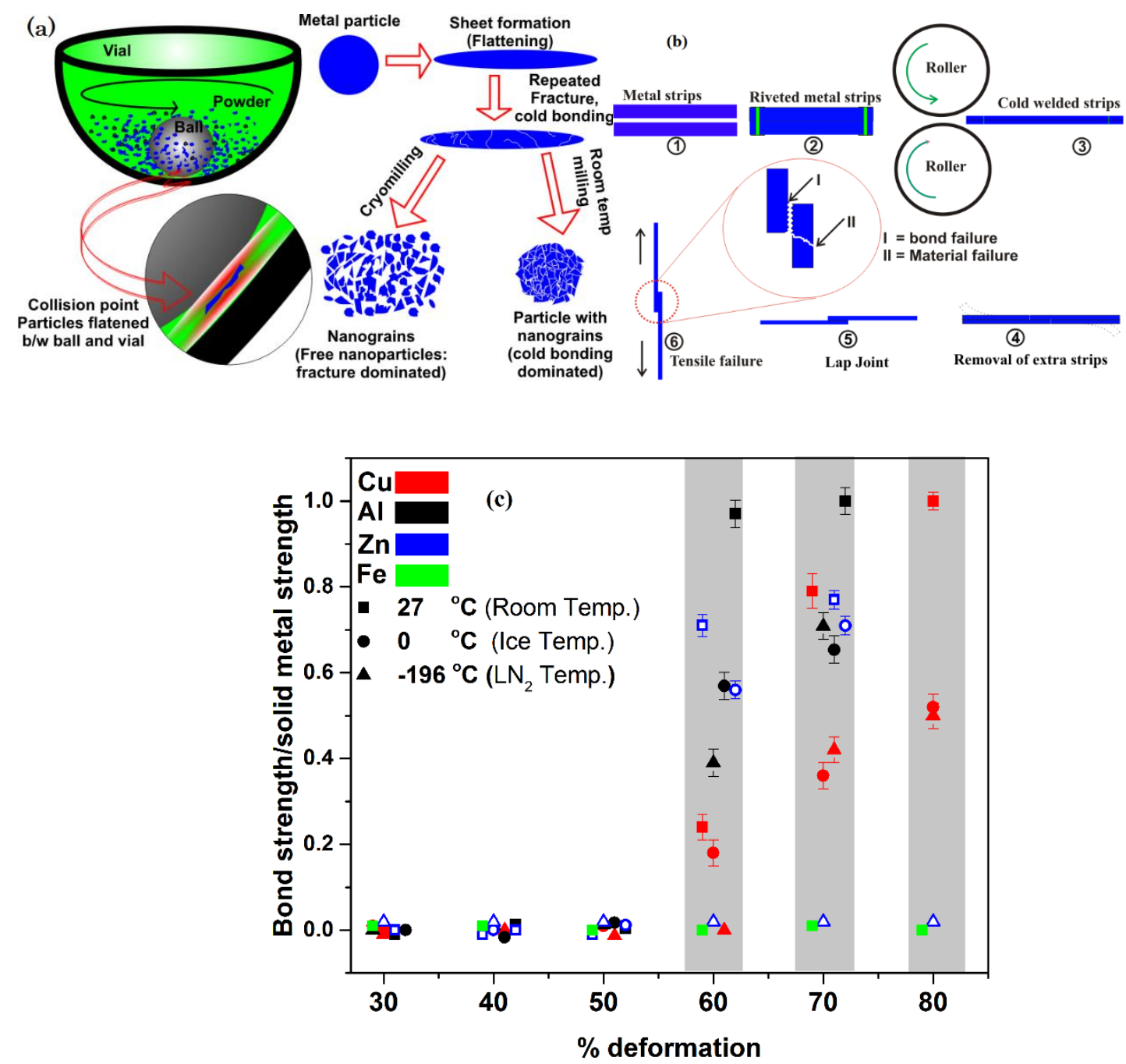
Figure 4 (a)Distinct nanostructure formation Cryomilling vs. room temperature milling(b) cold weld formation using rolling at different temperatures(c) Cold weld behaviour of materials at different temperatures and different percent deformation [31].

\subsection{Effect of Temperature of Milling on Nanostructured Materials}

In the previous section, it has been shown that there are many advantages associated with the cryomilling process in comparison with conventional or room temperature mechanical milling. One of them is related to the suppression of recovery during the milling process. During milling, the crystalline lattice of the material is plastically deformed, leading to the accumulation of dislocations and other defects. Extensive plastic deformation or cold working leads to the accumulation of these defects, lowering the plasticity of the materials. Hence further generation of defects is no longer possible. Dynamic recovery is the basic mechanism that leads to the annihilation of dislocations during deformation [18], and hence, ductility of the deformed materials can be recovered. It has been reported that the cross slip of screw dislocations helps to achieve dynamic recovery at cryo-temperature., At the higher temperature, vacancy climb dominates $[104,105]$. Hallen et al. have investigated the dynamic recovery of FCC metals at different temperatures and compared with theoretically calculated values [105]. Recrystallized specimens of pure nickel, aluminium, and copper and austenitic stainless steels were investigated via tensile test carried out at the various temperatures and strain rates $\left(\mathrm{Al}=0.5 \times 10^{2}, \mathrm{Cu}=1.3 \times 10^{2}, \mathrm{Ni}=0.5 \times 10^{2} \mathrm{~s}^{-1}\right)$.

According to the authors, the dynamic recovery is coupled with both processes of cross slip and vacancy climb and thus [105];

$$
\Omega=\Omega_{c s}+\Omega_{v c}
$$

$\Omega_{c s}(\mathrm{CS}=$ cross slip) is the dynamic recovery constant at low temperatures, where vacancy diffusion is negligible and $\Omega_{v c}(\mathrm{VC}=$ vacancy climb) rate of recovery constant at high temperature,

$$
\Omega_{c s}=C \exp \left(-Q_{c} / R T\right)
$$


Here, $\Omega$ is a factor describing the rate of dynamic recovery. The rate of recovery is also directly proportional to the instantaneous level of dislocation density $\rho$. Nevertheless, the dynamic recovery significantly decreases at low temperature (especially at or below $<123 \mathrm{~K}$ ), as shown in Figure 5, compared to room temperature (300K) for the most of FCC metals and alloys [105]. Therefore, milling at low temperature (cryogenic-temperature) will lead to extensive storage of dislocations during repeated mechanical milling of materials, causing a substantial increase in the strain hardening. This leads to a reduction of ductility, toughness, and increases the probability of fracture at a lower level of strain.

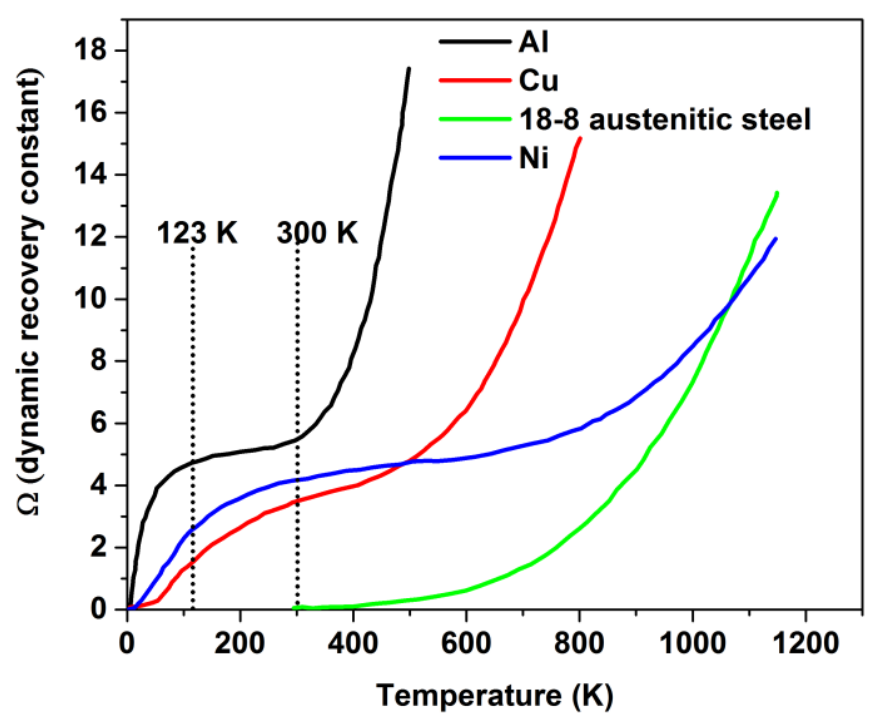

Figure 5:Experimental values of dynamic recovery constant variation against temperature formation FCC metals and alloy [105]

Another important factor is the suppression in the oxidation rate of metallic nanoparticles at low temperature. Oxidation is predominately observed in the nanocrystalline metals and alloys during synthesis via mechanical milling at room temperature. Hence, many metallic nanoparticles exhibit oxidized surface layers, impeding their applications. The oxidation of pure metals takes place over the surface, and hence the nanoparticles of pure metals are highly prone to oxidation due to high ratio of surface area to volume [106]. Therefore, lower milling temperature helps to reduce the rate of oxidation during milling. Rhodin et al.[21] 
have reported the formation of an oxide layer over the metallic surface of $\mathrm{Cu}$ with time at different temperatures. The growth of the oxide layer at $78 \mathrm{~K}$ in a controlled experiment is negligible even after 100 hours. However, at the higher temperature (>273 K), the thickness of the oxide layer increases extensively with the time, as shown in Figure 6 [21]. Therefore, it is evident that the rate of oxidation at low-temperature milling expected to be low, and the possibility of synthesis of pure metallic NPs, almost free of contamination or oxide layer, called native particles or particles with virgin surfaces can be achieved.

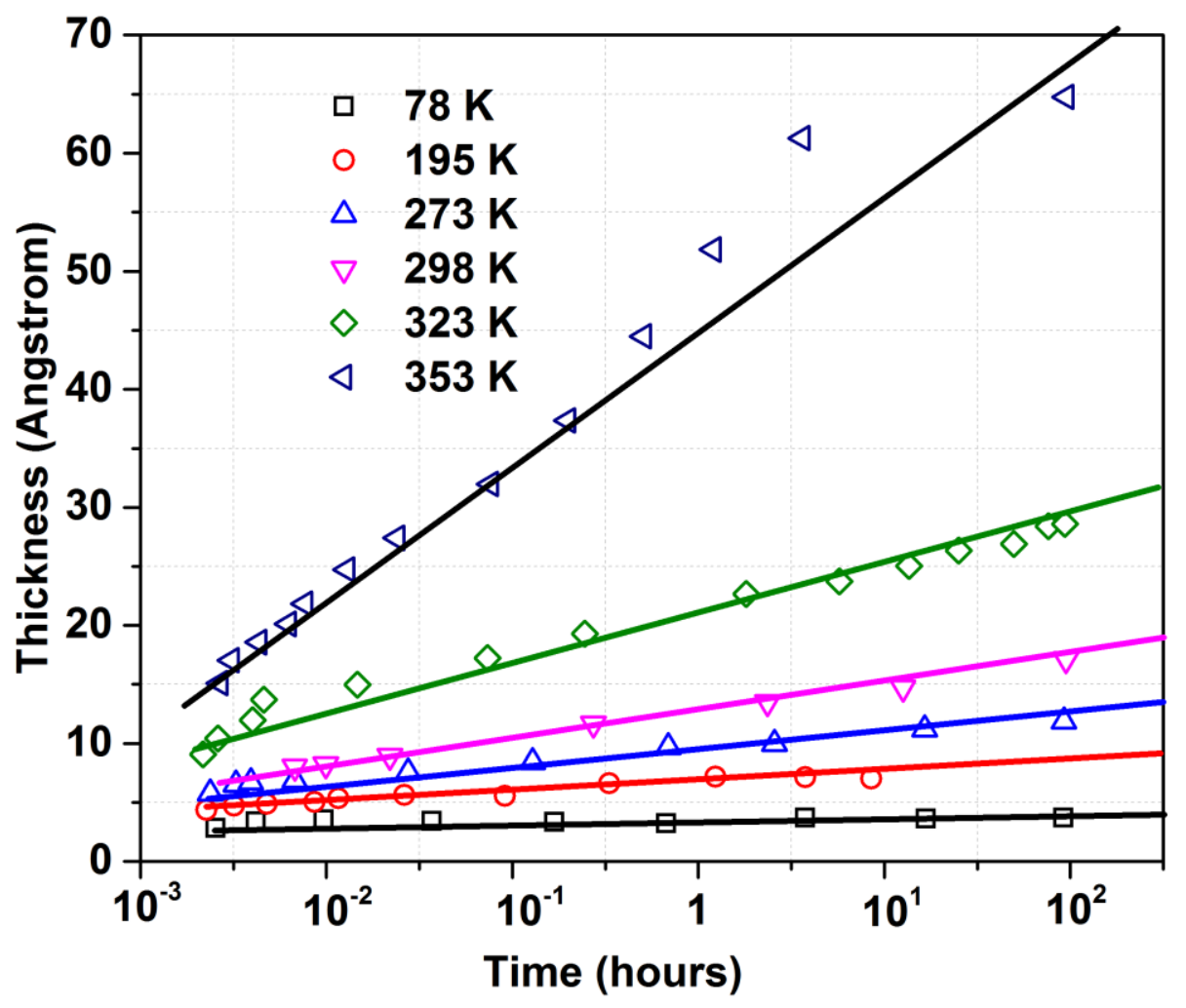

Figure 6:Oxidation behaviour of $\mathrm{Cu}$ at different temperatures as the effective film thickness of $\mathrm{Cu}$ oxide against temperature[21].

However, there are other sources of contamination in the milled powder. The interaction of the balls, and vials with powder can also cause the production of debris, which is the main source of contamination in many milling operations. This debris from milling tools is directly affected by milling parameters, especially ball to powder ratio, time, and speed. It is also 
dependent on the milling materials and shape of the vials. Thus, one can compare the level of contamination between milling at room temperature and cryogenic temperature ball, provided other milling parameters are kept the same. If the conventional ball milling is compared with cryo-milling for the same material and the shape of vials, it is evident that the milling time will decide the level of unavoidable contamination contributed from the milling tools. Therefore, the cryomilling has this distinct advantage to reduce the contamination imparting from milling tools because the refinement is faster during cryomilling since the fracture phenomenon dominates over plastic deformation and reduces the time of milling. As seen in Figure 7, 100 hours of milling time required to obtain the NPs, when conventional ball milling is utilized. On the other hand, it requires 5 to 10 hours utilizing the cryomilling for the same.

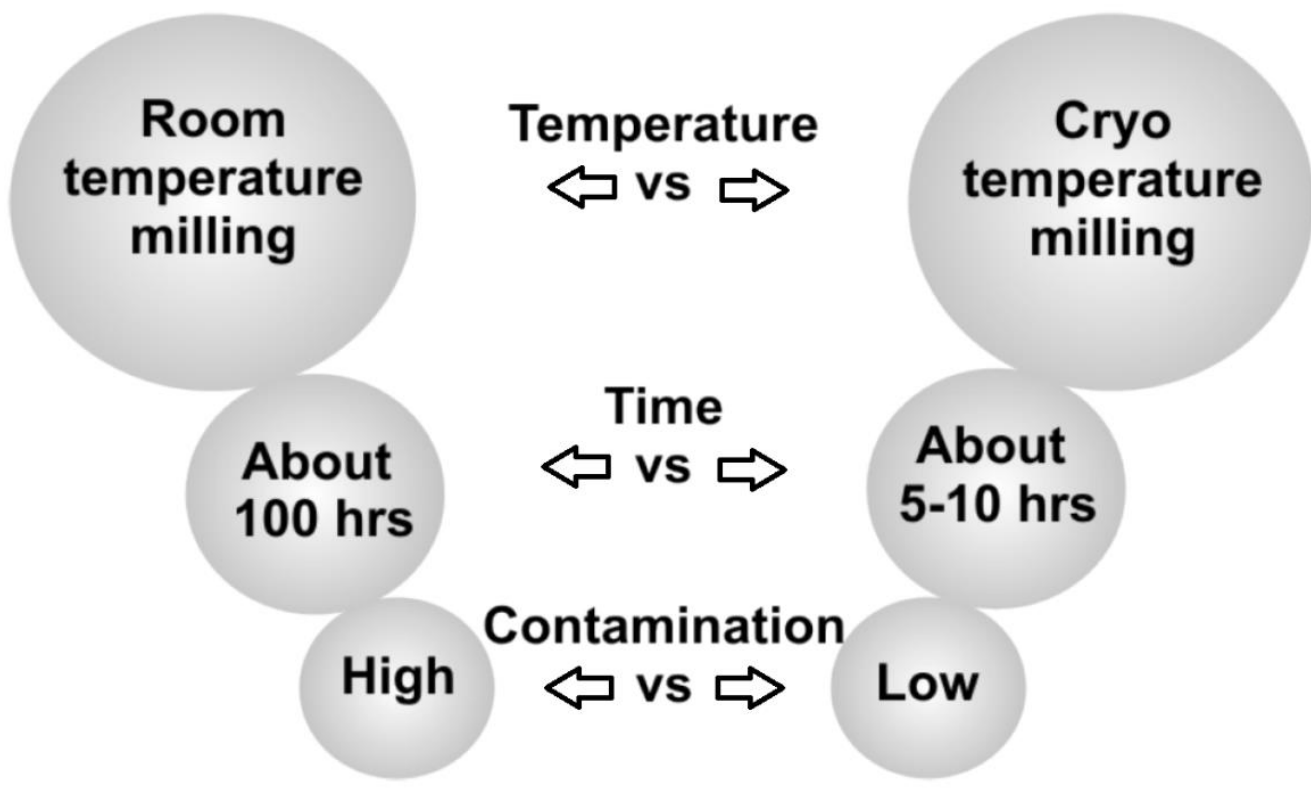

Figure 7: Comparison of conventional ball milling against cryo ball milling to get NPs.

\section{Cryomilling Setup: Types and Variation}

The cryomilling, carried out at or below cryogenic temperature, exhibits distinctly different features as compared to mechanical milling at room temperature. In this regard, the cooling 
of the powder and milling media are considered a prominent factor for the design and development of cryomills. Cooling of powders, before milling or during milling using cryogenic liquids, is the distinctly different step in the cryomilling or grinding. Based on cooling, the cryomilling can be classified into two types, wet milling (milling materials mixed with cryogenic liquid) and dry milling (milling chamber is cooled externally). However, spices, medicines, and polymeric powders are precooled, and milling is subsequently performed on the pre-cooled powder [84]. Based on cooling, the cryomills can further be classified based on whether the cryogenic liquid and milling materials never come in contact with each other. The cryogenic liquid is directly added in the milling chamber, containing ball and powder for wet milling. On the other hand, the coolant is kept in the reservoir adjacent to the milling chamber for cooling the milling materials in case of for dry milling. The wet milling can cause contamination arising from coolant liquid as it is directly in contact with milling materials for a long time. Hofmeister et al.[107] have estimated the nitrogen concentration of AA5083 alloy during prolong cryomilling in slurry form, and found nitrogen concentration of $1.64 \pm 0.17$ at $\%$, and $19.12 \pm 1.10$ at $\%$ for 8 and 72 hours cryomilling respectively. Sometimes, the ice flakes may also enter in the milling chamber along with the $\mathrm{LN}_{2}$. Consequently, the materials can get oxidized, as ice flakes turn to water due to heating up after taking out the milled powder from the mill. In contrast, dry-milling can eliminate or even reduce this problem. In addition, the milling under inert gas environment can provide a better quality product. Therefore, the addition of inert gas purging assembly with cryomill is of prime importance for synthesizing good quality nanomaterials. The continuous purging inert gas is difficult in a planetary ball mill as compared to the shaker and vibratory cryomill. It is also important that the milling assembly should be compatible with cryogenic liquid to avoid brittle fracture of the milling accessories. As some cryogenic 
liquids may cause harm to the human body during direct contact, extra safety features are also needed to be incorporated in the cryomill.

In the niche markets, various types of the cryomills are available; Fritsch GmbH [89], Retsch

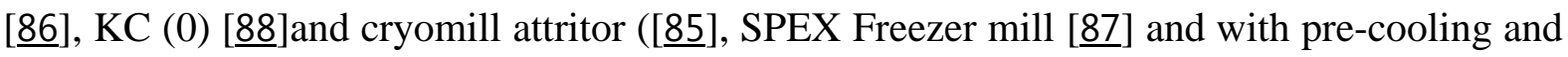
low-temperature grinder (two-step cryo-grinder) for spices [108]. In the subsequent section, we shall discuss different cryomills and their evolution over time.

\subsection{Evolution of Cryomilling over Time}

The main objective of cryomilling is the reduction of particle size and the prevention of decomposition of temperature-sensitive materials during reduction. It is part of conventional mechanical milling, as shown in the schematic

Figure 8. In fact, the milling/grinding at low temperature was reported in the literature as early as 1937 with articles title "An apparatus for grinding bacteria at low temperature," where the bacteria have been disrupted using a cryo-ball mill containing five hundred 0.25 inch stainless steel balls. The mill was cooled $-75^{\circ} \mathrm{C}$ using a mixture of methyl cellosolve and $\mathrm{CO}_{2}$. The stout pyrex flask of 1 litre containing bacteria and balls were rotated at $230 \mathrm{rpm}$ using an electric motor [109]. Similarly, design of the cryomill published from West Germany in the year 1973, having the title "Cryogen-Low temperature grinding of brittle materials". This described the cryomilling of plastic granules and flocks [110]. It is evident cryomilling was developed much earlier than conventional room temperature ball mills. However, the utilization of cryomill was limited. The invention of the Scanning Tunneling Microscope (STM) by IBM in the 1980s fuelled the research in nanostructure/nanomaterials synthesis, and many research groups started using cryomilling to synthesize nanomaterials. Some research groups even used the conventional ball mills as cryomill, just dipping the vial in $\mathrm{LN}_{2}$ prior to milling. There exist many mechanical mills in the research, academia, and industries; drum ball mill, jet ball mill, bead mill, horizontal rotatory ball mill, 
vibrations/shaker ball mill, attritor ball mill, etc. The selection of ball mill depends according to the purpose, such as mixing, pulverization, mechanical alloying, etc. Nonetheless, ball mills can be classified based on energy, medium, and temperature. On the basis of energy, milling can be divided into low energy and high energy milling. According to the medium, it is categorized as wet milling and dry milling. Similarly, it is classified in high-temperature milling, room temperature cryomilling based on temperature, as shown in a schematic

Figure 8. Some of the available cryomills for laboratory scale in the niche market has been discussed in Table 1.

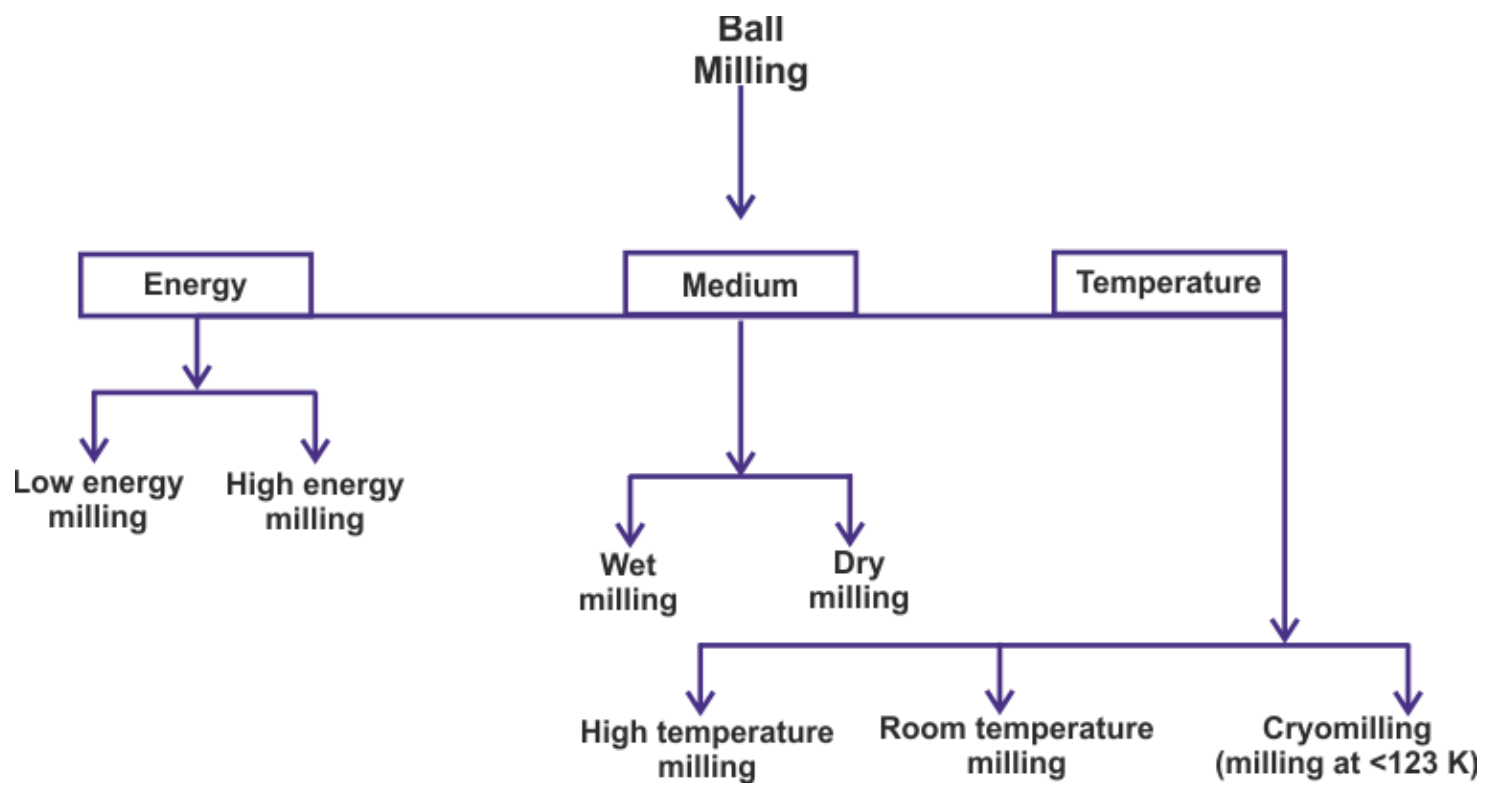

Figure 8: Schematic classification of ball milling based on energy, medium, and temperature.

The categorization based on high and low energy is primarily dependent on energy transfer through milling tools to the underlying materials [111]. Several factors, including the hardness difference of milling tools, milling materials, speed of the mill, ball to powder ratio, etc. determine the energy transfer. Moreover, in some designed mills, the magnet is placed close to the vial to apply a strong pulling force on the magnetic balls, and thereby the impact energy imparted can be made higher than the normal mill [112]. Cryomills utilized for the 
synthesis of nanoparticles; other aspects need to be considered, including homogeneity and the protection of nanomaterials from oxidation and nitridation. Recently, the free-standing nanocrystalline materials are considered an active and promising area of research in materials science, biomedical imaging, physics, chemistry, etc. [113]. The use of cryomills and their importance will be discussed in subsequent sections in detail.

\subsection{How to Achieve Cryogenic Temperature with Different Cryo-liquids}

Achieving proper cooling to obtain temperature below $123 \mathrm{~K}$ is considered the primary objective of the cryomilling. Hence, cryomills are designed to be compatible with different coolants. During the milling process, the milling media, along with powder, are being cooled using cryogenic liquids having an extremely low boiling temperature such as liquid oxygen (90 K); liquid argon (87 K); liquid neon $(27 \mathrm{~K})$ and liquid nitrogen $(77 \mathrm{~K})$, etc. Although liquid argon and nitrogen have primarily been utilized as a coolant in the cryomills, liquid nitrogen is widely used. The liquid nitrogen $\left(\mathrm{LN}_{2}\right)$ is considered a cost-effective cryogenic liquid and non-toxic for the environment. It is released in the form of $\mathrm{N}_{2}$ gas, which is omnipresent ( 78 volume \%) in our environment, and we breathe it along with oxygen. The $\mathrm{LN}_{2}$ is the safest coolant in the cryomilling compared to another coolant such as liquid Ar. Argon is dangerous if inhaled in large amounts as it can get trapped in the lungs and can displace the oxygen.

Kumar et al.[9] have described the cooling profile of custom-built cryomill, utilizing $\mathrm{LN}_{2}$ and compared the temperature variation and running positions. The temperature of the milling chamber was monitored online by a K-type thermocouple. $\mathrm{LN}_{2}$ was poured in the cryomilling via $\mathrm{LN}_{2}$ inlet (schematically shown in Figure 9(a)) in five minutes interval. Subsequently, the temperature was reduced and reached steady state $-170{ }^{\circ} \mathrm{C}$ after 60 minutes (Figure 9(b)). The cooling (Figure 9(c)) profile reveals that the temperature varies from -140 to $-180^{\circ} \mathrm{C}$ next 5 minutes during the operation of the cryomill. 

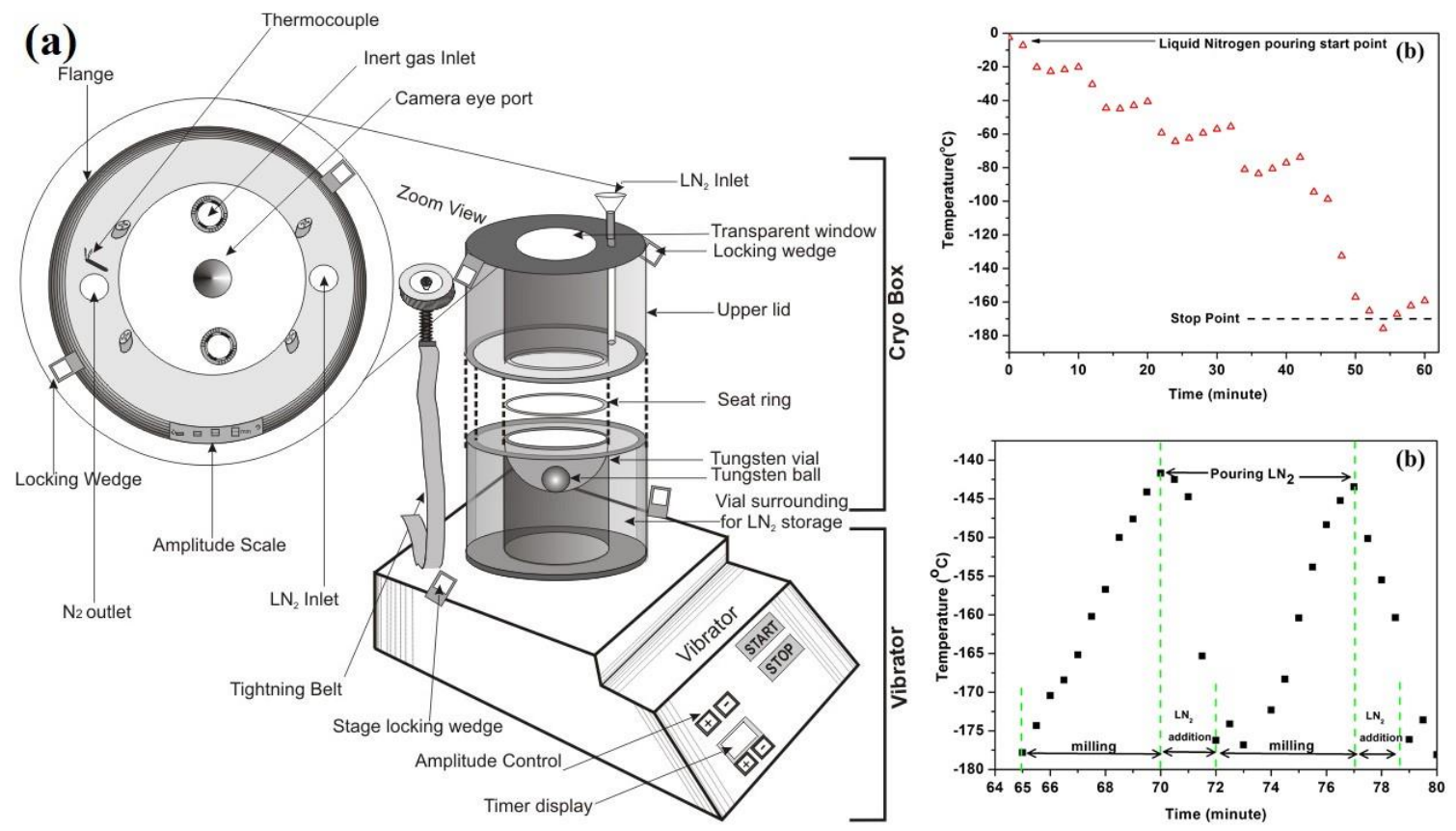

Figure 9: (a) Schematic of custom build cryomill(b) cooling profile of cryomilling in stop position (c) temperature variation during milling ( $\mathrm{LN}_{2}$ added in each 5-minutes interval)[9]

\subsection{Issues in Fabrication of Cryomill}

It is also important to handle several basic issues while designing a mill working at an extremely low temperature. The balls and vial materials, along with their accessories, must withstand the cryogenic temperature. The tungsten carbide and stainless steels have been reported to have the capability to sustain low temperatures and bear the shock load with minimum wear and tear. Similarly, UHMWPE (Ultra-high molecular weight polyethylene) is reported to withstand shock load at liquid nitrogen for a longer duration. It is a good insulator [114], which can be used for fabricating coolant reservoir and other accessories to reduce heat loss. In addition, the stainless steel (SS316 type) can be used for fabricating the outer body of the mill. The available cryomills in the market are shaker, vibratory, and attritor types [111], primarily due to the easy handling of the liquid coolant. The planetary type cryomill is difficult to fabricate due to the need for additional accessories for supplying cryogenic liquid. 
In fact, there is no planetary [13] type cryomill in the niche market because of the fact that planetary rotation does not allow the handling of liquid coolant.

Additionally, there are other challenging issues to be considered for the design of the cryochamber. This includes maintenance of the proper temperature in case of dry milling and the inert gas environment over the milling materials to avoid oxidation of the milled materials. In the case of wet milling (milling materials along with coolant liquid), the flow of $\mathrm{LN}_{2}$ is not continuous instead of the dosing of $\mathrm{LN}_{2}$ at certain intervals. There are high chances of the formation of ice flakes, which can enter into the milling chamber with the dosing of $\mathrm{LN}_{2}$. Moisture present in the chamber can freeze and form ice flakes. Hence, it is essential to stop these ice flakes entering in the cryo-chamber. The each type of cryomill has a different energy transfer rate, and it critically depends on its working principle as well as hardness difference between under milling powder and ball-vial.

The UNION ACRON, UK-based company, has designed an attritor-based cryomill. The schematic of the cryo-chamber is shown in Figure 10(a), in which the powder and balls are charged into the chamber, and the surrounding body is cooled with cryogenic liquid. In the attritor, the balls are rotated via impeller in the cryo-chamber $[111, \underline{115}]$. Similarly, Germanybased company RETSCH has designed a shaker cryomill [116], in which the materials and liquid coolant are mixed and subsequently milled in the cryo-chamber (ball and vial), shown in Figure 10(b). The milling action is achieved by mechanical shaking of the cryo-chamber, and $\mathrm{LN}_{2}$ can be filled inside or outer body of the cryo chamber. The cryomill is used for the spices and food industries. In this type of mill, the milling materials are first cooled by cooling of the conveyor, and milling is done in a separate chamber, as shown in Figure 10(c) [117]. 
There are some other custom-built cryo-mills, as shown in Figure 10(d). Kumar et al.[9] has reported the design and development of a vibratory custom cryo-chamber, as shown in Figure 10(d). This mill is endowed with features including separate liquid coolant reservoir, in situ monitoring of temperature, in situ monitoring of ball motion, and inert gas environment to protect materials from oxidation. Similarly, KC0 cryomill, designed and developed by Tau Instrument, India, has several built-in facilities; a separate chamber for liquid coolant and well-protected hood to reduce noise generated during milling.

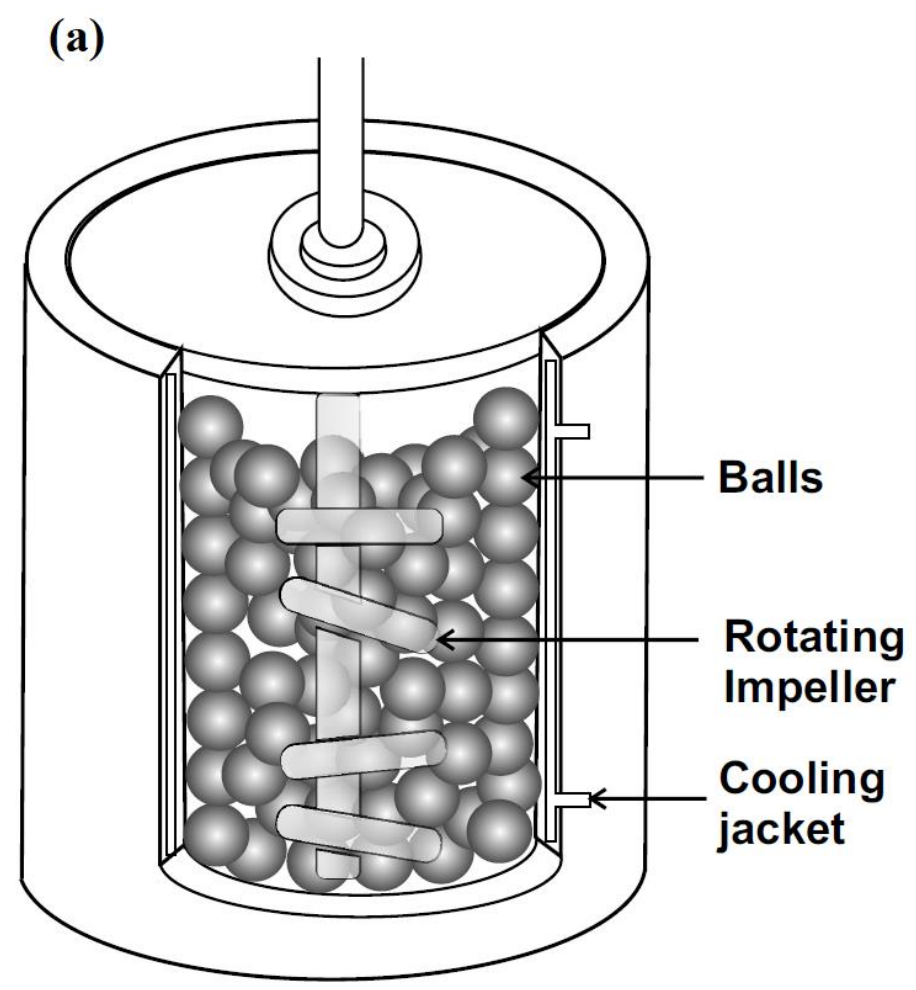




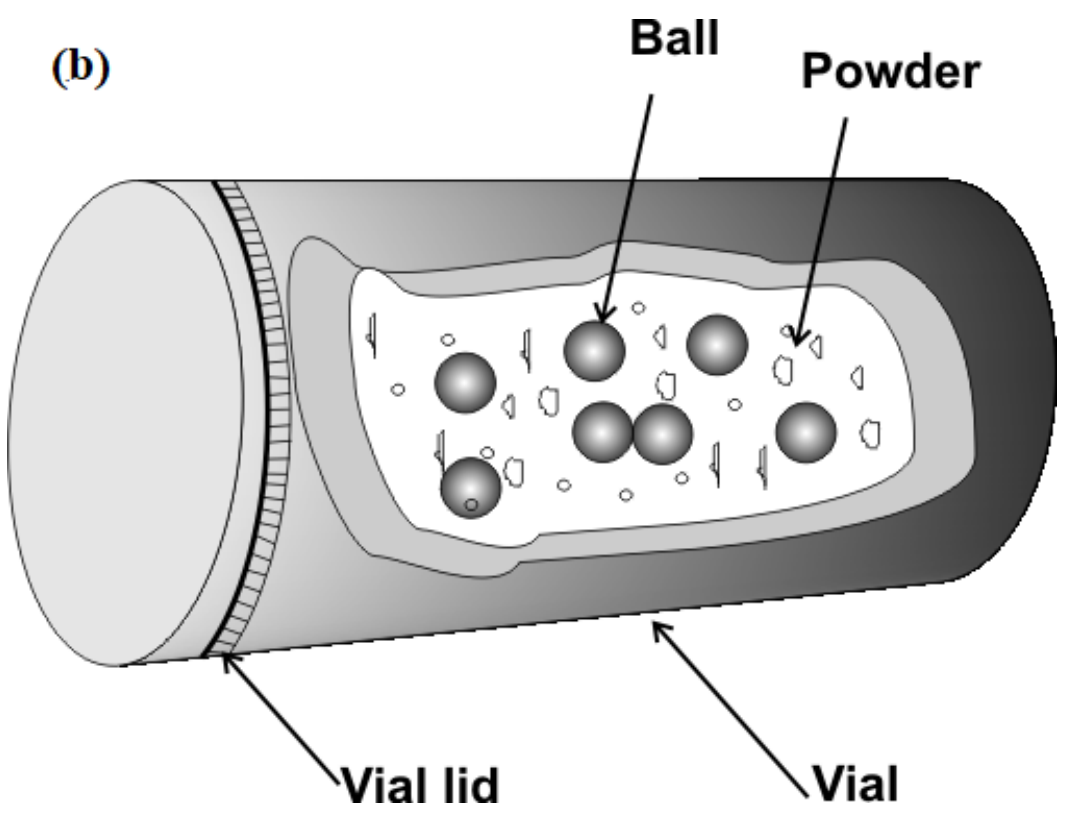

(c)

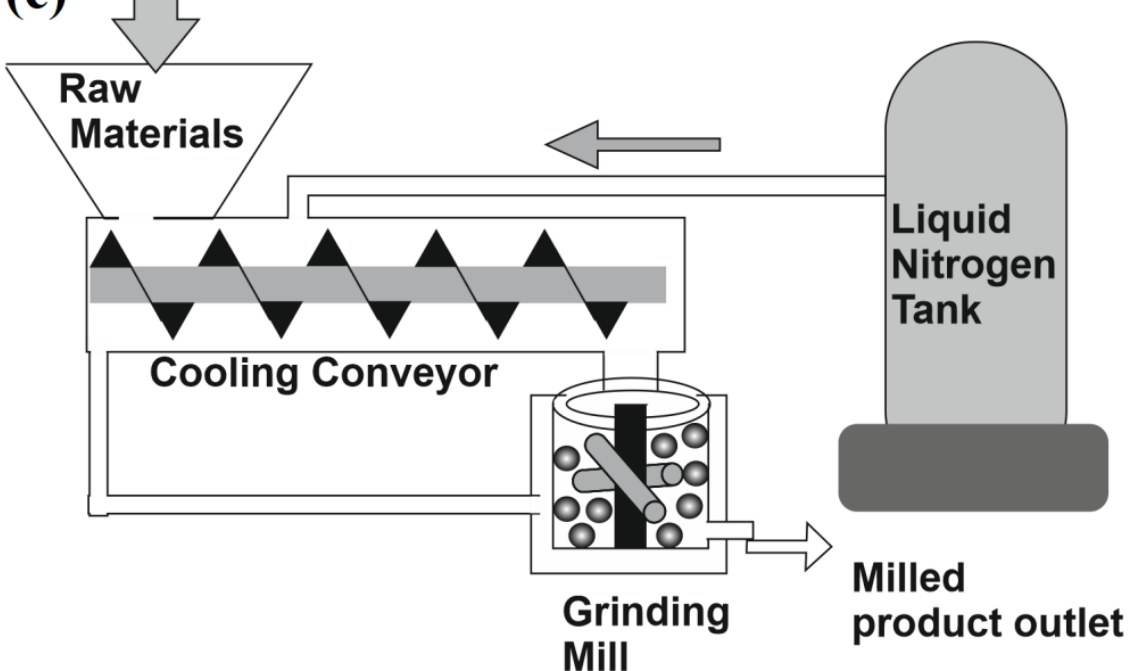




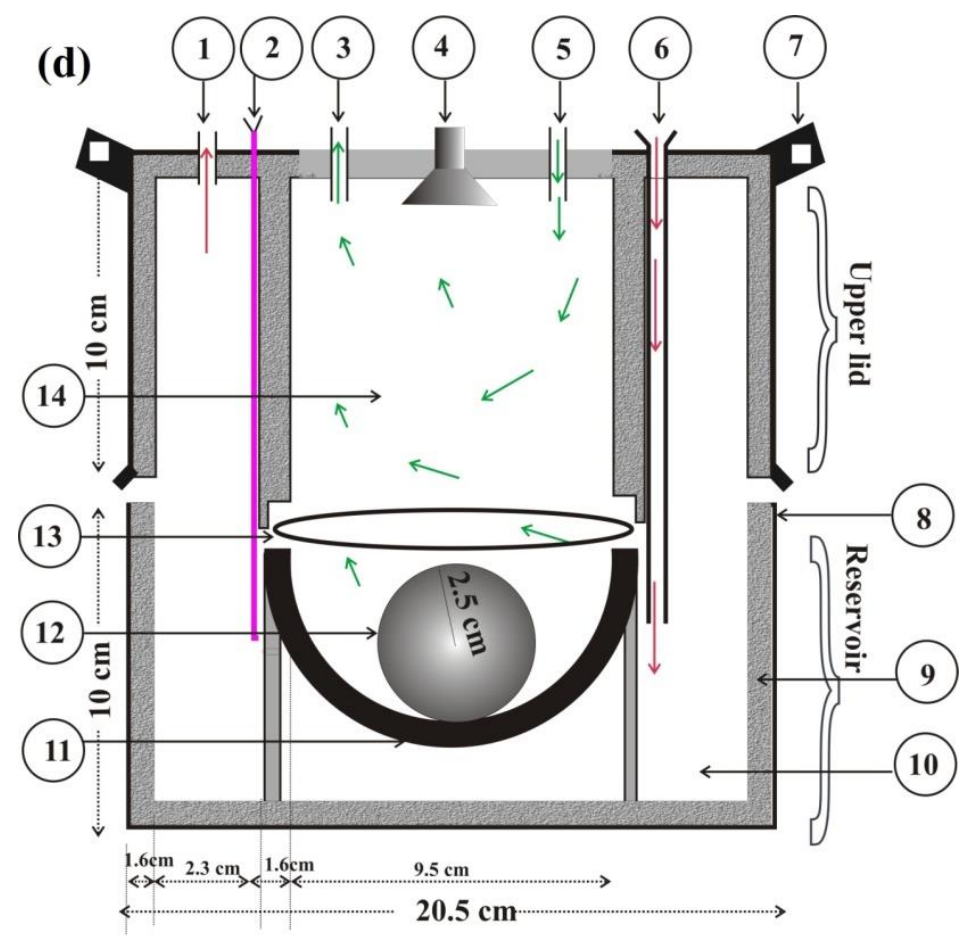

Figure 10: (a) Union process UK cryomill chamber ball and vials[ $\underline{85}$;;(b) Schematics of Retsch cryomill chamber ball and vials[116];(c)Cryo conveyor for precooling milling materials[117];(d) schematic of cryobox with details 1 . outlet of $\mathrm{N}_{2}, 2$. thermocouple, 3. exit of inert gas, 4. eyepiece, 5. inlet inert gas, 6. inlet LN2, 7. locking wedge, 8. Stainless steel outer body, 9. UHMWPE thermal insulator body, 10. annular space ( $\mathrm{LN}_{2}$ reservoir), 11. tungsten carbide vial, 12. tungsten carbide ball, 13. neoprene seat-ring, 14. inert gas atmosphere in milling space [9]

\section{Cryomilling of Metals and Alloys}

It has earlier been mentioned that cryomilling has extensively been utilized for the synthesis of nanoparticles, metals, alloys, ceramics, polymers, composites, and hybrids to showcase the uniqueness of this processing route in the synthesis of various materials. In the following, we shall discuss the synthesis of each of these materials with detailed analyses on the efficacy of the process. In addition, cryomilled powders have been used to obtain various shapes. Cryomilling has also been utilized to synthesize advanced materials; graphene, $\mathrm{MoS}_{2}$, etc.

\subsection{Pristine Metallic Nanoparticles}

The metallic nanoparticles having zero/negligible foreign contamination know as pristine metallic nanoparticles., The preparation technique may impart/induce foreign substances 
during synthesis, leading to contamination of the NPs. Pristine NPs, with reactive surface due to high surface to volume ratio, are prone to bind with airborne contaminations. Consequently, the preparation of metallic nanoparticles is challenging. The existing techniques to prepare nanoparticles have been summarized in Figure 11. In general, basically, the preparation of nanoparticles has been classified into two types; 'top-down' and 'bottomup' approaches. Both approaches have many drawbacks, i.e., low yield of the nanomaterials, the requirement of hazardous chemicals (processing agents) to prevent coarsening of NPs, stabilization, etc. On the other hand, the mechanical milling process is capable of producing a large quantity of NPs. However, it requires a long time of milling, inducing the debris as contamination or foreign atom during preparation. The metallic materials are also prone to oxidization during the extended hours of milling. However, the formation of the robust oxide layer over nanoparticles or the utilization of capping agents on the surface of the nanoparticles to protect theme can even lead to the loss of their native properties. This review focused on the cryomilling, which belongs to the top-down approach 


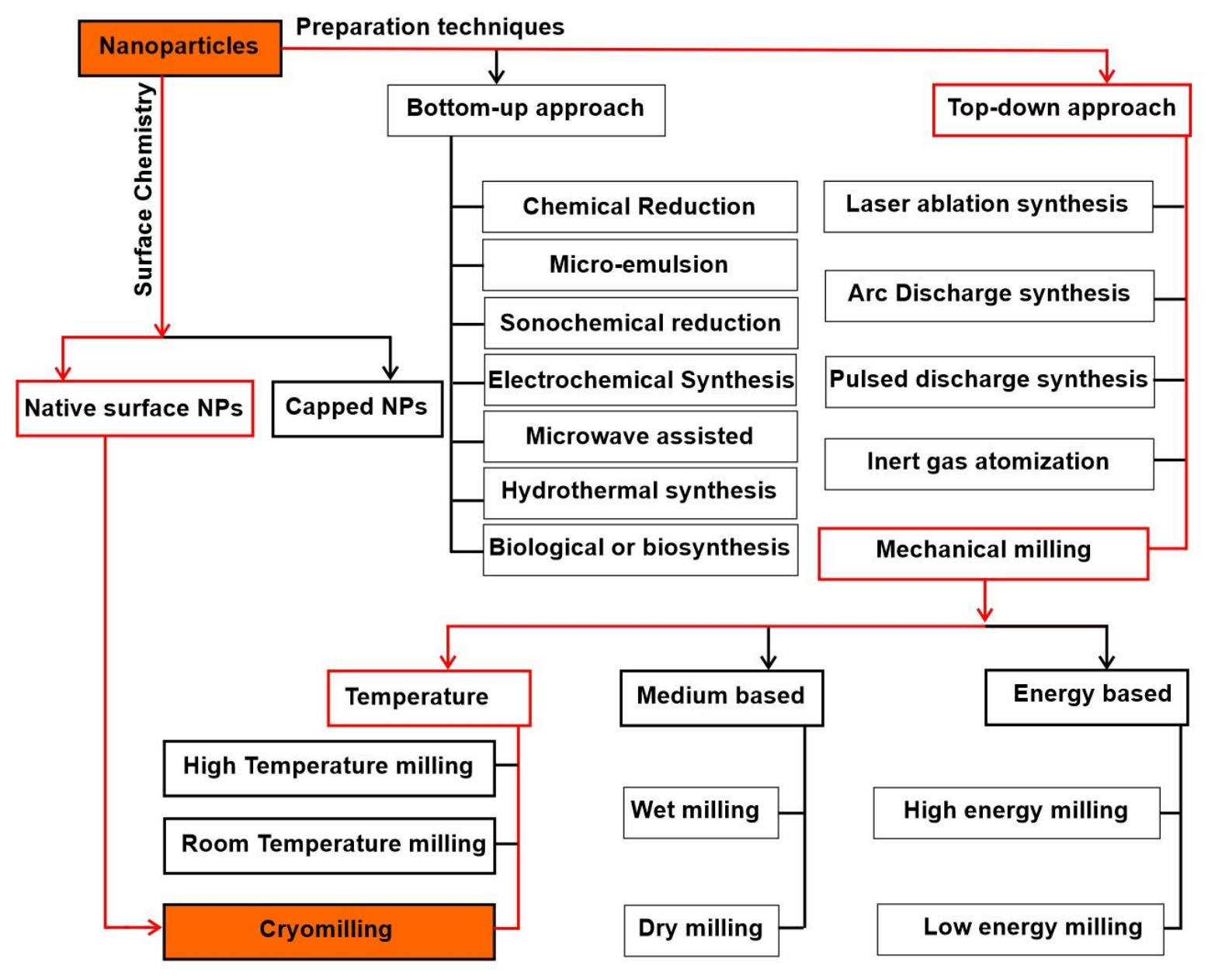

Figure 11: Preparation nanoparticles by different techniques

In comparison to other techniques, cryomilling is found to be a useful technique to prepare high pure metallic NPs in large quantities. It takes advantage of low temperatures, such as materials, to get fractures very easily at low-temperature and also reduces the oxidation/nitridation rate. Therefore, foreign and induced contamination can be reduced up to a negligible level. In the following, the synthesis of the nanoparticles/nanocrystals reported. The consolidation of the nanoparticles has been discussed in section 4.3.

First, the synthesis of pristine metallic NPs via cryomilling will be discussed. Several pristine metallic NPs have been synthesized via cryomilling such as $\mathrm{Cu}, \mathrm{Ag}, \mathrm{Fe}, \mathrm{Zn}$, etc. The important characteristics of these metallic NPs are rapid grain refinement, narrow size distribution, contamination-free. In fact, some of these metallic NPs are found to be free- 
standing in liquids; methanol, ethanol, benzene, etc. Barai et al.[30] have reported the successful synthesis of free-standing $\mathrm{Cu}$ nanoparticles using cryomilling. Similarly, Zn freestanding nanoparticles were synthesized using combined cryomilling and room temperature milling [102]. However, Zhang et al.[118, 119] have reported that the average grain of Zn can be reduced to only $17 \mathrm{~nm}$ in 12 hours of cryomilling. Interestingly, a large number of grains with size varying from 2 to6 $\mathrm{nm}$ forms in the early-stage of cryomilling. Hence, cryomilling is effective in achieving finer scale NPs with less hours of cryomilling.

In comparison to room temperature milling, the cryomilling reduces the particle size rapidly with finer particle size. The variation of size with milling at room temperature and cryotemperature is shown in Figure 12. After three hours of room temperature milling, the size of the average nanoparticles was $50 \pm 4 \mathrm{~nm}$. Similarly, the average size of the nanoparticles is $32 \pm 4 \mathrm{~nm}$ by cryomilling. Although the main purpose of cryomilling is to obtain pristine nanoparticles, it also leads to finer refinement of the NPs [120]. 


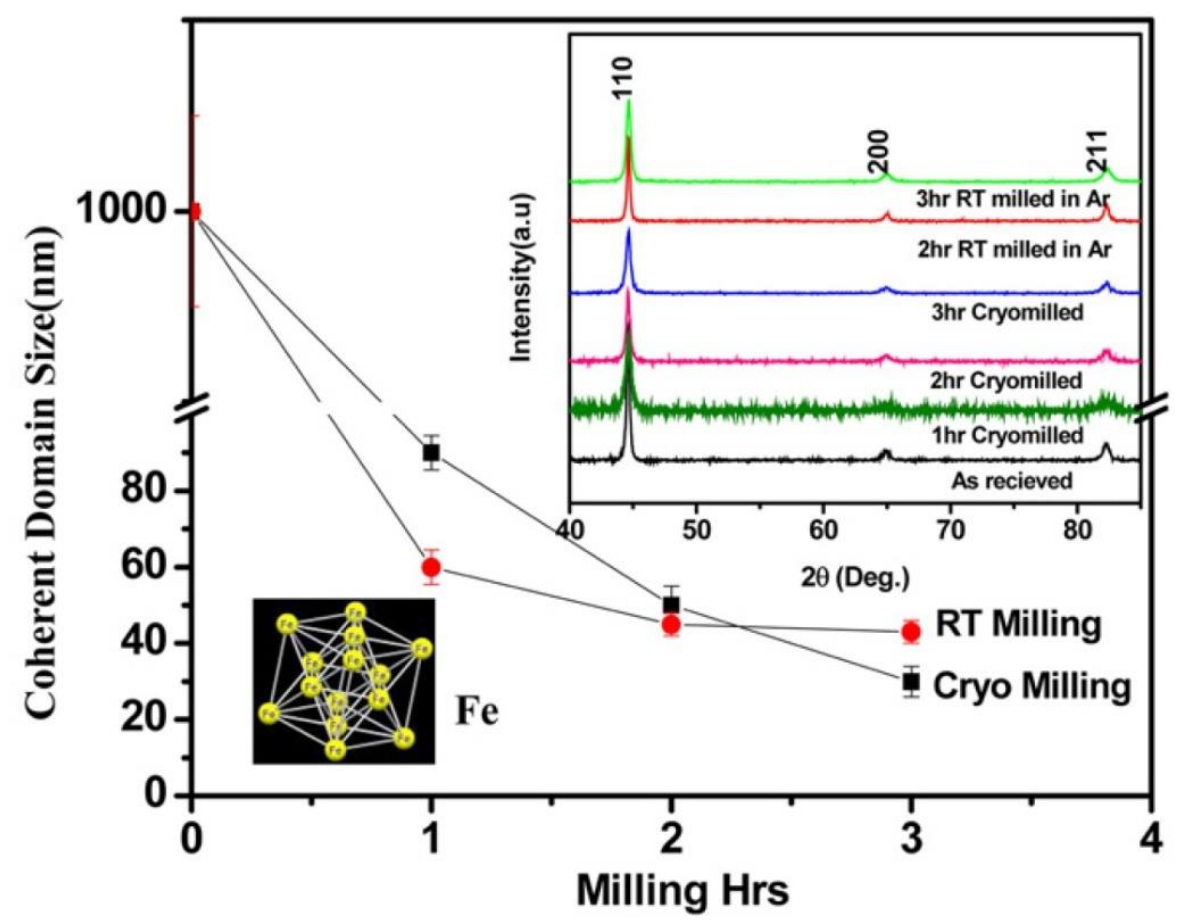

Figure 12: variation of particle size against the time of milling at room temperature and cryogenic temperature (inset shows the XRD pattern of iron nanoparticles)[120].

Kumar et al. $[\underline{10}, \underline{11}, \underline{31]}$ have reported the synthesis of pristine metallic nanoparticles with the same technique. The surfactant-free (pristine surface NPs) Ag and Al NPs exhibit narrow size distribution, as shown in Figure 13(b). Interestingly, Ag and Al NPs don't exhibit any surface contamination probed using X-ray photoelectron spectroscopy (XPS). The compositions of NPs are summarized in Table 2 and Table 3. [11]. Similarly, there is no oxide content in the Al NPs as compared to as-received powder, indicated by the XPS investigation [11]. The total contribution of oxygen can be related to sources such as surface adsorbed oxygen $(533.5 \mathrm{eV})$ [121], hydroxide/oxyhydroxide $(532.4 \mathrm{eV})[\underline{122}, \underline{123}]$, and aluminium oxide $(531.33 \mathrm{eV})$ [124] 

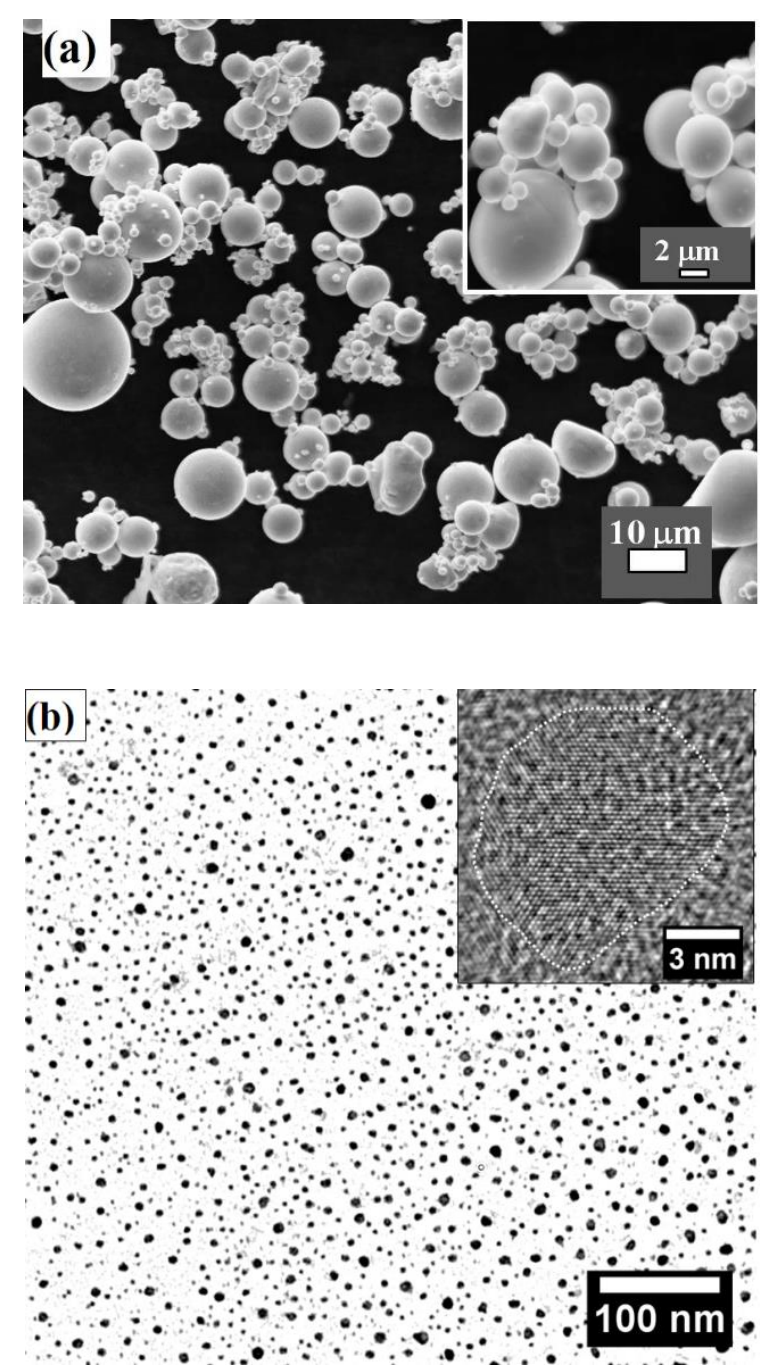

Figure 13: (a) FESEM image of silver particles as received (b) TEM bright-field micrograph of Ag nanoparticles after 7 hours of cryomilling (inset shows a high-resolution image)[11]

Table 2 : Surface composition of as received and after 7 hours of Cryomilling using XPS

\begin{tabular}{cccc}
\hline \hline Name of sample & $\begin{array}{c}\mathbf{A g} \\
(\text { atom\%) }\end{array}$ & $\begin{array}{c}\mathbf{C} \\
\text { (atom\%) }\end{array}$ & $\begin{array}{c}\mathbf{O} \\
\text { (atom\%) }\end{array}$ \\
\hline \hline As received Ag & 58.57 & 33.96 & 7.46 \\
\hline 7 h cryomilled Ag NPs & 67.03 & 20.84 & 12.13 \\
\hline
\end{tabular}


Table 3: Surface composition of $\mathrm{Al}$ (as received) and $\mathrm{Al}$ (Cryomilled) as NPs estimated by XPS.

\begin{tabular}{ccc}
\hline \hline Element & $\begin{array}{c}\text { As received (Al) } \\
(\text { atom \% })\end{array}$ & $\begin{array}{c}\text { Cryomilled (Al) } \\
\text { (atom \%) }\end{array}$ \\
\hline \hline $\mathrm{Al}$ & $33.73 \pm 0.5$ & $35.54 \pm 0.5$ \\
\hline $\mathrm{O}$ & $48.09 \pm 1$ & $47.40 \pm 1$ \\
\hline
\end{tabular}

\subsection{Pristine Alloys Nanoparticles}

The foreign contaminations, which are generally induced during processing, include oxide/nitride formed during synthesis or handling due to a high surface to volume ratio of NPs. During the chemical synthesis of NPs, the surface of particles is normally protected by using capping agents. The synthesis of pristine alloy NPs is a challenging task in the scientific community because of the difference in the chemical potential of the materials in the pristine form vis-à-vis compound. The different reactivity of the components either promotes the formation of intermetallic compounds or separates out from the matrix. A long time of milling is required to achieve nanosized particles during the mechanical milling at room temperature, and this can slowly introduce impurities from the milling tool or the environment, which is unavoidable during synthesis. However, the cryomilling process accelerates the fracturing process and form nanoparticles within 6-8 hours, reducing the milling debris at the negligible level and capable of synthesizing even pristine alloy nanoparticles, which is discussed next.

\subsubsection{Nanoparticles from Cast and Homogenized Ingot}

A combination of casting and cryomilling can be utilized to synthesize homogeneous alloy nanoparticles, which is thus considered a novel technique. It has more advantages as contamination from the milling media, and oxidation is expected to be low. The cast and homogenized ingot can be used as starting materials allowing the synthesis of NPs with better compositional homogeneity. Kumar et al.[12] have reported the synthesis of the high entropy 
alloy (HEA) nanoparticles consisting of five metallic elements in a single phase. First, the HEA alloys were synthesized by casting routes, instead of longer mechanical alloying (MA) of a mixture of five elemental powders. The ingots were substantially homogenized at elevated temperature. After crushing them, smaller pieces were milled at cryo-temperature to obtain pristine single-phase HEA nanoparticles of three different alloy systems $\left(\mathrm{Cu}_{0.2} \mathrm{Ag}_{0.2} \mathrm{Au}_{0.2} \mathrm{Pt}_{0.2} \mathrm{Pd}_{0.2}\right),\left(\mathrm{Fe}_{0.2} \mathrm{Cr}_{0.2} \mathrm{Mn}_{0.2} \mathrm{~V}_{0.2} \mathrm{Al}_{0.2}\right)$, and $\left(\mathrm{Fe}_{0.2} \mathrm{Cr}_{0.2} \mathrm{Mn}_{0.2} \mathrm{Ni}_{0.2} \mathrm{Co}_{0.2}\right)$ [12]. The nanoparticles were found to be free from any foreign contamination, which is evidenced by EPMA (Electron probe microanalyzer)-WDS (wavelength dispersive spectrum), as shown in Figure 14 [12].

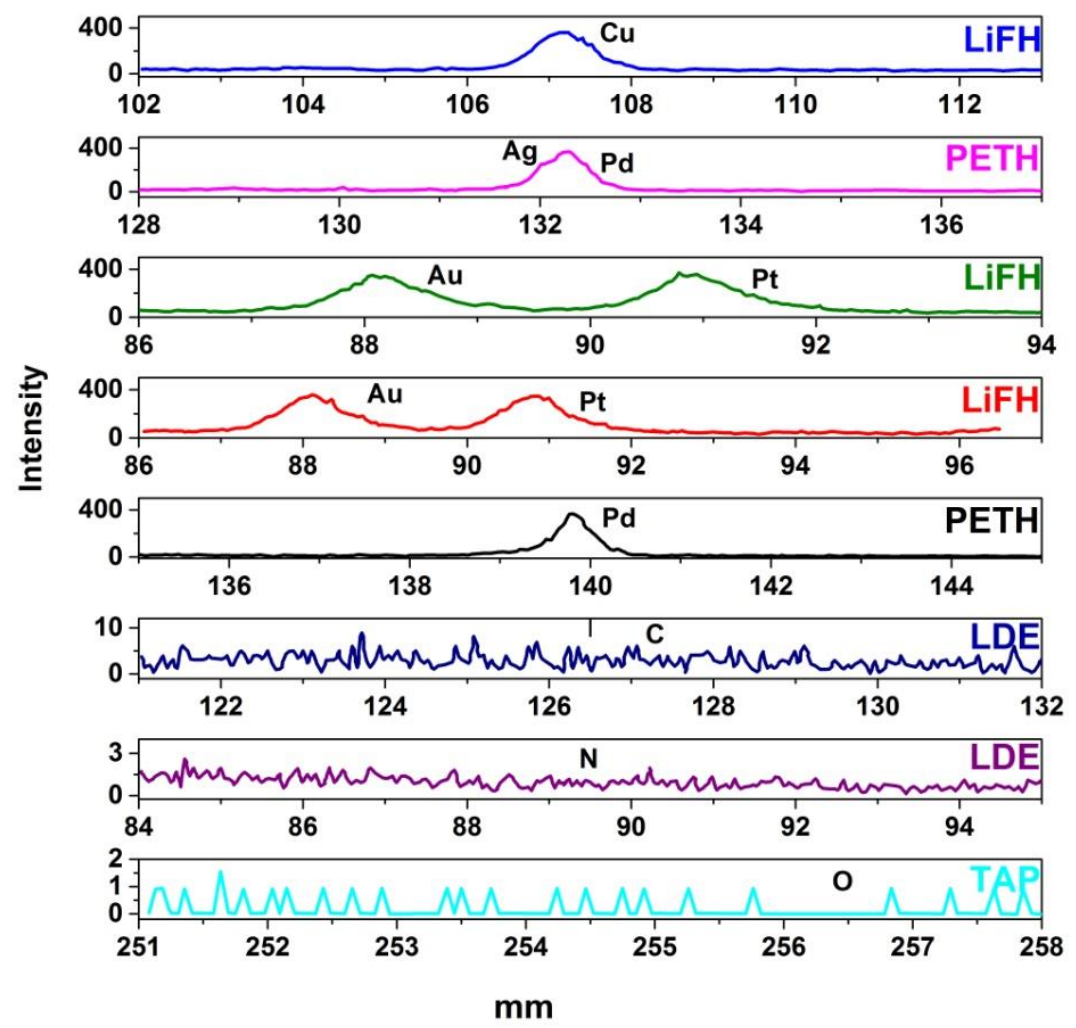

Figure 14: EPMA (WDS) spectra of $\mathrm{Cu}_{0.2} \mathrm{Ag}_{0.2} \mathrm{Au}_{0.2} \mathrm{Pt}_{0.2} \mathrm{Pd}_{0.2}$ nanoparticles [lithium fluoride $(\mathrm{LiFH})$ crystals; Layered dispersion element (LDE); pentaerythritol (PET); thallium acid phthalate (TAP)][12]. 


\subsection{Nanostructured Alloys and their consolidation}

The process of cryomilling also allows synthesizing nanocrystalline or ultra-fine grained bulk specimens from the powder. This can be done using a two-step process. First, milling is carried out to obtain the nanocrystalline powder, and this is subsequently followed by consolidation to obtain the bulk specimen. This even allows us to measure the properties of the bulk nanostructured materials. The nanostructured materials, synthesized by cryomilling, followed by consolidation, exhibit distinctly different properties as compared to the conventional ones. The final property will depend on the microstructural features (primarily grain size) of the consolidated specimens. It is important to note that the materials have grain size varying from 10-100 $\mathrm{nm}$ in a consolidated powder called nanostructured materials. In contrast, materials with grain size varying from 100 to $500 \mathrm{~nm}$, are known as ultra-fine grain (UFG) materials [르]. The consolidation route is found to dictate the final grain size. A large number of nanocrystalline material systems, prepared via cryomilling, followed by consolidation, are reported in the literature. They exhibit exceptional properties. This includes NiAl [125] NiCrAlY [126-128], CoNiCrAlY [129], Zn-22 \% Al [27, 130], Ti-6Al-4V [131] Fe-14Cr-3W-0.1Ti with $\mathrm{Y}_{2} \mathrm{O}_{3}$ [132], commercially pure Ti [133], Cu-Zn-Al [134], Al-Si alloy[25] etc. Although, during consolidation, the final grain size is expected to remain in the range of ultrafine range temperature rise, and the fact that the tendency of coarsening of the existing nanoparticles during consolidation. Interestingly, the surface of the nanoparticles can react with the liquid nitrogen, or atmospheric oxygen in the wet milling and tend to form layers of oxide and nitrides, leading to stabilization of the particle size during consolidation [135]. Therefore, the coarsening phenomenon can be controlled by adding some oxide and nitride NPs during cryomilling. For example; TiN nanoparticles were added during cryomilling of commercially pure titanium [136], 1 wt $\%$ diamantane nanoparticles in cryomilling of $\mathrm{Al}$ powder[137], 6.5 vol\% SiC nanoparticles in Al5083 alloy [138]; Al5083 
with $\mathrm{B}_{4} \mathrm{C}[139]$ to retain the size of the particles in the nanometric regime. $2 \mathrm{wt} \% \mathrm{AlN}$ nanoparticles added to $\mathrm{Ni}$ powder can even reduce $\mathrm{Ni}$ grain size up to $37 \mathrm{~nm}$ during cryomilling. In contrast, nanoparticles can only be reduced up to $100 \mathrm{~nm}$ without AlN [140]. The presence of process control agents (PCA) in the cryomilled powder can also affect the quality of consolidating powder. In an experiment, $\mathrm{Al}(99.9 \%)$ powder was wet-milled in a cryomill with initial average particles size $50 \mu \mathrm{m}$. Subsequently, $0.25 \mathrm{wt} \%$ stearic acid (as PCA) was added to reduce adhesion of the particles with ball and vial during milling. The consolidated Al powders, prepared by 4 hours and 8 hours of cryomilling, show an average grain size of $43 \mathrm{~nm}$ and $28 \mathrm{~nm}$, respectively. In addition, Al powder cryomilled for 4 hours was found to be less homogeneous compared to 8 hours [29]. The cryoliquid is also found to play a significant role in the quality and grain size of the consolidated powder. The cryomilled $\mathrm{Ni}$ shows higher lattice parameter when cryomilled in $\mathrm{LN}_{2}$ as compared to LAr. It has been concluded that the $\mathrm{N}$ atoms take part to form $\mathrm{Ni}-\mathrm{N}$ solid solution, leading to change of lattice parameter[141]. Some investigations have also been reported on the improvement of mechanical properties of the consolidated alloy powder, synthesized by cryomilling. Levernia et al. $[\underline{22}, \underline{99}, \underline{142}, \underline{143}]$ have reported the microstrain and average grain size variation after cryomilling and consolidation of $\mathrm{Al} 7.5 \% \mathrm{Mg}$ alloy. The alloys showed increased ductility and toughness after cryomilling. The fracture toughness has been found to improve from 8.3 to $17.5 \mathrm{MPa} \cdot \mathrm{m}^{1 / 2}$ and ductility from 4.4 to $14 \%$ [144]. Han et al.[145] have cryomilled the $5083 \mathrm{Al}$ alloy for 8 hours in nitrogen slurry and consolidated the milled powder using hot isostatic pressing (HIP). The consolidated sample showed higher creep resistance compared to the conventional $5083 \mathrm{Al}$ at same level of stress, exhibiting three distinct creep regions shown in Figure 15. This includes the low-stress region I with stress exponent 1.1, high stress region II with stress exponent 9, and the transition region. The microstructure of the cryomilled $5083 \mathrm{Al}$ alloy is reported to be stable even after annealing at 
573 and $623 \mathrm{~K}$ with only slight grain growth, possibly due to the presence of and aluminum oxide nano-precipitates[145] in the powder. In addition, the cryomilled $5083 \mathrm{Al}$ alloy exhibits higher ductility at a lower strain rate[146]. The reason for the high strength of the cryomilled materials is related to many contributions, mainly grain size and solid solution strengthening $[\underline{22}, \underline{147-150]}$.

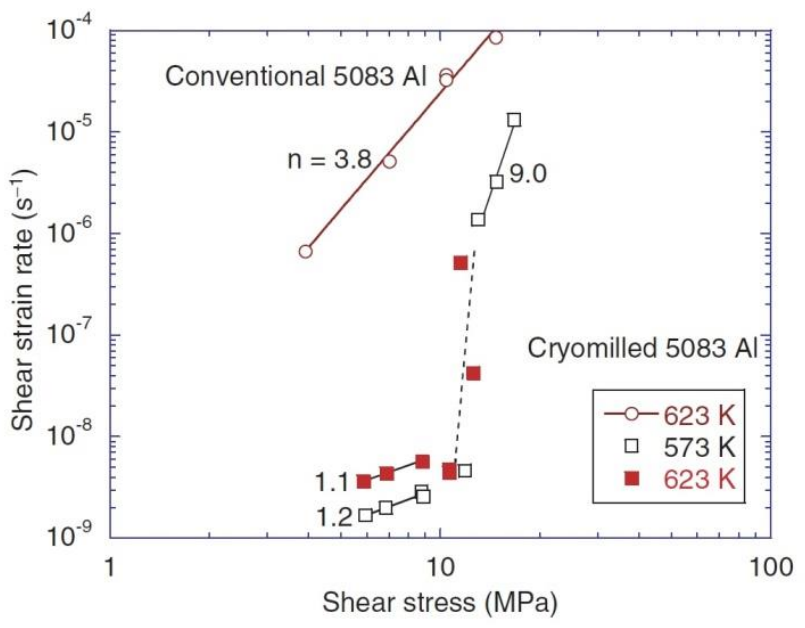

Figure 15: Shear stress vs. shear strain of conventional and cryomilled $5083 \mathrm{Al}$ alloy[145] The cryomilled reduced the size of particles and homogenized the alloy mixture with the addition of other additives metals/alloys[151].

In addition, the efforts have been made to prepare other materials in the bulk form using cryomilled powder. Kim et al.[132, 152] have reported the investigation on the effect of milling temperature to synthesize oxide dispersion strengthened (ODS) steels [152-154] at three different temperatures, such as room temperature, -70 and $-150^{\circ} \mathrm{C}$. The mixture of $\mathrm{Fe}-$ $14 \mathrm{Cr}-3 \mathrm{~W}-0.4 \mathrm{Ti}$ was cryomilled along with $\mathrm{Y}_{2} \mathrm{O}_{3}$ for 40 hours at three different temperatures. The results reveal that as temperature decreases, particle size also undergoes reduction (summarized in Table 4). It is also reported that the ODS steels prepared via cryomilling at $-150^{\circ} \mathrm{C}$ exhibits high tensile strength (1800 MPa) and good ductility due to the 
multimodal grain size distribution that can hold higher dislocation density inside the grain (Figure 16).

Table 4:Average particles size milled at room temperature, $-70^{\circ} \mathrm{C}$ and $-150^{\circ} \mathrm{C}$ [152]

\begin{tabular}{|c|c|c|c|}
\hline \multirow[t]{2}{*}{ Milling Temperature } & \multicolumn{3}{|c|}{ Milling duration in hours } \\
\hline & 0 & 10 & 40 \\
\hline Room Temperature & \multirow{3}{*}{$50 \pm 20(\square \mathrm{m})$} & $80 \pm 40(\square \mathrm{m})$ & $70 \pm 30(\square \mathrm{m})$ \\
\hline$-70^{\circ} \mathrm{C}$ & & $35 \pm 12(\square \mathrm{m})$ & $25 \pm 10(\square \mathrm{m})$ \\
\hline$-150^{\circ} \mathrm{C}$ & & $15 \pm 8(\square \mathrm{m})$ & $8 \pm 5(\square m)$ \\
\hline
\end{tabular}

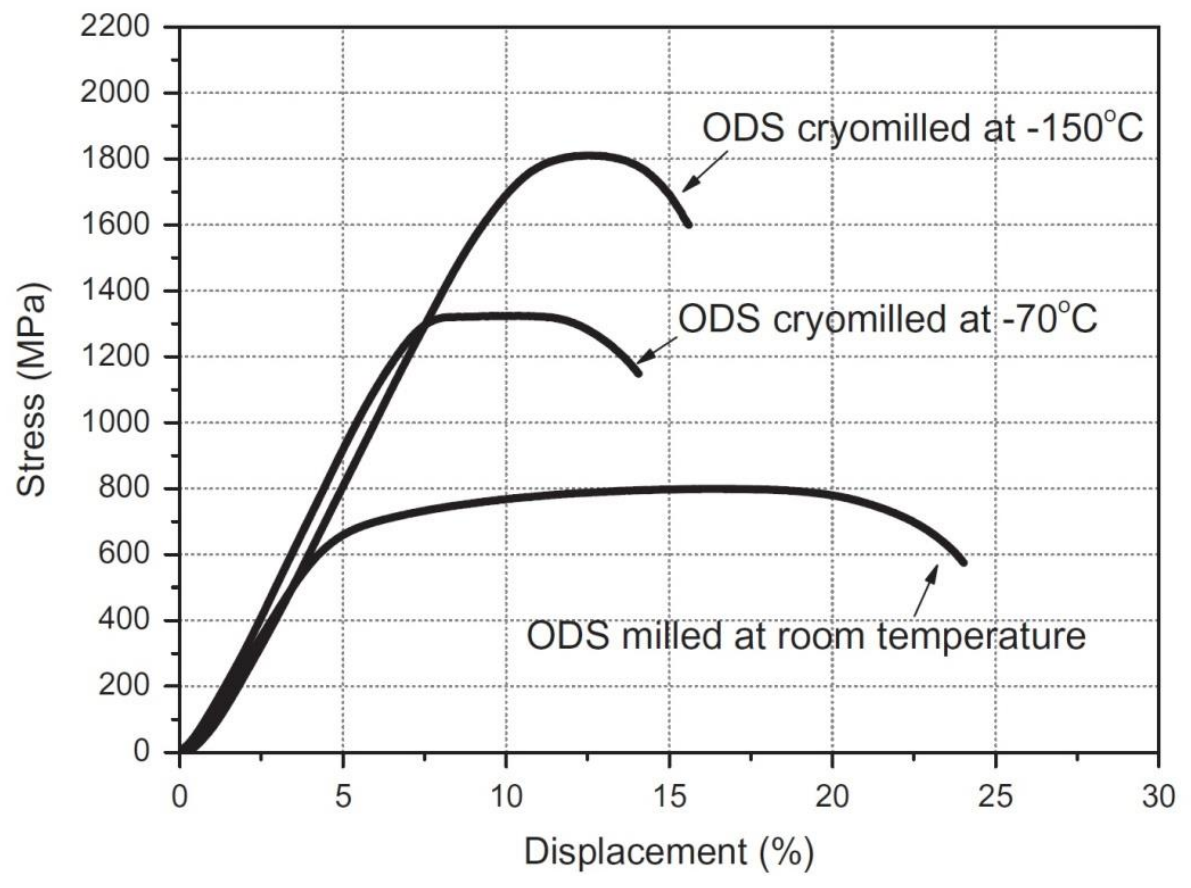

Figure 16: Engineering tensile stress vs. displacement of ODS steel synthesized at three different temperatures (temperature mentioned over the curve)[152].

Similarly, the TiFe alloy was milled with $4 \mathrm{wt} \% \mathrm{Zr}$ at room temperature in argon and at cryogenic temperature in air for improving the hydrogen absorption. Interestingly, the cryomilled powder doesn't show any absorption. It might be due to the presence of a very thin layer of oxide, which is not detected in characterization[155]. The more related literature is summarized in Table 5 for the interested reader. 
Table 5: Literature nanostructure prepared by cryomilling and their consolidation

\begin{tabular}{|c|c|c|c|c|c|}
\hline Materials & $\begin{array}{l}\text { Cryomilling } \\
\text { hours } \\
\text { (coolant) }\end{array}$ & $\begin{array}{l}\text { Sintering } \\
\text { technique }\end{array}$ & $\begin{array}{l}\text { Grains } \\
\text { size }\end{array}$ & Properties studied & References \\
\hline $\mathrm{Al}-7.5 \% \mathrm{Mg}$ & $8 \mathrm{~h},\left(\mathrm{LN}_{2}\right)$ & Hot isotactic & $\begin{array}{l}200- \\
300\end{array}$ & Mechanical strength & {$[\underline{156}, \underline{157]}$} \\
\hline Al5083 & $8 \mathrm{~h}\left(\mathrm{LN}_{2}\right)$ & $\begin{array}{l}\text { Spark } \\
\text { plasma } \\
\text { sintering }\end{array}$ & 51 & Mechanical strength & [158] \\
\hline $\mathrm{Ti}-45 \mathrm{Al}-8 \mathrm{Nb}$ & $40 \mathrm{~h}$ & $\begin{array}{l}\text { Spark } \\
\text { plasma } \\
\text { sintering }\end{array}$ & 217 & Fracture properties & [159] \\
\hline $\mathrm{Cu}-\mathrm{Al}-\mathrm{B}$ & $8 \mathrm{~h}\left(\mathrm{LN}_{2}\right)$ & - & $11 \mathrm{~nm}$ & Effect of B and stability & [160] \\
\hline $\mathrm{Al}-\mathrm{Zn}-\mathrm{Mg}-\mathrm{Cu}$ & 2 and 10 & - & - & Deformation twin & [161] \\
\hline $\begin{array}{l}\text { ODS steel- } \\
\mathrm{Y}_{2} \mathrm{O}_{3}\end{array}$ & $40 \mathrm{~h}\left(\mathrm{LN}_{2}\right)$ & $\begin{array}{l}\text { Hot isostatic } \\
\text { pressing }\end{array}$ & 300 & Microstructure and fracture & [162] \\
\hline NiCoCrAlY & $16 \mathrm{~h}\left(\mathrm{LN}_{2}\right)$ & Coating & 10 & Oxidation & [163] \\
\hline NiAl-AlN & $4 \mathrm{~h}\left(\mathrm{LN}_{2}\right)$ & Hot extruded & 25 & Mechanical & {$[\underline{164}, \underline{165]}$} \\
\hline $\mathrm{Fe}-10 \mathrm{wt} \% \mathrm{Al}$ & $\begin{array}{l}25 \mathrm{~h}\left(\mathrm{LN}_{2}\right. \\
\left.\text { and } \mathrm{LAr}_{2}\right)\end{array}$ & Hot press & 10 & Grain growth & {$[\underline{166}, \underline{167]}$} \\
\hline $\mathrm{Mg}$ AZ80 & $8 \mathrm{~h}\left(\mathrm{LN}_{2}\right)$ & $\begin{array}{l}\text { Spark } \\
\text { plasma } \\
\text { sintering }\end{array}$ & 40 & Strength & {$[\underline{28}]$} \\
\hline $\mathrm{Al}-7.5 \% \mathrm{Mg}$ & $8 \mathrm{~h}\left(\mathrm{LN}_{2}\right)$ & Extrusion & 300 & Tensile at high Temp & [143] \\
\hline $\mathrm{Al} 5083 / \mathrm{B}_{4} \mathrm{C}$ & $24 \mathrm{~h}\left(\mathrm{LN}_{2}\right)$ & $\begin{array}{l}\text { Cold } \\
\text { isotactic } \\
\text { pressing } \\
\text { and hot } \\
\text { extrusion }\end{array}$ & $\begin{array}{l}20- \\
100\end{array}$ & HRTEM, EELS & [168] \\
\hline $\mathrm{Cu}-05 \% \mathrm{Zr}$ & $8 \mathrm{~h}\left(\mathrm{LN}_{2}\right)$ & Annealing & 17 & Thermal stability & [169] \\
\hline $\mathrm{Cu}-12 \% \mathrm{Al}$ & $8 \mathrm{~h}\left(\mathrm{LN}_{2}\right)$ & Annealing & 40 & Grain size stabilization & [170] \\
\hline $\mathrm{AA} 7075 / \mathrm{B}_{4} \mathrm{C}$ & $8 \mathrm{~h}\left(\mathrm{LN}_{2}\right)$ & Plasma & 77 & Effect of Boron nano and & {$[\underline{171}, \underline{172]}$} \\
\hline
\end{tabular}




\begin{tabular}{|c|c|c|c|c|c|}
\hline & & activated & & microparticles & \\
\hline $\mathrm{AA} 7075 / \mathrm{B}_{4} \mathrm{C}$ & $8 \mathrm{~h}\left(\mathrm{LN}_{2}\right)$ & $\begin{array}{l}\text { Field } \\
\text { assistant } \\
\text { sintering }\end{array}$ & $\begin{array}{l}200- \\
300\end{array}$ & Precipitate segregation & [173] \\
\hline $\begin{array}{l}\text { Al- } \\
\text { diamantane }\end{array}$ & $8 \mathrm{~h}\left(\mathrm{LN}_{2}\right)$ & $\begin{array}{l}\text { Hot } \\
\text { isostatic }\end{array}$ & 155 & $\begin{array}{l}\text { Inverse Hall-Petch } \\
\text { behavior }\end{array}$ & [174] \\
\hline Al5000/AlN & $6 \mathrm{~h}\left(\mathrm{LN}_{2}\right)$ & Powder & 50 & Contamination & {$[\underline{20}]$} \\
\hline $\mathrm{Al} 5083 / \mathrm{B}_{4} \mathrm{C}$ & $12 \mathrm{~h}\left(\mathrm{LN}_{2}\right)$ & $\begin{array}{l}\text { Hot } \\
\text { isostatic }\end{array}$ & 38 & Mechanical properties & [175] \\
\hline $\mathrm{Al}-7.5 \% \mathrm{Mg}$ & $8 \mathrm{~h}\left(\mathrm{LN}_{2}\right)$ & $\begin{array}{l}\text { High- } \\
\text { pressure } \\
\text { torsion }\end{array}$ & $\begin{array}{l}20- \\
200\end{array}$ & $\begin{array}{l}\text { Microstructure and } \\
\text { hardness }\end{array}$ & [176] \\
\hline $\begin{array}{l}\mathrm{Cu}-\mathrm{Y}_{2} \mathrm{O}_{3} \mathrm{Cu}- \\
\mathrm{CaO}\end{array}$ & $20 \mathrm{~h}\left(\mathrm{LN}_{2}\right)$ & $\begin{array}{l}\text { Hot } \\
\text { pressing }\end{array}$ & 150 & $\begin{array}{l}\text { Microstructure and } \\
\text { hardening }\end{array}$ & [177] \\
\hline $\mathrm{Ti}$ & $8 \mathrm{~h}$ (LAr) & $\begin{array}{l}\text { Spark } \\
\text { plasma } \\
\text { sintering }\end{array}$ & $50-80$ & Microstructure and texture & [178] \\
\hline Al5083 & $8 \mathrm{~h}\left(\mathrm{LN}_{2}\right)$ & $\begin{array}{l}\text { Hot } \\
\text { Isostatic } \\
\text { pressing }\end{array}$ & $10-50$ & Microstructure & [179] \\
\hline $\begin{array}{l}\mathrm{Al}-10 \% \mathrm{Zn}- \\
3 \% \mathrm{Mg}- \\
1.8 \% \mathrm{Cu}\end{array}$ & $10 \mathrm{~h}\left(\mathrm{LN}_{2}\right)$ & $\begin{array}{l}\text { Spark } \\
\text { plasma } \\
\text { sintering }\end{array}$ & 28 & $\begin{array}{l}\text { Microstructure and } \\
\text { precipitates }\end{array}$ & [180] \\
\hline Al5083 & $12 \mathrm{~h}$ (LAr) & $\begin{array}{l}\text { Hot press } \\
\text { and hot } \\
\text { extrusion }\end{array}$ & 57 & Tribological behavior & [181] \\
\hline Al5083 & $10 \mathrm{hr}\left(\mathrm{LN}_{2}\right)$ & Extruded & 305 & $\begin{array}{l}\text { High strain rate } \\
\text { superplasticity }\end{array}$ & [182] \\
\hline$\square$-TiAl & $8 \mathrm{hr}\left(\mathrm{LN}_{2}\right)$ & $\begin{array}{l}\text { Spark } \\
\text { plasma } \\
\text { sintering }\end{array}$ & $40 \mathrm{~nm}$ & Grain refinement & [183] \\
\hline $\mathrm{Fe}_{78} \mathrm{Bi}_{13} \mathrm{Si} 9$ & $8 \mathrm{hr}\left(\mathrm{LN}_{2}\right)$ & - & $2 \mathrm{~nm}$ & Recrystallization & [184] \\
\hline $\mathrm{Fe}_{10} \mathrm{Al}$ & $\begin{array}{l}25 \\
\text { hours }\left(\mathrm{LN}_{2}\right)\end{array}$ & Compacted & 11 & $\begin{array}{l}\text { Thermal stability of } \\
\text { nancrystalline grains }\end{array}$ & [185] \\
\hline
\end{tabular}




\section{Other Applications of Cryomilling}

It is evident that the cryomilling has extensively been used for the pulverization of the materials as well as the synthesis of nanoparticles of various materials. In addition, it has also been utilized for other applications, including solid-state reactions, waste beneficiation, etc. In the following, some of these applications will be discussed in detail to bring about the basic and unique features of this process. Here, we shall focus on the functional properties of the cryomilled products. The salient examples are provided here to highlight the uniqueness of the cryomilling route in providing functional properties.

The Pd-10Rh alloy has been prepared by atomization and cryomilling. Further, both the asprepared powder has been tested for hydrogen absorption and found that cryomilled powder exhibits the highest hydrogen uptake, as shown in Figure 17. In contrast, the atomized powder shows lower hydrogen uptake. It might be due to the increased surface area to volume ratio, and relatively clean surface, promoting chemisorption on the surface of the alloy [186]. 


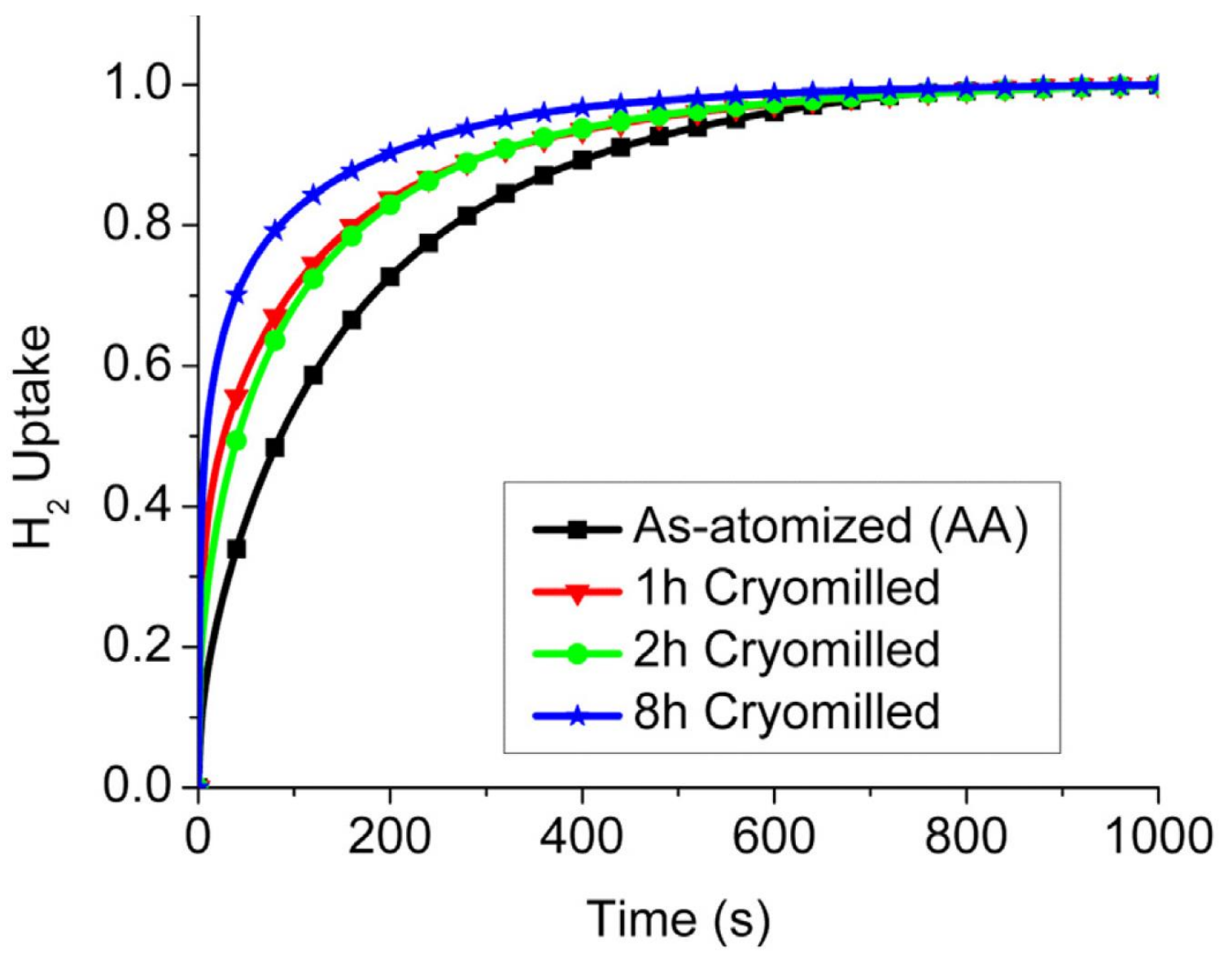

Figure 17: The hydrogen uptake of cryomilled and atomized Pd-10Rh alloy as a function of time[186].

In this same direction, Lee at el.[187] has studied the effects of cryomilling on the adsorption and desorption of hydrogen on multi-wall carbon nanotubes (MWCNTs). The MWCNTs, cryomilled at 300 and $700 \mathrm{rpm}$ for 2 and 6 hours, have been found to show the reduction of the agglomeration tendency at higher milling speed with a simultaneous reduction in size. The MWCNTs after cryomilling reveal broken, shorten, and rugged surface compared to the unmilled MWCNTs, as shown in Figure 18 (a-c). Hence, cryomilled MWCNTs adsorb 22\% more hydrogen, containing enhanced $34.9 \%$ pore volume as compared to the unmilled MWCNTs (as shown in Figure 18(d)). The decreased pore size and increase in the surface area are cited to be the reasons for significantly higher adsorption ofhydrogen [187]. The addition of cryomilled CNTs in chitosan further improves the conductivity of nanocomposites due to well dispersion and reduction of entanglements and agglomeration 
due to cryomilling [188]. In a nutshell, the effect of cryomilling offers increased surface area with a clean surface of the synthesized nanoparticles, improving the functional properties.
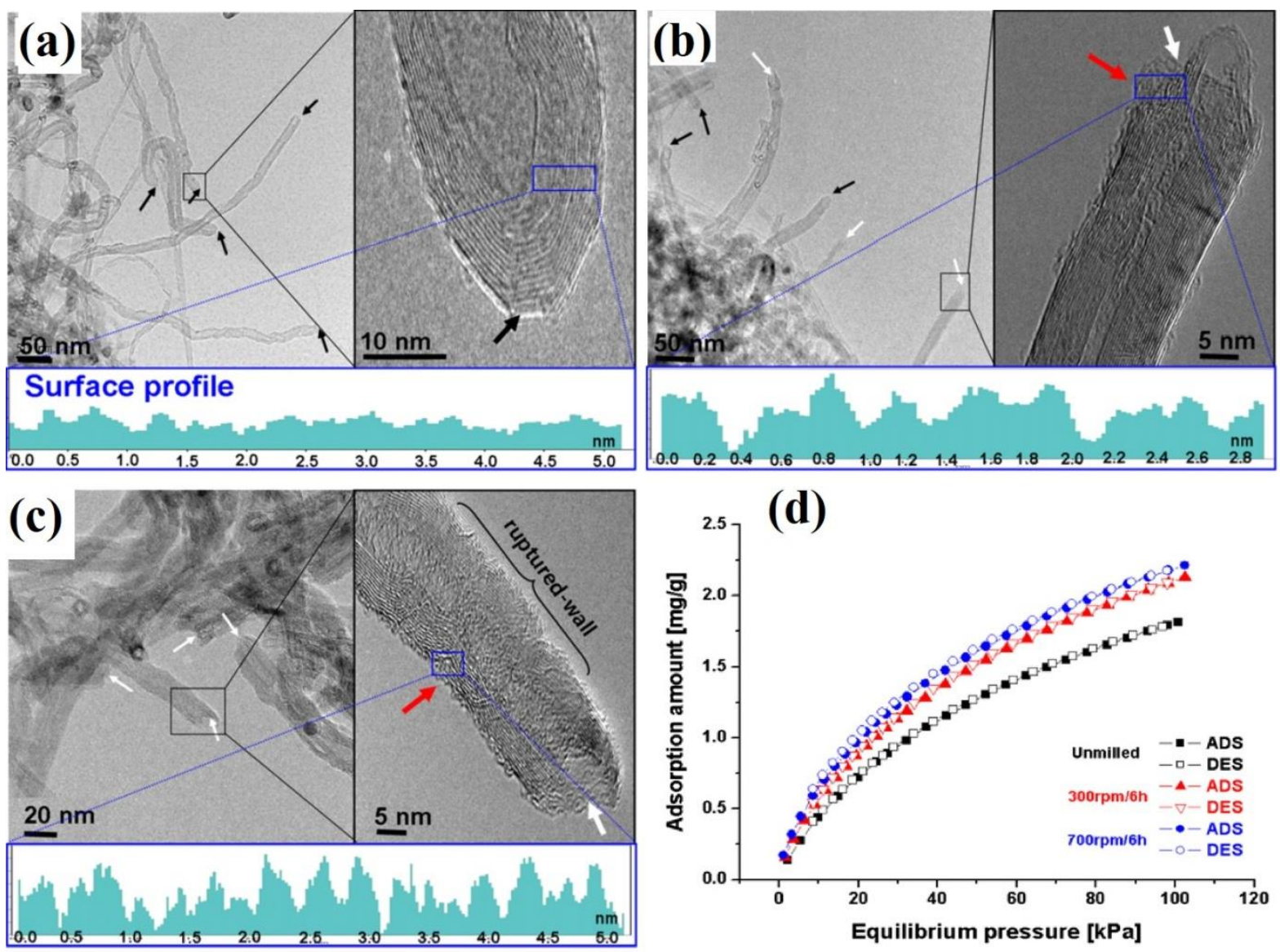

Figure 18: TEM bright-field image and profile images of unmilled and cryomilled multiwall carbon nanotubes (MWCNTs)(a) unmilled, (b) 300, and (c) $700 \mathrm{rpm}$ for $6 \mathrm{~h}$. (d)hydrogen storage adsorption (ADS) and desorption (DES) capacity[187].

\subsection{Cryomilling with in-situ Solid-State Reactions}

Mechanochemical synthesis; simultaneous mechanical milling and the chemical reaction were even widely utilized to prepare novel nanostructured materials. It is important to note that the mechanochemical process is mechanical milling with a chemical reaction, which can induce the chemical transformation in the materials by utilizing mechanical energy[189]. The temperature-sensitive materials can be milled at low-temperature due to the instability of materials at room and high temperatures. It includes the alkaline earth- Al metal complex 
$\left(\mathrm{Ti}\left(\mathrm{AlH}_{4}\right)_{4}, \mathrm{Fe}\left(\mathrm{AlH}_{4}\right)_{2}\right)$, which becomes unstable at $0^{\circ} \mathrm{C}$ and requires to be synthesized at low temperature. Pommerin et al. [190] have probed the stability of the $\mathrm{AlH}_{3}$ using ball milling and cryomilling and found that the room temperature milling for 1 hour leads to the decomposition of the $\mathrm{AlH}_{3}$ into $\mathrm{Al}$. On the other hand, cryomilling prevented the decomposition, and the final product was $\mathrm{AlH}_{3}$. Although the cryomilling of $\mathrm{AlH}_{3}$ along with $\mathrm{MeH}(\mathrm{M}: \mathrm{Li}, \mathrm{Na}, \mathrm{K})$ (eq. 10) does not lead to the synthesis of $\mathrm{MeAlH}_{4}$ as a by-product, neither a reactant nor $\mathrm{Al}$ metal was found to form.

$$
\mathrm{MeH}+\mathrm{AlH}_{3} \quad \text {---回Ball milling }\left(-196^{\circ} \mathrm{C}\right) \text {------- 回 } \mathrm{MeAlH}_{4}(\mathrm{Me}=\mathrm{Li}, \mathrm{Na}, \mathrm{K}) \ldots \ldots \text { (10) }
$$

The cryomilling can also be used for the in-situ reaction of two solids or solid with gas. Therefore, cryomill can also be considered as a chemical reactor. In this regard, Cai et al.[191] have reported the synthesis of $\mathrm{Mg}-\mathrm{MgO}$ nanocomposite using reactive cryomilling because milling at room temperature is found to be unable to refine the size of $\mathrm{Mg}$ due to extensive dynamic recovery. These authors have utilized a unique approach consisting of RT milling, followed by cryomilling to obtain the composites. $\mathrm{Mg}$ powder having particle size 80 $\mu \mathrm{m}$ was milled at room temperature for 5 hours under inert gas (Argon environment). Subsequently, the chamber was evacuated and refilled with 50\% Ar and $50 \% \mathrm{O}$ (internal gas pressure 1 bar) and cryomilled for 30 minutes (assumed that reaction completed in each cycle and achieved $5 \mathrm{vol} \% \mathrm{MgO}$ ). The mechanical properties of $\mathrm{Mg}-\mathrm{MgO}$ improved exceptionally compared to nanocrystalline $\mathrm{Mg}$. The key for the exceptional property was found to be reduction in the grain size and fine distribution of $\mathrm{MgO}$ nanoparticles located at grain boundaries[191]. The nanosized lithium particles (highly reactive) having a size less than 500 $\mathrm{nm}$ were prepared using cryomilling with an ionic liquid to protect the powder particles at nano size/. It shows exceptional electrochemical properties for lithium-ion batteries[192]. 
The cryomilling also can be utilized to induce the polymorphic transformations and has vigorously been utilized in the drug industry [193]. This process is found to very effective in reducing the risk of recrystallization and increase the drug solubility as some articles listed in Table 6.

Table 6: Cryomilling used for different drugs amorphization

\begin{tabular}{|c|c|c|c|}
\hline Drug & Cryomilling & Studied Properties & Reference \\
\hline $\begin{array}{l}\text { TMC125 } \\
\text { (Etravirine) }\end{array}$ & 3 hours $\left(\mathrm{LN}_{2}\right)$ & $\begin{array}{l}\text { Crystallization behavior at above and below } \\
\text { glass transition temperature }\end{array}$ & [194] \\
\hline Simvastatin & $\begin{array}{ll}1.5 & \text { hours } \\
\left(\mathrm{LN}_{2}\right) & \end{array}$ & $\begin{array}{l}\text { Amorphization of drug and compared stability } \\
\text { cryomilling vs. melted and quenched cooled }\end{array}$ & [195] \\
\hline Indomethacin & 1 hour & $\begin{array}{l}\text { Effect of cryomill on } \square \square \square \text { and } \square \text {, phase } \\
\text { Indomethacin }\end{array}$ & [196] \\
\hline $\begin{array}{l}\text { Ranitidine } \\
\text { hydrochloride } \\
\text { form } 1 \text {, and } 2\end{array}$ & 1 hour & $\begin{array}{l}\text { Synthesis of amorphous drug and capability to } \\
\text { retain stability }\end{array}$ & [197] \\
\hline $\begin{array}{l}\text { Sulfathiazole } \\
\text { form I and II }\end{array}$ & 2.5 hours & $\begin{array}{l}\text { The formation, physical stability, and } \\
\text { quantification of process-induced disorder }\end{array}$ & [198] \\
\hline Gliclazide & 3 hours & $\begin{array}{l}\text { Cocrystal and amorphous system with } \\
\text { chlorothiazide (CTZ), hydrochlorothiazide } \\
\text { (HTZ), indapamide (IND), triamterene (TRI) } \\
\text { and nifedipine (NIF) as well as benzamidine } \\
\text { (BZA) }\end{array}$ & [199] \\
\hline Piroxicam & 2 hours & $\begin{array}{l}\text { Mechanochromism } \quad \text { of } \\
\text { Accompanied by Intermolecular Proxicam } \\
\text { Transfer Probed by Spectroscopic Methods } \\
\text { and Solid-Phase Changes }\end{array}$ & [200] \\
\hline $\begin{array}{l}\text { Ziprasidone } \\
\text { and its } \\
\text { hydrochloride } \\
\text { salt }\end{array}$ & 1.5 hours & $\begin{array}{l}\text { Obtained amorphous state drug and estimated } \\
\text { the solubility against crystalline drug }\end{array}$ & [201] \\
\hline Furosemide & 1.5 hours & $\begin{array}{l}\text { Stabilization of furosemide and the role of } \\
\text { hydrogen bonding }\end{array}$ & [202] \\
\hline Furosemide & 2 hours & Chemical stability on cryogrinding & {$[\underline{203]}$} \\
\hline Simvastatin & 1.5 hours & Solid-state reactivity and powder crystallinity & {$[\underline{204}]$} \\
\hline Felodipine & 2.5 hours & Rate of dissolution and disintegration & {$[\underline{205]}$} \\
\hline $\begin{array}{l}\text { Caffeine-- } \\
\text { oxalic acid }\end{array}$ & 120 seconds & $\begin{array}{l}\text { Role of lattice distortion and dissociation of } \\
\text { co-crystal. }\end{array}$ & [206] \\
\hline
\end{tabular}




\begin{tabular}{|l|l|l|l|}
\hline $\begin{array}{l}\text { (CAFOXA) } \\
\text { and } \\
\text { dicalcium } \\
\text { phosphate } \\
\text { anhydrate } \\
\text { (DCPA) }\end{array}$ & & & \\
\hline Griseofulvin & 1 hour & Evaluation of crystal phase after cryomilling & [207] \\
\hline
\end{tabular}

\subsection{Cryomilling for Waste Beneficiation}

The increasing demands of plastics, electronics, non-renewable materials, etc. and their use in our daily life at an alarming rate have been causing unexpected and unprecedented damage to our ecosystem [208, 209]. The waste can cause severe environmental degradation with the rise in the air and water pollution as well as pollution of the food chain, leading to long term damage to the ecosystem $[\underline{209}, \underline{210}]$. Hence, proper disposal of these wastes as well as retrieve, reuse, and utilization of materials from the waste have been sought after for a long time. Recovery of precious metals, ceramics, and polymers from the waste will add value to society and make the usage of these materials sustainable. Although there are many techniques available for beneficiation of materials from these wastes, waste recycling utilizing cryomilling is relatively new, providing an excellent alternative with a high recovery rate, environmentally benign, and relatively cheap. It is expected that mechanical milling at extremely low temperatures will lead to breaking of the waste into ultrafine or nanocrystalline form as well as segregation into different types, allowing separating them. In the following, some specific examples from the literature are provided to highlight the uniqueness of cryomilling in this regard.

It is worth mentioning that a new strategy of recycling tires by cryomilling has first been reported by Smith et al. [211], in which the highly dispersed blended composites were synthesized. The used or waste tires and thermoplastics were cryomilled together to synthesize chemically active surfaces as no chemical interaction is expected between the 
thermoplastic and tires. This allows the synthesis of the good composite without any reaction product. V. Gente et al.[212] has studied the recycling of plastic waste from spent lead batteries and medical packaging blisters using cryo-comminution. Extremely low temperature is useful because of the embrittlement of the plastics. While room temperature is not useful because the comminution process generates heat, including partial melting of plastic [212]. This allows the usage of plastic and spent batteries to obtain useful materials. Jonna et al.[213] have reported recycling the mixed waste flaks (polypropylene and polyethylene) using the cryomilling process. The milled powder after consolidation found to exhibit $45 \%$ increment in the apparent modulus as no specific chemistry or specific polymer is being used for food packaging (milk, beverage, etc.), making it difficult for recycling the wastage (junk of many polymers).

However, waste beneficiation of electronic chips and circuits (computer electronic circuit boards) is even more challenging as they contain different types of materials, including oxides, pure metals, alloys, and polymers. Some of them are highly toxic and harmful for humankind when exposed to the open environment. Tiwary et al.[57] have reported a successful approach to recover materials from the printed electronics board using cryomilling. The $\mathrm{Cu}-\mathrm{Zn}-\mathrm{Sn}-\mathrm{Fe}-\mathrm{Ni}$ nanostructured alloy was synthesized by combined cryomilling and room temperature ball milling of waste PCBs[214]. The low-temperature milling enhanced separation and recovery of ceramics, metallic, and polymeric materials from the PCBs. The waste beneficiation of PCBs via cryomilling has been reported to provide more benefits as compared to other existing techniques. The cryomilling provides the highest recovery in less time and energy, as seen in Figure 19(a-b). 

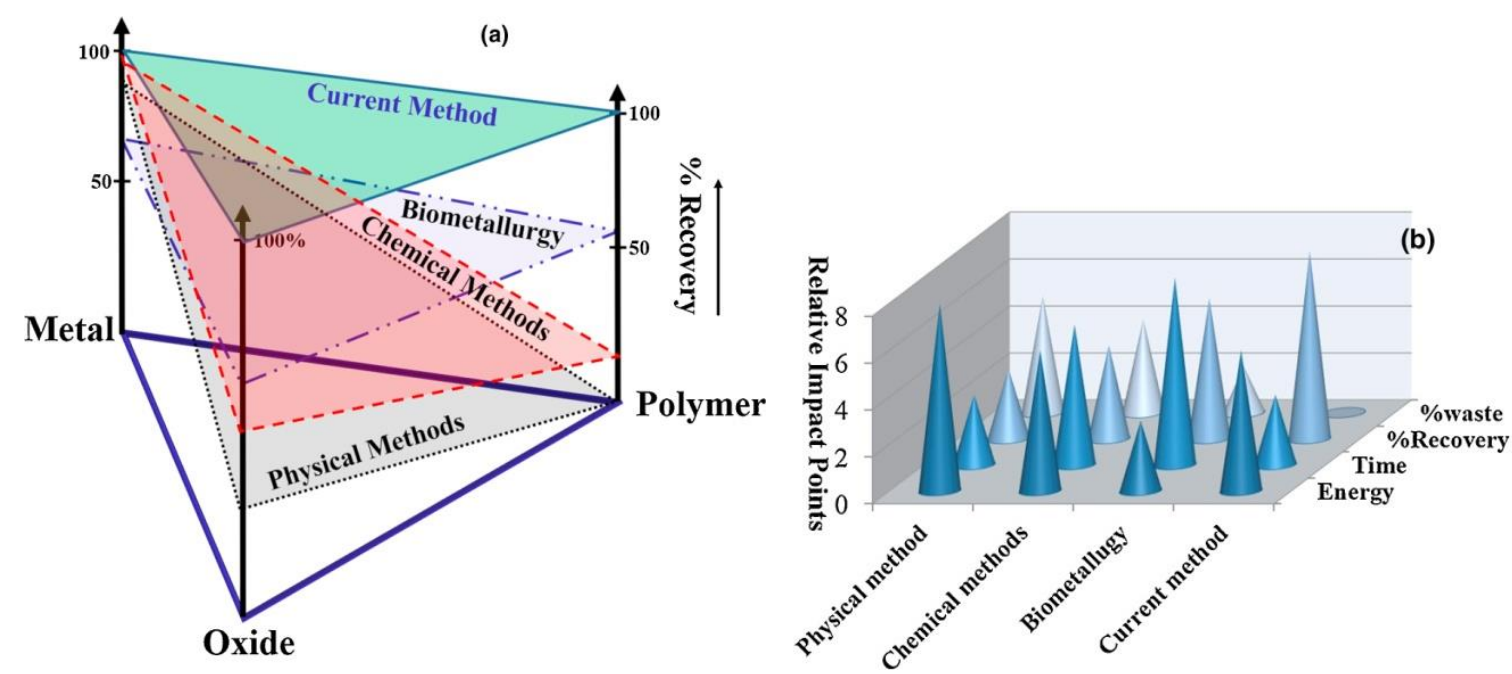

Figure 19: (a) Comparison of the recovery process in waste beneficiation ; (b) difference in the waste beneficiation based on energy, time, recovery, and \% waste.

\section{Cryomilling of Ceramics}

Cryomilling has been successful in the synthesis of NPs of different ceramics. We shall discuss the salient features below.

\subsubsection{Cryomilling of Halides}

The alkali metals bonded with halogen $(\mathrm{F}, \mathrm{Cl}, \mathrm{Br}, \mathrm{I})$ are called halides, in which the electronegative halogen ions are bonded with an electropositive metallic ion via ionic bond. Basically, the alkali halides, such as $\mathrm{NaCl}, \mathrm{KCl}, \mathrm{CsCl}$, etc. are considered as perfect crystal in Mother Nature. The halides crystals are very reactive in nature at the nanocrystalline size and poses challenges to prepare by the bottom-up approach. Although, mechanical milling process (top-down approach) at room temperature is capable of preparing ultrafine halide particles, crystallite size reduction is severely limited but due to sintering at the higher temperature. In fact, it is difficult to reduce them from ultrafine to nanocrystalline sizes. However, cryomilling can sustain more defects in the crystal due to suppression of dynamic recovery as well as sintering, and hence, the particle size can further be reduced. In contrast, higher accumulation of defects in the crystals also can reduce the grain size by polygonization, in which the high angle grain boundaries disintegrate into low angle 
boundary sub-grains (rearrangements of the dislocations). Since the re-arrangement of dislocations is limited at cryogenic temperature, the combined cryo- followed by RT milling can be used to store more defects and, subsequently, polygonization. Therefore, combined cryomilling and RT milling can be used to take advantage of both. In the literature, there are many reports on the successful synthesis of cryomilling halides at a cryogenic temperature [63-65]. Verma et al.[64] have reported the preparation of nanocrystalline $\mathrm{NaCl}$ using combined cryo- and room temperature milling. The as-received particles are in a cuboidal shape, and after cryomilling, they are massively fractured as morphology is shown in Figure 20(a-d). It has been found that the combined milling (cryomilling and room temperature (RT)) can reduce the average particle size to $13 \pm 7 \mathrm{~nm}$ after $4 \mathrm{~h}$ cryo and $10 \mathrm{~h}$ RT milling [64]. The longer RT milling introduced the effect of deformation-induced sintering. Therefore, mechanical deformation during milling also needs to be optimized to obtain a minimum grain size. Tiwary et al. [ㅎ5] have reported the nanocrystalline $\mathrm{CsCl}$ and $\mathrm{KCl}$ formation using combined cryo and RT milling. 

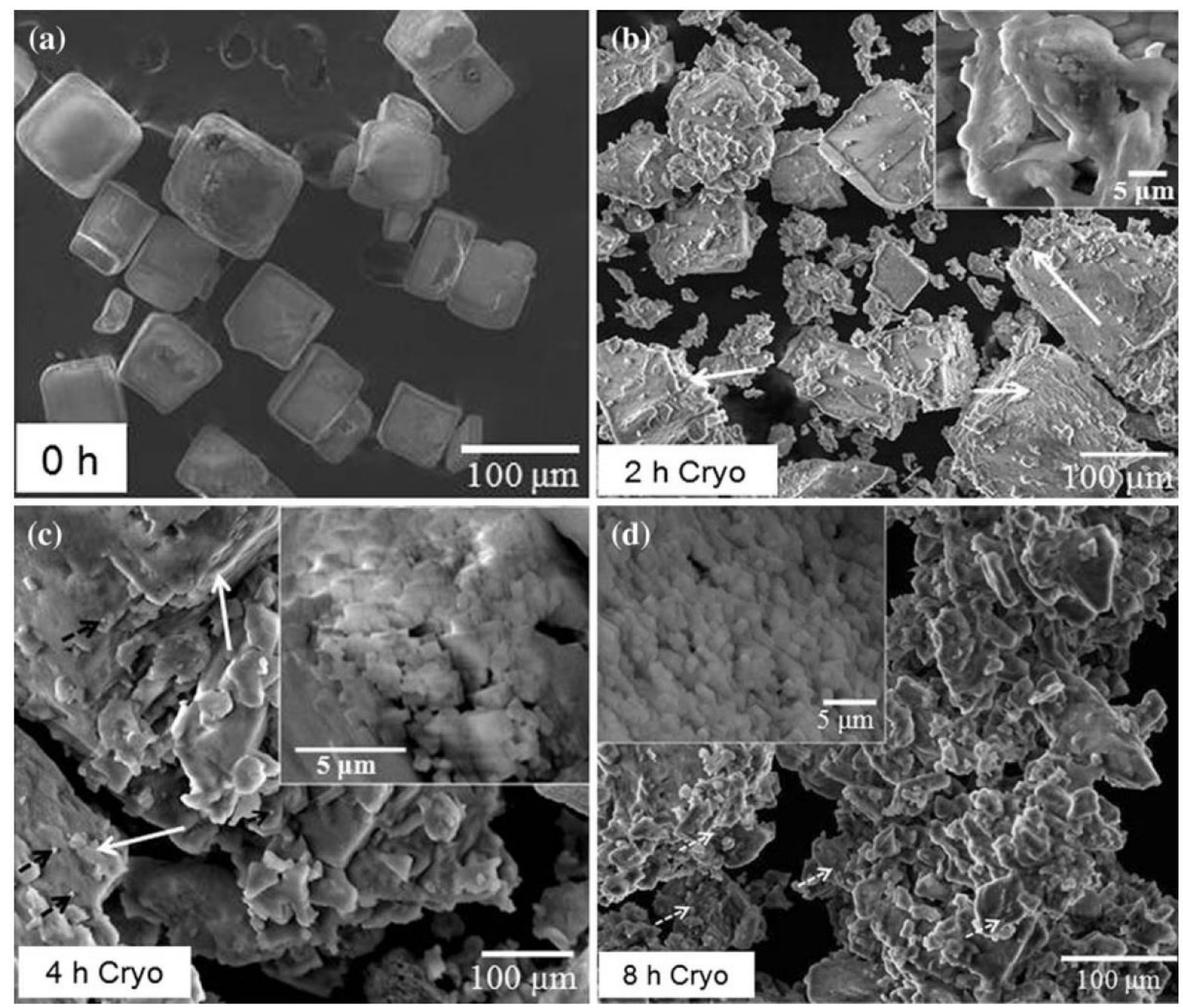

Figure 20: $\mathrm{SEM}$ microstructure of cryomilled $\mathrm{NaCl}$ (a) as received $\mathrm{NaCl}$ (b) 2 hours cryomilling (c) 4 hours cryomilling (d) 8 hours cryomilling(inset shows higher magnification)[64].

\subsubsection{Cryomilling of oxides}

The nanocrystalline oxides are important in science and technology, including semiconductor materials for optoelectronic devices. As these oxides play a significant role in technological development, it is important to find proper processing routes to obtain in the nanocrystalline form. In the following, we shall deliberate on the efficacy of cryomilling on the synthesis of some nanocrystalline oxides. Fabián et al. [215] have reported the synthesis of nanocrystalline $\mathrm{ZnO}$ using reactive cryomilling. Pure $\mathrm{Zn}$ was cryomilled in the presence of oxygen (air) until the coarse $\mathrm{Zn}$ was transformed into nanocrystalline $\mathrm{ZnO}$. The formation of $\mathrm{ZnO}$ was analyzed using X-ray diffraction in some time interval. The $\mathrm{Zn}$ was found to be 
completely transformed in nanocrystalline $\mathrm{ZnO}$ after 48 hours of cryomilling, with size ranging from 10-30 $\mathrm{nm}$. Hence, reactive cryomilling works well for the synthesis of nanocrystalline oxides.

Floriano et al.[216] have reported cryomilling of magnesium hydride $\left(\mathrm{MgH}_{2}\right)$ in the presence of iron and niobium oxide/fluoride as additives for enhanced hydrogen storage. The presence of fluoride during cryomilling increases the reduction of the crystallite size compared to the oxides because the fluorides act as lubricating agent/dispersing agent helping to reduce the crystallite size of $\mathrm{MgH}_{2}$. The cryomilling also has also been used to incorporate $\mathrm{ZnO}$ in $\mathrm{Co}_{2} \mathrm{O}_{3}$ oxide for photocatalyst applications [217].

\section{Cryogrinding of Polymer and Polymer-based Composites}

The process of cryomilling is also termed as cryogenic grinding. This process has extensively been used for the amorphization of drugs and their dispersion [47, 218-221], blending two or more immiscible polymers and change in their morphology [ $[\underline{5}, \underline{222-224}]$ and dispersion of second phase materials in some polymeric matrix [225-227]. In fact, the utilization of this process for polymeric and polymer-based composites is more extensive than for metallic materials.

\subsection{Polymer}

In principle, the process of cryomilling can be utilized to prepare fine powder of polymeric substances [223], blending of the immiscible polymer [196, 228-230] and biopolymer nanocomposite [231, 232]. For medical science applications, cryomilling has widely been used for the high loading of drugs in polymeric substances, which can reduce the burden of multi-tablets medication. There are a large number of reports available in the literature on the effective use of cryomilling for the synthesis and delivery of drugs at higher dispersion. For example, the polyvinylpyrrolidone (PVP) was cryomilled along with a naproxen drug for 
high loading [233]. Similarly, the PVP has been cryomilled with anti-inflammatory drugs, mefenamic acid (MFA) for good dispersion. The cryomilled drugs become amorphous because of the fact the extremely low temperature inhibits the restoration process of the polymeric materials [47]. Cryo-grinding is being used now-a-days for plastic-rich automotive shredder[58], reducing $98 \%$ particles below $250 \mu \mathrm{m}$ and having 95.8 to $99.7 \%$ elemental recovery[58]. Cryogrinding is considered as a milestone to mix two immiscible polymers for preparing new materials or combined properties. M. Stranz et al.[234] have investigated the mixing of imimicible polymers. Figure 21(a-b) revealed that the morphology of the immiscible syndiotactic polystyrene (sPS) and isotactic polypropylene (iPP) by cryogenic mechanical milling [234]). However, the cryomilling based blending process of sPS and iPP shows the dispersion of the spherical iPP domain in sPS, as shown in Figure 21. Smith et al. $[\underline{228}, \underline{235}, \underline{236}]$ has observed anomalous phase inversion in cryomilling of poly(ethylenealt-propylene) and poly(methylmethacrylate) (PMMA).In another study, change in the impact strength due to incorporation of polyisoprene (PI) in poly(ethylene-alt-propylene) and poly(methylmethacrylate) (PMMA) using cryo-mechanical alloying is shown in Figure 22. 

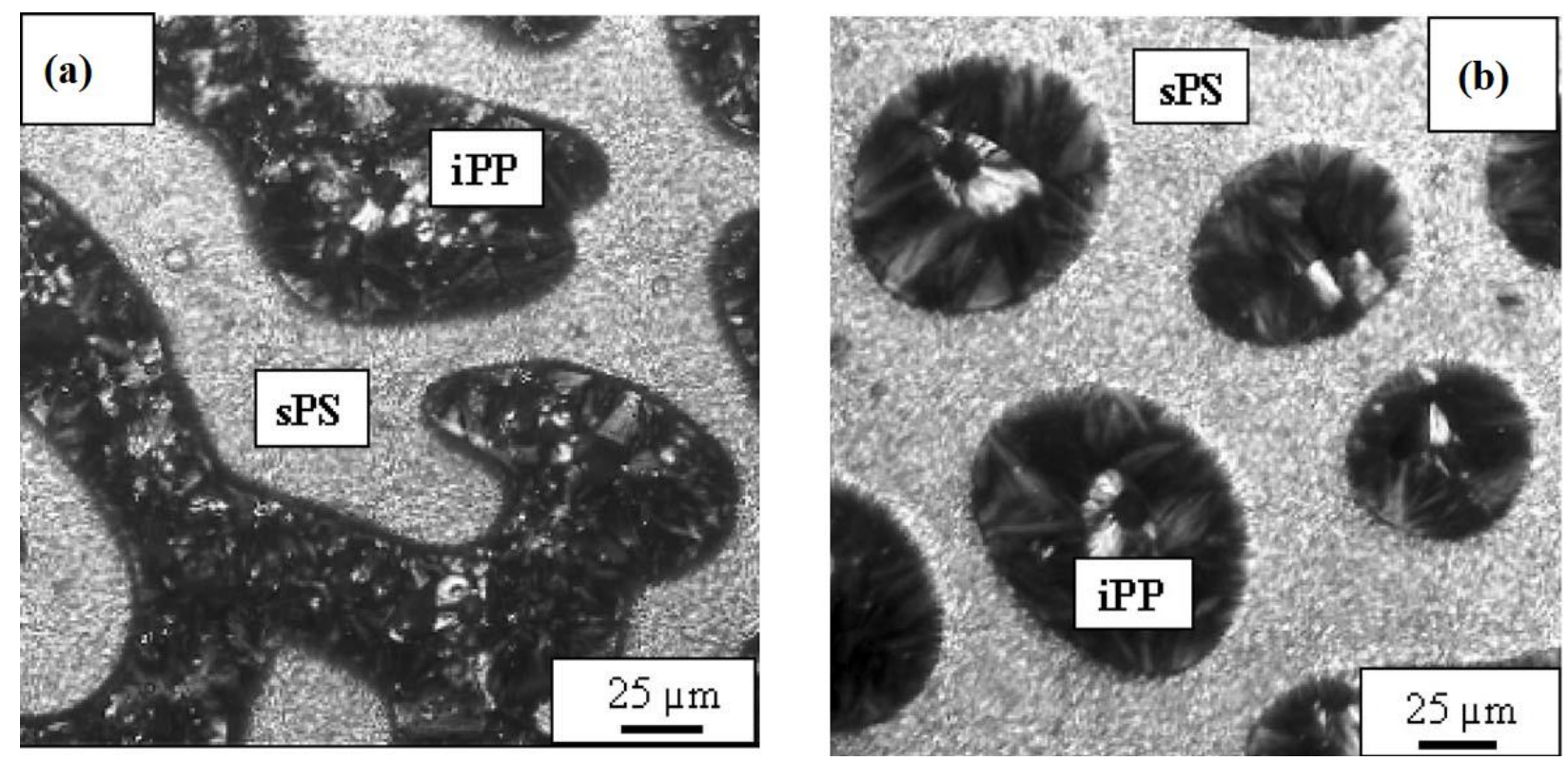

Figure 21: (a) Morphology of the sPS/iPP (50/50 wt $\%$ ) extruded blend and (b) of the sPS/iPP 50/50 wt $\%$ ) prepared by cryogenic milling after both were crystallized from the melt[235].

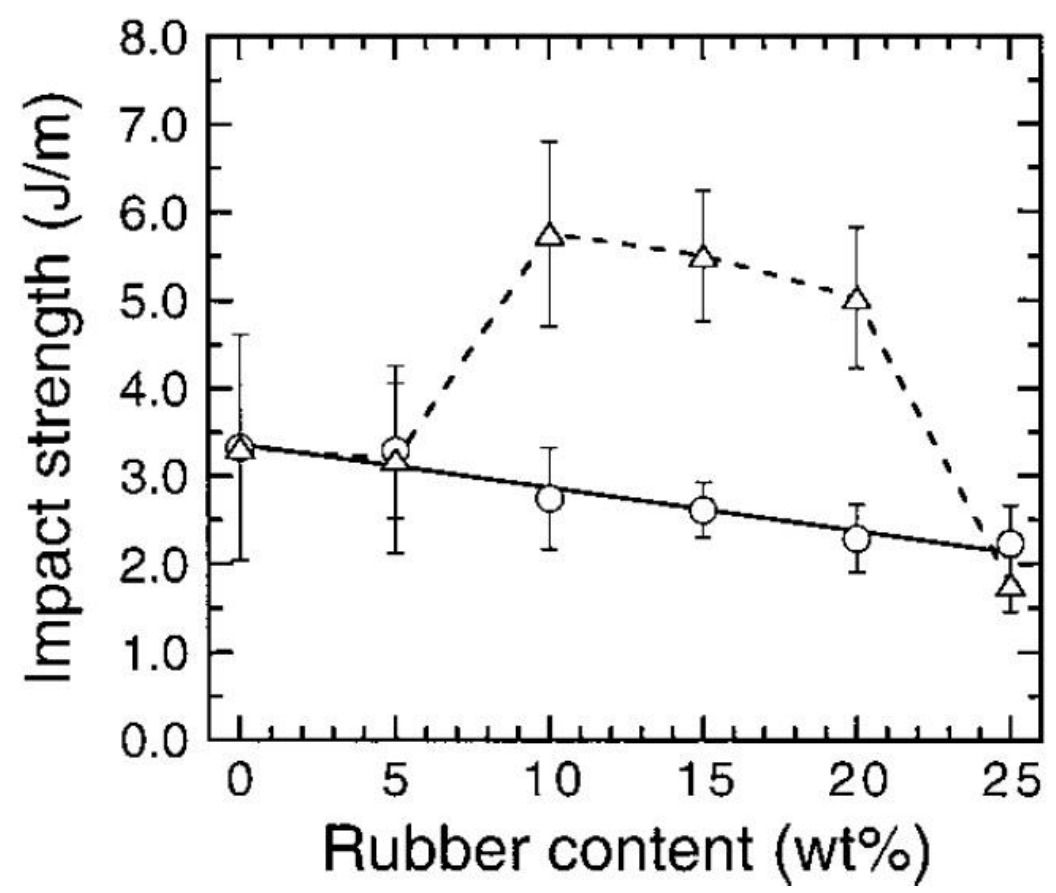

Figure 22: Variation of impact strength with rubber concentration for PEP/PMMA and PI/PMMA blends cryomilled for 5h.for 25/75 PEP/PMMA blends (O), 25/75 PI/PMMA blends $(\Delta)$. The solid line denotes a linear regression of thePEP/PMMA data, while the dashed line connects the PI/PMMA data points[237].

The highly porous and water-absorbing scaffolds of biodegradable poly(e-caprolactone) (PCL) and poly(glycolic acid) (PGL) polymers have also been synthesized by cryomilling for 
articular cartilage tissues engineering applications [238]. Figure 23 shows the morphology of the scaffold after 12 and 180 minutes of cryomilling, respectively. The porosity of the scaffolds is about $99 \%$ and does not depend on particle size due to cryomilling [238]. The morphology and mechanical properties of PGL/PCL scaffolds primarily depend on the time of cryomilling. Zhu et al.[239] has found that the thermal behavior of cryomilled poly(ethylene terephthalate) polymer is different in comparison to original and quenched PET. The heating curve of the cryomilled PET doesn't show the recrystallization, whereas the quenched and cryomilled PET are amorphous in nature, and the original PET is nonamorphous [239]. Hence, cryomilling can expand the processing of polymers by using different ingenuity of the process and process variables.
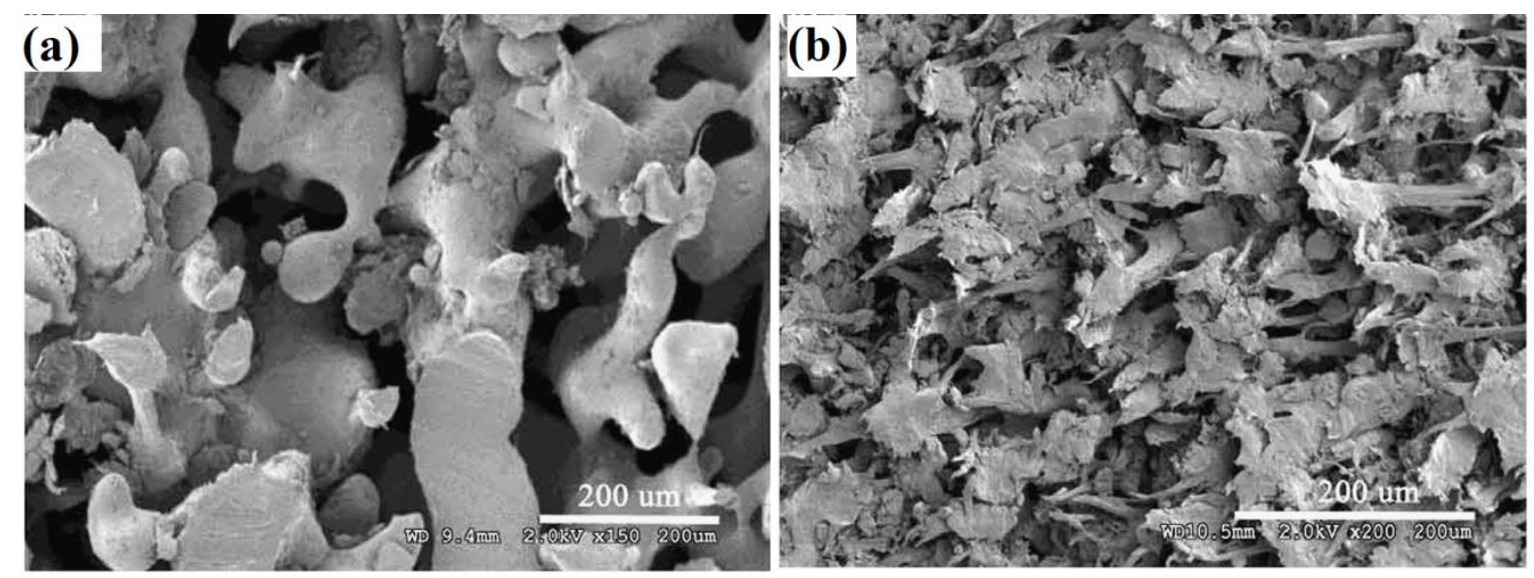

Figure 23: SEM micro-graphs of scaffolds PCL/PGA moulded at $100^{\circ} \mathrm{C}$ and made fromPCL/PGA/PEO (poly(ethylene oxide))powders(a) cryomilled for 12 minutes(b) cryomilled for $180 \mathrm{~min}[\underline{238}]$.

\subsection{Cryomilling of composites}

Cryomilling can also be utilized for the preparation of composites. We have already provided a few examples of polymer composites in the last section. The versatile nature of the cryomilling process allows synthesizing the nanocomposites, i.e., rapid nanocrystallization, homogeneous mixing, and distribution. It is worth mentioning here that the nanocomposites are the materials having two or more components with at least one of the components has any 
one of the dimensions in the nanometric domain. Zhu et al.[240] has reported the preparation of polymer-metal nanocomposites using cryomilling techniques and revealed that it is a promising technique for such systems because of homogeneous dispersion of the nanostructured phase in the matrix. All the advantages of cryomilling can be made to achieve good nanocomposites. In the preparation of ABS resin powder-based nanocomposites with atomized iron particles $\left(\mathrm{ABS}_{1-\mathrm{x}} \mathrm{Fe}_{\mathrm{x}} ; x\right.$ is volume fraction), the composite having grains size less than $100 \mathrm{~nm}$ with atomized Fe powder $(20 \mathrm{~nm})$ were obtained after 20 hours milling at a cryogenic temperature [240]. Similarly, PET/SiO ${ }_{2}$ was cryomilled for 10 hours and found that the $\mathrm{SiO}_{2}$ nanoparticles are in size $<30 \mathrm{~nm}$. The three-step model for the formation of nanocomposites has been suggested; the massive reduction of powder, good dispersion of $\mathrm{SiO}_{2}$ in the matrix, and size reduction of secondary composites particles[241, 242]. Pietrzykowska et al.[243] have even prepared orthopedic implant nanocomposite (hydroxyapatite and polylactide in the proportion of 1:1) using mechanical milling at extremely low temperatures $\left(-195^{\circ} \mathrm{C}\right)$. After warm isotactic pressing, the materials exhibit compressive strength, equivalent to natural bones. Cryomilling also provides enhanced dispersion of luminescent materials in a polymer matrix, which is the cause of improved afterglow characteristics [244]. Similarly, there are many other nanocomposites reported in

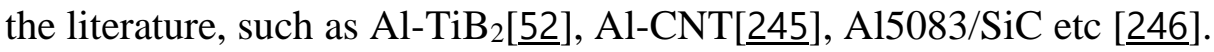

The few interesting applications of cryomilling were also reported for the synthesis of even advanced materials, indicating the versatile nature of the process. The aluminium foam was prepared and reinforced by graphene nanoflakes using cryomilling[247]. Cryomilling can be used to apply the strong shear load, which can then convert graphene into nanoflakes and cover surfaces of aluminium powder particles to form reinforced aluminium foam [247]. The addition of graphene nanoflakes (GNFs) up to $1 \mathrm{wt} \%$ GNFs in an aluminum can lead to exceptional enhancement of the ductility of the composites [248]. However, the addition of a 
higher amount of GNFs starts degrading the strength and ductility, as shown in Figure 24(ab).
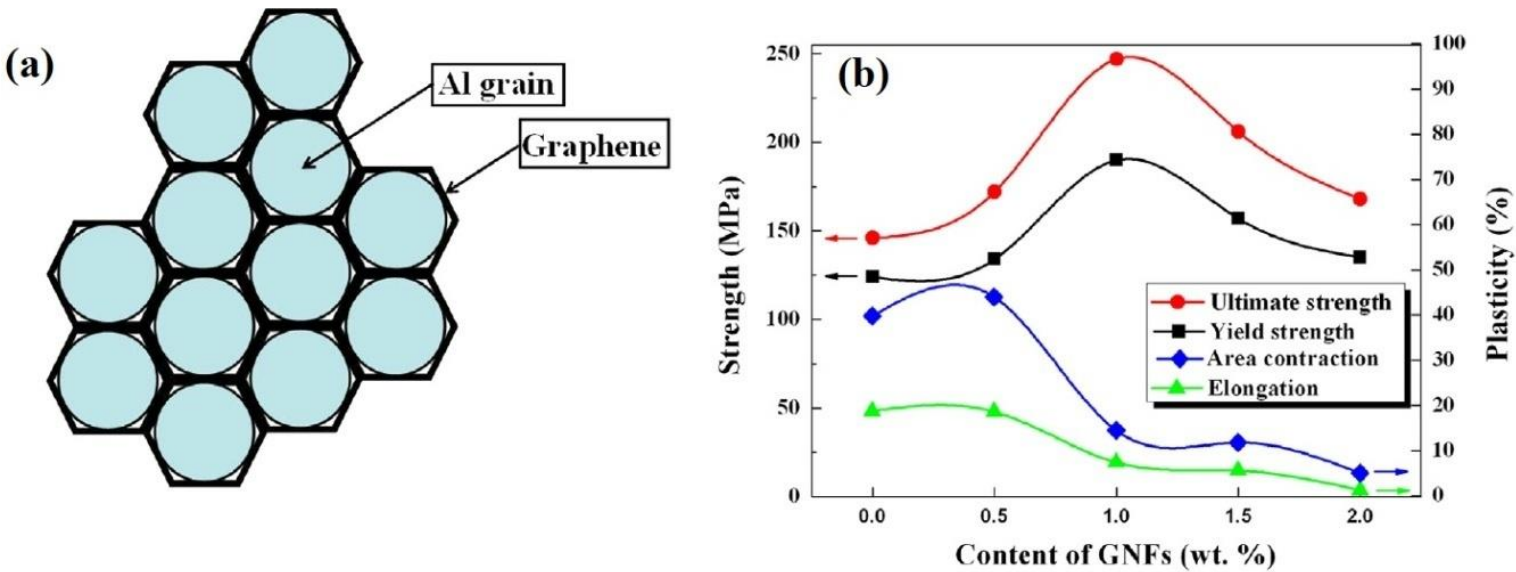

Figure 24: (a)Schematic of Al-GNFs composites(b) tensile properties of the composite[248] The cold compacted, homogenized and extruded cryomilled Al Al6061 alloy along with 1 wt\% CNT shows higher resistance against delamination and crack initiation during wear test in comparison mechanical milling.

\subsection{Hybrid magnet materials}

Cryomilling can also be used to synthesize novel hybrids consisting of inorganic/organic or vice versa from waste products, making a unique route for the synthesis of hybrid materials. The recycling of waste magnets from the additive manufacturing is considered environmentally benign method. These can be recycled using the cryomilling (experimental process shown in Figure 25) and simultaneously used to make the hybrids. The synthesis of the recycled bonded magnet, as shown in Figure 26(c), is a fully green synthesis process. Importantly, the recycled additive magnets exhibit improved remnant magnetization and saturation magnetization by $4 \%$ and $6.5 \%$, respectively [249]. The hybrid materials (inorganic/organic); Fe-NPs/PANI (polyaniline), and Fe micrometer particles/ PANI have been prepared by cryomilling for 10 hours, provide improved coercivity because the 
nanoparticles have a high surface area to volume ratio and can homogenously be dispersed as shown in Figure 27[250].

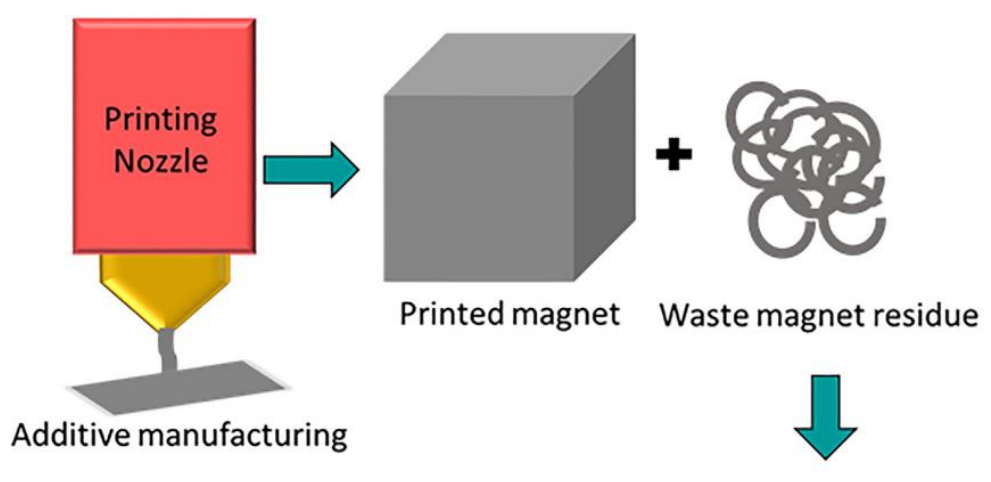

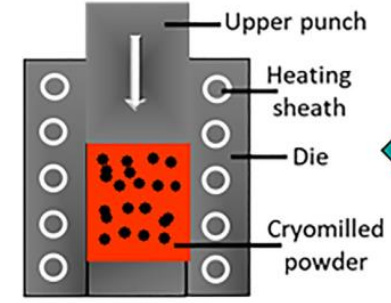

Warm compaction

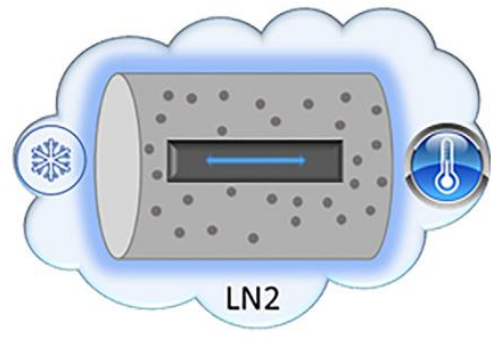

Cryomilling

Figure 25: Experimental procedure for recycling additively printed bonded magnets by Cryomilling [249].

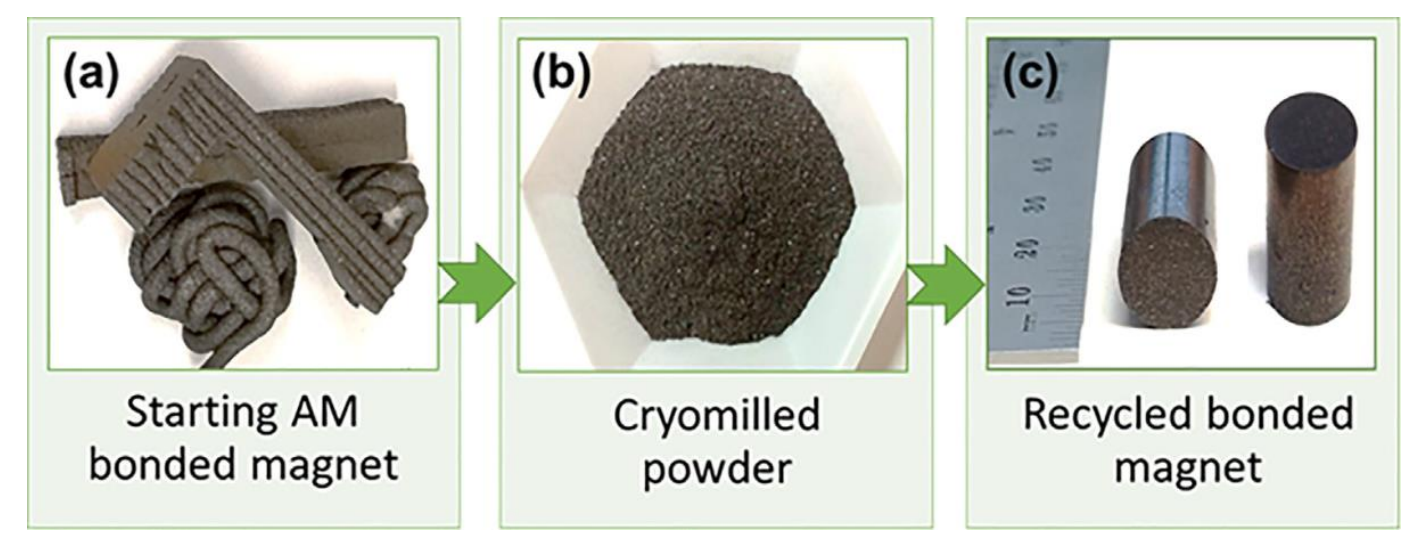

Figure 26: (a) Started additive manufacture (AM) bonded magnet (b) cryomilled powder (c) recycled bonded magnet[249]. 

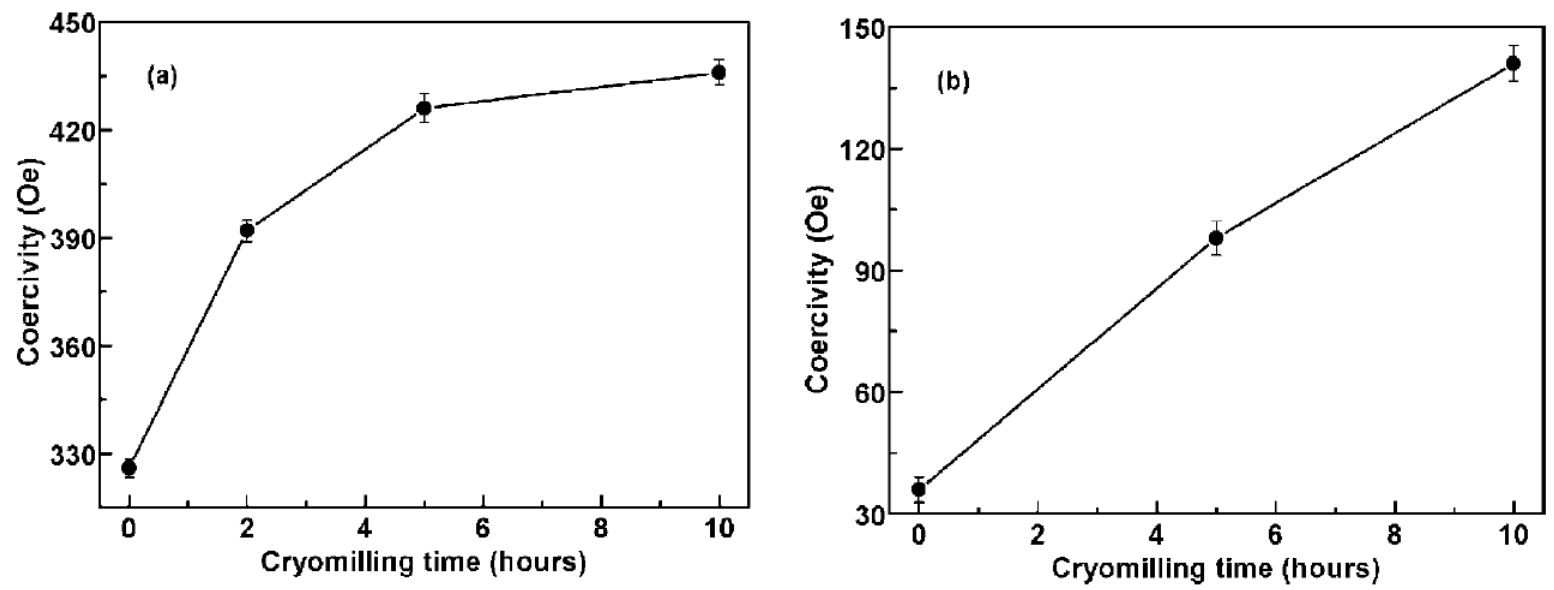

Figure 27: Coercivity vs Cryomilling time (a) composite PANI/Fe NPs (b) Composites PANI/ Fe micro-meter particles[250].

In contrast, the Nd-Fe-B magnet has been prepared using cryomilling up to 12 hours after hydrogenation disproportionation (HD) of $\left(\mathrm{Nd}_{13.5} \mathrm{Fe}_{73} \mathrm{Co}_{7.5} \mathrm{~B}_{6}\right)$ and found that coercivity of the powder decreases from 8.32 to $5.93 \mathrm{kOe}$ after desorption recombination (DR) of the cryomilled powder as the time of cryomilling increased. The decrease in the coercivity is due to the production of ultra-fine grains using cryomilling as the finer grains are providing strong exchange coupling [251]., The milling with surfactant can increase the amount of surfactant adsorption over grain surface in both cases of room temperature as well lowtemperature milling. However milling at cryotemperature can cause less adsorption of the surfactant due to weak interaction of surfactant and Nd-Fe-B grains as shown in Figure 28 [252]. 


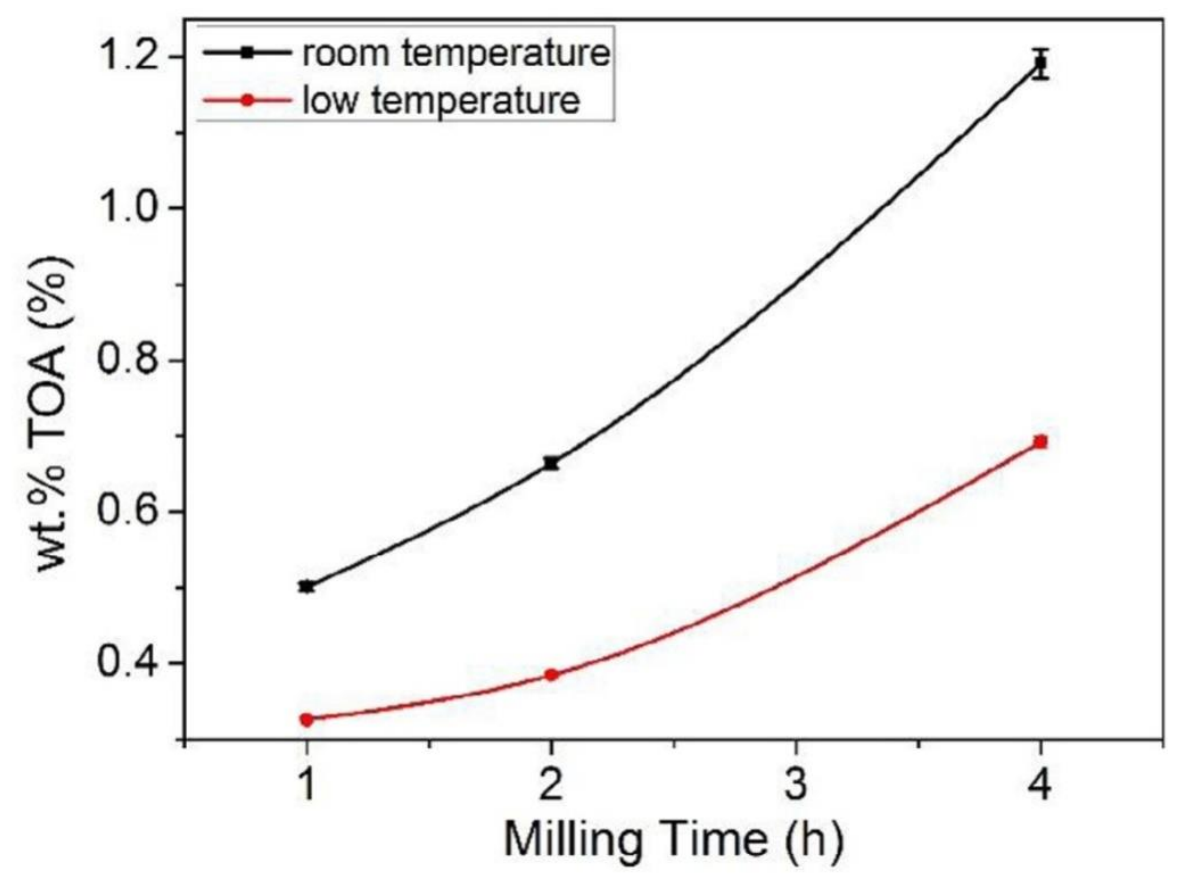

Figure 28: Comparison of surfactant (TOA: trioctylamine) mass percent in room temperature and low-temperature Nd-Fe-B powder milling[롤].

Therefore, it is evident that cryomilling can effectively be utilized to obtain high-quality magnets by incorporation of the nanosize magnetic phase homogeneously in a matrix, even from wastes, making this process unique. This approach was further extended to the synthesis of other magnetic as well as catalytic materials. There are reports in the literature on magnetic materials being prepared by cryomilling in the nanocrystalline form, such as- NiCrAlY [253], NiCoCrAlYSi [163, 254] MnBi [255], $\tau-\operatorname{MnAlC~[256}, \underline{257}$ ], MnAlC/ $\alpha-\mathrm{Fe}$ [258], Carbon doped MnAl [259], Cobalt ferrite [260], $\gamma-\mathrm{Fe}_{4} \mathrm{~N}$ [261], $\mathrm{BiFeO}_{3}$ [262]. The change in magnetic properties is mainly due to altering in crystallinity of the materials by cryomilling [263]. Similarly, Ni-Nb-Y was cryomilled for catalytic activity and showed higher activity for hydrogen evolution [264]. 


\section{Cryomilling of spices or food materials}

It is well known that conventional mechanical milling at room temperature leads to the temperature rise during the milling (discussed in section 2.1) due to the collision of balls with vials and powder. This is deemed to have a degrading effect on spices or food. The generated heat can affect the qualitative and quantitative properties of these materials. The temperature rise can reduce $30-40 \%$ volatile etheric oils/fatty oils present in the spices and loss of the appealing color of the spices $[\underline{84}, \underline{265}]$ and hence can be detrimental for properties of spices and food materials. On the other hand, cryomilling has the advantage of overcoming these limitations and producing high-quality products with finer particle size. Therefore, cryogrinding was widely being used to maintain the flavor and color of spices. At cryo- or low temperature, fatty oils solidify in the spices and turn the spice seeds brittle, which is the cause for reduction to finer particle size. In addition, the solidified fatty oil allows the spices to retain it in each particle equally. There are a number of reports in the literature on the utilization of cryo- grinding to provide fine particles of spices [265-268]. Although cryogrinding is effective, the spices need to be cooled to temperature low enough prior to the milling to avoid any contact with coolant during grinding. To achieve it, Singh et al.[269] have modeled the cryo-grinding as a two-step process, in which the spices are first cooled and then ground in another chamber. However, the temperature of both the chambers is maintained below $-70^{\circ} \mathrm{C}$, which is suitable to stop clogging the sieves utilized to sort the spices subsequently. Specifically, Singh et al. [270] have reported that the increasing temperature of the milling operation reduced the quality of king chilli powder. More related literature is summarized in Table 7 to showcase the importance of this technique to obtain spice powder. 
Table 7: Summary for food and spices prepared using cryogrinding

\begin{tabular}{|c|c|c|c|}
\hline Spices Name & Cryogrinding & Finding & Reference \\
\hline Spices & Cryogriding & $\begin{array}{l}\text { Comparison of color at ambient and } \\
\text { cryotemperature }\end{array}$ & {$[271]$} \\
\hline Cumin seeds & Cryogrinding & $\begin{array}{l}\text { At different temperatures variation in } \\
\text { volatile oil content }\end{array}$ & {$[272, \underline{273}$} \\
\hline Turmeric & Cryogrinding & $\begin{array}{l}\text { Shape and size analysis of cryo and } \\
\text { ambient grinding temperature }\end{array}$ & {$[\underline{274}, \underline{275}$} \\
\hline Cloves & Cryogrinding & $\begin{array}{l}\text { Oil content and sticking nature with the } \\
\text { sieve }\end{array}$ & {$[276]$} \\
\hline Black pepper & Cryogrinding & $\begin{array}{l}\text { Different feed rate and content of volatile } \\
\text { oils }\end{array}$ & [277] \\
\hline Fenugreek & Cryogrinding & Flow behavior and cryogenic effects & {$[278-280]$} \\
\hline $\begin{array}{l}\text { Fenugreek and } \\
\text { black pepper }\end{array}$ & $\begin{array}{l}\text { Rotor, ball, } \\
\text { hammer and } \\
\text { pin mill }\end{array}$ & Effect of different grinders & {$[\underline{281]}$} \\
\hline Coriander & Cryogrinding & $\begin{array}{l}\text { Effect of low-temperature milling and } \\
\text { anti-oxidant property }\end{array}$ & [282] \\
\hline $\begin{array}{l}\text { Cassia } \\
\text { (Cinnamomum) }\end{array}$ & Cryogrinding & Cryogenic milling optimized & [283] \\
\hline Black pepper & Cryogrinding & $\begin{array}{l}\text { The thermal and mechanical property of } \\
\text { seed at low-temperature cryogrinding }\end{array}$ & {$[\underline{284]}$} \\
\hline Pepper Seeds & $\begin{array}{l}\text { Modeling } \\
\text { Discrete } \\
\text { element } \\
\text { method }\end{array}$ & $\begin{array}{l}\text { Flow behavior of pepper seeds at in } \\
\text { cryogrinding }\end{array}$ & [285] \\
\hline $\begin{array}{l}\text { Black Pepper } \\
\text { seeds }\end{array}$ & Modeling & $\begin{array}{l}\text { Breakage phenomena of seeds at cryo } \\
\text { temperature }\end{array}$ & {$[286]$} \\
\hline Cumin seeds & Cryogrinding & $\begin{array}{l}\text { The optimum condition for high-quality } \\
\text { cumin powder }\end{array}$ & [287] \\
\hline Mango peel & Cryogrinding & Retention of important gradients & {$[288]$} \\
\hline
\end{tabular}




\section{Cryomilling as Environmentally Friendly Synthesis Route to Prepare Nanomaterials}

We have already discussed and demonstrated the versatile nature of the cryomilling process to synthesize various nanostructured materials. Importantly, unlike many other processes for the synthesis of nanostructured materials, this process is eco-friendly. During the milling process, it does not leave any toxic materials or chemicals in the environment or drainage. It even satisfies the conditions of the green synthesis process and detailed conditions (12 points) as per the Handbook of green chemistry [77]. In the following, we shall discuss in detailed the life cycle assessment, eco-friendliness of the process, and health risk assessment to arrive at conclusions regarding the eco-friendly nature of the process.

\subsection{Life cycle Assessment}

The life cycle assessment of the nanomaterials is primarily related to the applications in the nanotechnology, and it is meant to provide broad scope about the pros and cons of utilizing nanomaterials in different sectors [289, 290], encompassing almost every sector of human life. This review article is limited to the production of nanomaterials utilizing cryomilling/cryogrinding and their environmental impact. The assessment of the potential environment and human health risk from applications of nanomaterials as end products in different areas is beyond the scope of the present article. Nonetheless, the large-scale synthesis of nanostructured/nanomaterials via cryomilling can be utilized in different areas, as shown in Figure 29. The coolant $\mathrm{LN}_{2}$ (liquid nitrogen) is the most economical and efficient one to be used because of its eco-friendly nature as it turns into $\mathrm{N}_{2}$ gas, which is the most abundant gas in our environment (78\%) and non-toxic for humankind. Therefore, the major input raw materials in cryomilling are coolants, and milling materials and output materials are pristine and nanostructure powder of metals, ceramic, polymers, or their combination. It is worth to note that cryomills require sustained power (electricity) for operation. Like any other 
processing route, the powder is a necessity; hence, we shall not discuss the effect of energy usage to make any conclusion on the eco-friendly nature of cryomilling. It would be suffice to point out that there are many green and sustainable means for the generation of powder (wind, solar, bio, etc.) that are available in the world today. The byproduct is $\mathrm{N}_{2}$ gas, which is freed directly to the environment and doesn't have any worse impact on the environment. In addition, the cryomilling does not leave any other by products, and the prepared nanomaterials can be used in various applications (Figure 29). Hence, one also needs to analyze the effect of these nanostructured materials on the environment, human life.

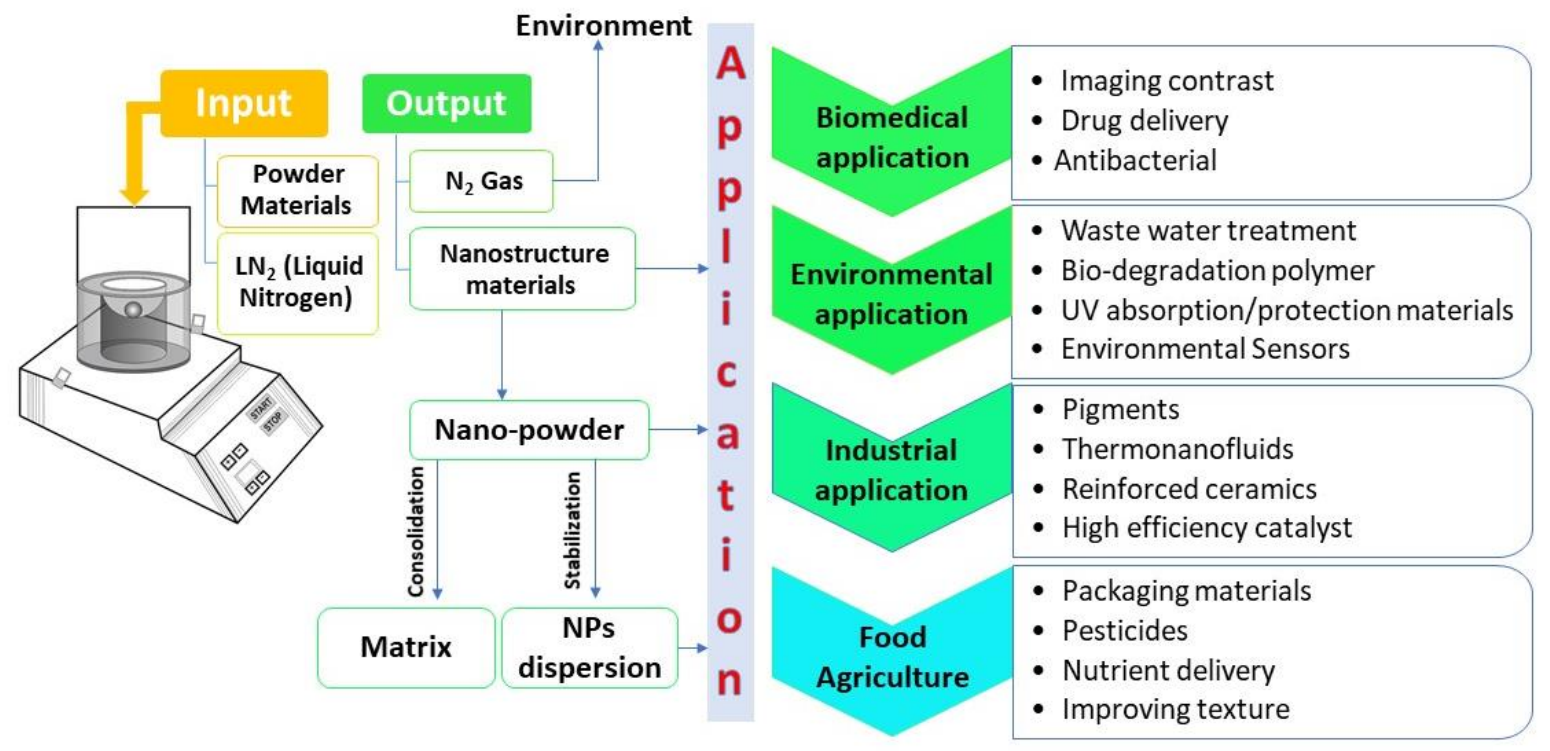

Figure 29: Life cycle assessment of cryomill product and by-product and final application

\subsection{Conditions for Eco-friendly Process}

Any synthesis process is required to fulfil some conditions to be called an eco-friendly process. Wasserscheid et al.[77] have described twelve principles in his classic book 'Handbook of green Chemistry' for deciding any process to be called as a green or ecofriendly process, and detailed principles can be found elsewhere [77]. The cryomilling/cryogrinding process, is an eco-friendly or green synthesis process to prepare nanomaterials because 
- Cryogrinding does not leave any toxic waste in the environment

- It is a process, which can produce nanomaterials in large quantity with high yield compared to another existing process

- $\quad$ There is no use of toxic chemicals or release of the chemical during the synthesis process

- $\quad$ The process can be used for waste beneficiation in large scale (polymers, electronics plates, etc.)

- Easy handling and economical process, where coolant liquid needs to be used carefully.

\subsection{Cryomilling: wastage vs. use of eco-friendly materials}

An important aspect of any eco-friendly process is wastage during the manufacture of any product. In this process, the yield of nanomaterials is reported to be $97 \%$ for metallic materials $(\mathrm{Ag}, \mathrm{Al}, \mathrm{Cu})$, which is much higher as compared to other processes $[\underline{7}, \underline{10}, \underline{11}]$. The remaining $\sim 3 \%$ is mainly consumed as a coating of the metals over balls and vials of the milling apparatus. The coated remnant even can be detached from the balls and vials by milling with other materials such as table salt, glass, or sand and disposed of them according to the protocol. In fact, the materials coated on the surface of the ball are helpful to reduce the contamination (milling debris due to friction) in the nanomaterials and provide a high-quality product. In some other cases, such as halide $(\mathrm{NaCl}, \mathrm{CsCl})$ and polymers, the coating is almost not observed, and one can recover almost $100 \%$ as a product. In some cases, the researcher may use extra precaution and continuously purge inert gas in the milling chamber to protect the oxidation/nitridation of milling materials. It is to be noted that the lightweight materials in nanophase can slowly exit with the release of inert gas. Consequently, they mix with the environment, and hence, can cause adverse effects. However, such a study is not reported regarding cryomilling so far. Nonetheless, it is evident that cryomilling, as compared to 
another manufacturing process, can be used to minimize wastage, causing the least healthhazards with high recovery.

\subsection{Issues on Sustainability and Environmental Benignness}

In modern days, many developing and some developed countries have been plagued by environmental pollution, such as air, soil, and water pollution due to improper waste disposal, generation of polluting agents in large quantity left to the environment without treatment [291]. The main concern is to reduce the waste from industries, laboratories, and properly dispose of them to reduce the effect of such pollutants, which can directly impact life on Earth. In the research community, the persistent efforts are being taken across the globe to develop eco-friendly processes for the synthesis of nanomaterials/nanostructure, which can reduce the wastage and even utilization of the wastage for sustenance. There are many green synthesis routes for metallic nanoparticles, utilizing plant leaf or naturally available materials. However, these processes suffer from low yield and not economically viable $[\underline{71}, \underline{72}, \underline{292}]$. In this regard, cryomilling can fulfill the burgeoning requirements of nanomaterials in the market. It is considered a green synthesis route and relatively safe for our ecosystem and sustainable in a sense as the supply of liquid $\mathrm{N}_{2}$ as consumable is required.

\subsection{Health Risk Assessment}

We shall now discuss the health risk assessment of the product during usage. It is essential because the nature and type of nanomaterials prepared via cryomilling vary substantially depending on the requirement. The nanomaterials, after usages, are let into nature, and drainage of these can cause a serious health hazard. Like any other process utilized to synthesize nanomaterials, this is a common problem with cryomilling. The drainage of nanoparticles, synthesized by cryomilling, can directly contaminate the groundwater, and it is even challenging to separate from the water. Various nanoparticles in different size ranges 
behave distinctly differently during drainage. Therefore, it is too early to generalize assessment regarding human health risk from nanomaterials synthesized via cryomilling. Nonetheless, the foreign contamination in the human body always creates health risks, when it enters into our body by daily chores of life such as breathing, drinking water, and eating food. There are many lightweight materials such as carbon in nanometric size, and certain other metallic nanoparticles exist in the environment. They can get mixed with air or water on slight disturbance, if not handled properly. Several nanomaterials are even utilized for human health, such as silver nanoparticles. They are well known anti-bacterial materials, but it shows negative consequences in human macrophages [293]. As compared to other processes, the cryomilling is well protected and safe for users if handled carefully. In wet chemical synthesis, the nanoparticles, in general, are capped by capping agents to protect them from the environment or stop coarsening in the solution [7]. These capping agents or chemical process agent can also be harmful to the human. On the other hand, the waste of synthesis is directly drained into the drainage, which can eventually are mixed with river and ocean water. Nanomaterials contaminated water can be highly dangerous for our marine system as well as human because of the consumption of infected food.

The study of nanotechnology has a high impact on human life, such as medicines, drug delivery, smaller electronic devices, solar cells, and cosmetics, etc., and it is envisaged to create more impact on our life in the near future. However, it might be turned into a nightmare if not handled in a controlled way. Many developing countries have a huge population and do not have any protocol to dispose of nanomaterials properly with no specific norms for their utilization. For example, the utilization of nanoparticles in cosmetics is extremely large in quantity. The cosmetics/creams are directly washout during bathing from our body, and they contain NPs, which are subsequently mixed into the drainage. If a huge population utilizes such products, it can spread massively in the drainage system. 
Therefore, by utilization of nanomaterials in an uncontrolled way means we are placing human health at stake. Hence, like any other manufacturing process, the health hazard of the nanoparticles, synthesized by cryomilling, will remain a burning issue, if not handled with proper care.

\section{Scale Up and Cost Effectiveness of Cryomilling in Nanomaterial Synthesis}

The synthesis of nanomaterials is still challenging because we need to control the size, shape, distribution, prevent the tendency of agglomeration/coarsening behavior, protection of the surface of nanoparticles as they have a high surface area to volume ratio and proneness to bind with other contamination in the environment/solution (gas molecules, nascent oxygen atoms or other gases and organic atoms or molecules). These challenges make the cost of the nanomaterials is reasonably high. In this regard, cryomilling has the advantage of overcoming some of these problems, making the synthesis of nanoparticles cost-effective [294]. This is important, in particular, for the processing of nanoparticles as compared to room temperature mechanical milling or other chemical routes. It is now evident (earlier discussion) that it is possible to achieve better process control during the synthesis of nanoparticles and hence reduce/nullify many problems associated with other similar processing routes. In addition, cryomilling can easily be scaled up without compromising product quality $[\underline{9}, \underline{11}]$. Like other mechanical milling routes, it is possible to scale up easily by design and development of larger mills with better cooling efficiency as liquid nitrogen usage will exponentially increase with bigger mills due to heat loss and evaporation. In this regard, one needs to design the mill (geometry, milling materials, thermal management, etc.) considering all possible aspects for scaling up. The literature has not discussed and hence, would require the attention of the researchers and technologists for the design and development of cryomills for industrial usage. 


\subsection{Method to Prepare Nanomaterials in Large Quantity}

Like conventional mechanical mills, cryomills can be scaled up to industrial-level production of nanomaterials. The burgeoning need of nanotechnology can only be satisfied by the supply of a large quantity of high-quality nanomaterials, i.e., size, distribution, chemistry, contamination; determining the quality. Most of the available techniques in the niche market are not capable of preparing good quality nanomaterials encompassing metals, ceramics, polymer, composites, medicines, and spices. To the best of the authors' knowledge, there is no processing route available, other than cryomilling, which is capable of preparing such gamut of nanoparticles in large quantities. In the following, we shall provide the production capability of metallic materials of an existing cryomills and the possibility of scaling up to obtain nanomaterials in large quantity. In the case of metals and alloys, a custom-built cryomill having $250 \mathrm{cc}$ of the vial and $150 \mathrm{cc}$ ball can mill $24 \mathrm{~g}$ powder at a time, and milling

of 7 hours is required to produce nanoparticles $[\underline{9}, \underline{11}]$. Therefore, in a day or 24 hours (approximates three batches of production) of the desired quality, one can produce around 70 g nanoparticles. This process has a yield of around 97\% with little (3\%) lost due to the coating on ball and vial during milling $[\underline{10}, \underline{11}$. In addition, the cryomill also can be scaled to have a large volume with a large number of balls to prepare nanomaterials. It is evident that it is a flexible processing route in order to scale up, and fulfill the requirement of the market needing a large amount of various nanomaterials for a gamut of applications, thermonanofluids, cosmetics, antifouling nanoparticles, semiconductor, thermoelectric, applications, etc. $[\underline{188}, \underline{295}, \underline{296}]$.

\subsection{Cost-Effectiveness of This Route vis-a-via Other SPD processes}

The cryomilling process can produce the nanopowder in large quantity, and the requirement of these nanopowders are felt in many active sectors such as structural materials (nano- 
composites), antifouling coating (ship hull, etc.), catalytic nanomaterials, biosensors, solar voltaic cell, etc.

It is indeed a tedious effort to estimate cost of any nanomaterials in the world today. It depends on the availability of raw materials, synthesis route, yield, social structure, and even environmental friendliness. Some of these are extremely difficult to estimate. Nonetheless, the cost of nanoparticles primarily depends on the cost of raw materials. For example, there is a huge difference in their basic prices of micron sized powder of gold and copper as raw materials. However, the copper is highly prone to oxidize and required extra precaution to store them in the nanosized form in comparison to the gold. Therefore, storing of the nanoparticles, maintaining their purity, and transporting them in less quantity might have exceeded the cost compared to bulk gold. The cost also depends on the processing parameters required to achieve specific size range, surface functionalization, treatment, their property specification (crystallinity, amorphous, shape, surface plasmon resonance, stable dispersion solvent, etc.) as characterization of nanomaterials is quite costly.

The cost even depends on their production volume (lab-scale, small scale, and large scale) and their largely unknown requirement. At present, this field of synthesis of nanomaterials is growing, and hence their research and development cost itself is high. In the future, the cost of nanomaterials will also depend on the social or government restriction on different materials or their end-user policy, which will depend on their evolution to human friendliness, toxicity, etc. As nanotechnology is a rapidly growing field, the products are rapidly miniaturized with lower costs. Hence, the exact estimation of the cost of nanomaterials is not easy at present. Ashby et al.[294] has described the comparison of the cost of nanomaterials in the USA and found that the price of nanoclays is approximately the same as the gold. With functionalization, the cost of the nanomaterials will definitely increase manifold. Therefore, it is difficult to estimate the cost of any particular nanomaterial. 
Nonetheless, the preparation of the nanomaterials utilizing cryomilling will reduce the processing cost as this technique requires electricity and liquid coolant (preferably $\mathrm{LN}_{2}$ ), which is also quite cheaper. However, other costs, such as storing, functionalization, will still remain high.

\section{Summary and future direction}

The milling or grinding at cryogenic temperature, popularly known as cryomilling, is considered a novel eco-friendly processing route to prepare various types of nanostructured materials; metallic, ceramics, polymeric, composites, hybrids, spices, with low contamination and high yield. Mechanical milling at room temperature was widely utilized to synthesize some of these nanostructured materials. However, mechanical milling at room temperature has the many drawbacks; agglomeration, extensive cold welding, oxidation, contamination from milling the media, etc. These can easily be overcome by the cryomilling. In this background, the present review is intended to provide a detailed account of the cryomilling technique with emphasis on materials development as well as recovery from waste. The salient features of material synthesis and recovery via cryomilling with future perspectives are provided here. Starting with the basics of mechanical milling as a synthesis route for nanomaterials, the advantage of cryomilling over room temperature milling has been described with the mechanical behaviour of materials at extremely low temperatures. Cryomilling as a severe plastic deformation (SPD) route has many advantages, including suppression of recovery and recrystallization, dominant fracturing over cold welding, low oxidation and contamination primarily due to extremely low temperature.

However, material synthesis will strongly depend on the design of cryomill available in the niche market. In the simplified version of a cryomill, the powder and the milling media are mixed with the cryogenic liquid $\left(\mathrm{LN}_{2}\right)$ to reach extremely low temperatures. As metals and 
some ceramics are prone to nitridation, and hence, latter design has been made such a way that powder can never come in contact with $\mathrm{LN}_{2}$, reducing the chance of nitridation of the milled powder. However, this leads to lower cooling efficiency, which can be compensated by online measurement of the temperature of the milled powder. The fundamental aspects related to these factors have been dealt with scientifically to provide an in-depth understanding of deformation and oxidation behavior of the materials at cryogenic temperature leading to the synthesis of nanoparticles. The synthesis of various nanomaterials, especially metallic, ceramics, polymeric, spices, hybrids and medicines along with composites is discussed in details to prove the efficacy of the technique for the synthesis of nanostructured materials in large quantity. This is considered as the need of the hour for various applications, including nano-ink for printing electronic circuit boards, large-scale production of for smart devices; nanofluids, semiconductor devices, long dispersible (highly stable) medicinal and aroma preserving spices for the food industry. Wththe novel applications, cryomill have expanded with the economic recovery of materials from electronic and other wastes, which are hazardous and detrimental to the environment. Finally, the eco-friendly nature and scaling up for industrial use as a processing route for many applications has been shared. In a nutshell, cryomilling is economical, environmental friendly as well as technologically via the route to obtain various nanomaterials.

However, cryomilling cannot be considered the panacea for the synthesis of the nanostructured materials. It has its own problems. It is evident cryomilling cannot be used for mechanical alloying due to problems associated with significantly low diffusion at cryogenic temperature. Mechanical alloying from individual powder mixture needs interdiffusion, which is sufficient only at elevated temperature, and hence cryomilling cannot be used for phase formation from individual powder mixture. Secondly, the cryogenic temperature is, in general, achieved by using $\mathrm{LN}_{2}$, which can lead to the formation of nitrides for many metals 
and ceramics. Hence, extreme care must be exercised to avoid the formation of the unwanted nitrides during the synthesis of nanostructured materials. Thirdly, there are materials, which undergo phase transformation while cooling down to extremely low temperatures, and thus, cryomilling can alter the phase and microstructure in those phase-changing materials. In addition, cryomilling is associated with the handling of $\mathrm{LN}_{2}$, which can cause cold burn; if it comes in contact with the human skin. Proper care must be taken to ensure that $\mathrm{LN}_{2}$ does not come in contact with exposed body parts. Nevertheless, a detailed literature survey reveals that cryomilling can provide a solution to the synthesis of various nanomaterials with a better-quality product. Therefore, this processing route is deemed to grow to satisfy the burgeoning area of nanotechnology. However, fundamental research as well as technological issues on scaling up need to be looked into by the research community to take it to the next level for better productivity, quality of product, and economy.

\section{Acknowledgments}

K.B would like to thank various funding agencies, Department of Science and Technology, Indian Space Research Organization, Board of Research on Nuclear Materials, Ministry of Human Resource Development for funding research activities, and IIT Kanpur for providing various characterization facilities. N.K.K would like to thank Royal Society UK for the award of Newton International Fellowship (NIF\R1\191571) fellowship to complete the manuscript.

The authors would like to thank Professor K. Chattopadhyay for stimulating discussion and support. 


\section{References:}

[1] Schmid, G., Nanoparticles: From Theory to Application. Wiley: 2010.

[2] Mader, K.; Brune, H.; Ernst, H.; Grunwald, A.; Grünwald, W.; Hofmann, H.; Krug, H.; Janich, P.; Mayor, M.; Rathgeber, W., Nanotechnology: Assessment and Perspectives. Springer Berlin Heidelberg: 2006.

[3] Fendler, J. H.; Dékány, I., Nanoparticles in Solids and Solutions. Springer Netherlands: 1996.

[4] Abdalla, A. M.; Hossain, S.; Azad, A. T.; Petra, P. M. I.; Begum, F.; Eriksson, S. G.; Azad, A. K., Nanomaterials for solid oxide fuel cells: A review. Renew. Sust. Energ. Rev. 2018; 82, (Part 1): 353368.

[5] Yao, S.; Zhu, Y., Nanomaterial-Enabled Stretchable Conductors: Strategies, Materials and Devices. Adv. Mater. 2015; 27, (9): 1480-1511.

[6] Seil, J. T.; Webster, T. J., Antimicrobial applications of nanotechnology: methods and literature. Int. J. Nanomed. 2012; 7: 2767-2781.

[7] Rao, C. N. R.; Ramakrishna Matte, H. S. S.; Voggu, R.; Govindaraj, A., Recent progress in the synthesis of inorganic nanoparticles. Dalton Trans. 2012; 41, (17): 5089-5120.

[8] Yang, G. W., Laser ablation in liquids: Applications in the synthesis of nanocrystals. Prog. Mater Sci. 2007; 52, (4): 648-698.

[9] Kumar, N.; Biswas, K., Fabrication of novel cryomill for synthesis of high purity metallic nanoparticles. Rev. Sci. Instrum. 2015; 86, (8): 083903-8.

[10] Kumar, N.; Biswas, K., Cryomilling: An environment friendly approach of preparation large quantity ultra refined pure aluminium nanoparticles. J. Mater. Res. Technol. 2017; 8, (1): 63-74.

[11] Kumar, N.; Biswas, K.; Gupta, R. K., Green synthesis of Ag nanoparticles in large quantity by cryomilling. RSC Advances 2016; 6, (112): 111380-111388.

[12] Kumar, N.; Tiwary, C. S.; Biswas, K., Preparation of nanocrystalline high-entropy alloys via cryomilling of cast ingots. J. mater. Sci. 2018; 53, (19): 13411-13423.

[13] Suryanarayana, C., Mechanical alloying and milling. Prog. Mater Sci. 2001; 46, (1-2): 1-184.

[14] Goujon, C.; Goeuriot, P.; Chedru, M.; Vicens, J.; Chermant, J. L.; Bernard, F.; Niepce, J. C.; Verdier, P.; Laurent, Y., Cryomilling of Al/AIN powders. Powder Technol. 1999; 105, (1-3): 328-336. 
[15] Suryanarayana, C., Mechanical Alloying And Milling. CRC Press: 2004.

[16] Ruzica Petkovic-Luton; Vallone, J. Composite dispersion strengthened composite metal powders. 4619699, October 28, 19861986.

[17] Hayes, A. E., Cryogenics: Theory, processes and applications. Nova Science Publishers: 2011; p 1-171.

[18] Dieter, G. E., Mechanical metallurgy. McGraw-Hill: 1986.

[19] Fecht, H. J., Nanostructure formation by mechanical attrition. Nanostruct. Mater. 1995; 6, (1-4): 33-42.

[20] Goujon, C.; Goeuriot, P.; Delcroix, P.; Le Caër, G., Mechanical alloying during cryomilling of a 5000 Al alloy/AIN powder: the effect of contamination. J. Alloys Compd. 2001; 315, (1-2): 276-283.

[21] Rhodin, T. N., Low Temperature Oxidation of Copper. I. Physical Mechanism. J. Am. Chem. Soc., 1950; 72, (11): 5102-5106.

[22] Lavernia, E. J.; Han, B. Q.; Schoenung, J. M., Cryomilled nanostructured materials: Processing and properties. Mater. Sci. Eng. A. 2008; 493, (1-2): 207-214.

[23] Lee, J.; Zhou, F.; Chung, K. H.; Kim, N. J.; Lavernia, E. J., Grain growth of nanocrystalline Ni powders prepared by cryomilling. Metall. Mater. Trans. A 2001; 32, (12): 3109-3115.

[24] Lee, Z.; Nutt, S. R.; Rodriguez, R.; Hayes, R. W.; Lavernia, E. J., Microstructural evolution and deformation of cryomilled nanocrystalline Al-Ti-Cu Alloy. Metall and Mat Trans A 2003; 34, (7): 14731481.

[25] Milligan, J.; Vintila, R.; Brochu, M., Nanocrystalline eutectic Al-Si alloy produced by cryomilling. Mater. Sci. Eng. A. 2009; 508, (1-2): 43-49.

[26] Roy, D.; Mahesh, B. V.; Atwater, M. A.; Chan, T. E.; Scattergood, R. O.; Koch, C. C., Grain size stability and hardness in nanocrystalline $\mathrm{Cu}-\mathrm{Al}-\mathrm{Zr}$ and $\mathrm{Cu}-\mathrm{Al}-\mathrm{Y}$ alloys. Mater. Sci. Eng. A. 2014; 598: 217-223.

[27] Xun, Y.; Mohamed, F.; Lavernia, E., Synthesis of nanocrystalline Zn-22 Pct Al using cryomilling. Metall and Mat Trans A 2004; 35, (2): 573-581.

[28] Zheng, B.; Ertorer, O.; Li, Y.; Zhou, Y.; Mathaudhu, S. N.; Tsao, C. Y. A.; et, a. I., High strength, nano-structured Mg-Al-Zn alloy. Mater. Sci. Eng. A. 2011; 528, (4-5): 2180-2191. 
[29] Zhou, F.; Witkin, D.; Nutt, S. R.; Lavernia, E. J., Formation of nanostructure in Al produced by a low-energy ball milling at cryogenic temperature. Mater. Sci. Eng. A. 2004; 375-377, (0): 917-921.

[30] Barai, K.; Tiwary, C. S.; Chattopadhyay, P. P.; Chattopadhyay, K., Synthesis of free standing nanocrystalline $\mathrm{Cu}$ by ball milling at cryogenic temperature. Mater. Sci. Eng. A. 2012; 558, (0): 52-58.

[31] Katiyar, N. K.; Biswas, K.; Tiwary, C. S.; Machado, L. D.; Gupta, R. K., Stabilization of a Highly Concentrated Colloidal Suspension of Pristine Metallic Nanoparticles. Langmuir 2019.

[32] Jang, S.; Seo, Y.; Choi, J.; Kim, T.; Cho, J.; Kim, S.; Kim, D., Sintering of inkjet printed copper nanoparticles for flexible electronics. Scripta Materialia 2010; 62, (5): 258-261.

[33] Huang, L.; Zhao, S.; Wang, Z.; Wu, J.; Wang, J.; Wang, S., In situ immobilization of silver nanoparticles for improving permeability, antifouling and anti-bacterial properties of ultrafiltration membrane. J Membrane Sci. 2016; 499: 269-281.

[34] Li, D.; Fang, W.; Xie, W.; Xing, Y.; Guo, Y.; Lin, R., Preparation of well-dispersed silver nanoparticles for oil-based nanofluids. Ind Eng Chem Res 2010; 49.

[35] Li, D.; Xie, W.; Fang, W., Preparation and properties of copper-oil-based nanofluids. Nanoscale Res. Lett 2011; 6, (1): 373.

[36] Paul, G.; Sarkar, S.; Pal, T.; Das, P. K.; Manna, I., Concentration and size dependence of nanosilver dispersed water based nanofluids. J. Colloid Interface Sci. 2012; 371, (1): 20-27.

[37] Saterlie, M. S.; Sahin, H.; Kavlicoglu, B.; Liu, Y.; Graeve, O. A., Surfactant Effects on Dispersion Characteristics of Copper-Based Nanofluids: A Dynamic Light Scattering Study. Chem. Mater. 2012; 24, (17): 3299-3306.

[38] Polte, J., Fundamental growth principles of colloidal metal nanoparticles - a new perspective. CrystEngComm 2015; 17, (36): 6809-6830.

[39] Hunter, R. J.; Ottewill, R. H.; Rowell, R. L., Zeta Potential in Colloid Science: Principles and Applications. Elsevier Science: 1981.

[40] De Jaeghere, W.; De Beer, T.; Van Bocxlaer, J.; Remon, J. P.; Vervaet, C., Hot-melt extrusion of polyvinyl alcohol for oral immediate release applications. Int. J. Pharm 2015; 492, (1): 1-9.

[41] Jayaramudu, T.; Raghavendra, G. M.; Varaprasad, K.; Reddy, G. V. S.; Reddy, A. B.; Sudhakar, K.; Sadiku, E. R., Preparation and characterization of poly(ethylene glycol) stabilized nano silver particles by a mechanochemical assisted ball mill process. J. Appl. Polym. Sci. 2016; 133, (7). 
[42] Metal Powder ReportJournal of Physics D: Applied PhysicsWatanabe, A.; Mori, K.; Kunimoto, M.; Andou, T.; Kimura, S., Cryo-Milling of Nutmeg Studies on the Cryo-Milling Process of Spices, Part I. Nippon Shokuhin Kogyo Gakkaishi 1978; 25, (8): 465-470.

[43] Travan, A.; Marsich, E.; Donati, I.; Paoletti, S., Silver Nanocomposites and Their Biomedical Applications. In Nanotechnologies for the Life Sciences, Wiley-VCH Verlag GmbH \& Co. KGaA: 2007.

[44] Fereshteh-Saniee, N.; Reynolds, N.; Kelly, C. A.; Wilson, P. R.; Jenkins, M. J.; Kendall, K. N., Introducing cryomilling for reliable determination of resin content and degree of cure in structural carbon fibre reinforced thermoset composites. Compos Part A Appl Sci Manuf. 2018; 107: 197-204.

[45] Gao, Y.; Lim, J.; Han, Y.; Wang, L.; Chong, M. S. K.; Teoh, S. H.; Xu, C., Cryomilling for the fabrication of doxorubicin-containing silica-nanoparticle/polycaprolactone nanocomposite films. Nanoscale 2016; 8, (5): 2568-2574.

[46] Mittal, G.; Rhee, K. Y.; Park, S. J., The effects of cryomilling CNTs on the thermal and electrical properties of CNT/PMMA composites. Polymers 2016; 8, (5).

[47] Kang, N.; Lee, J.; Choi, J. N.; Mao, C.; Lee, E. H., Cryomilling-induced solid dispersion of poor glass forming/poorly water-soluble mefenamic acid with polyvinylpyrrolidone K12. Drug Dev. Ind. Pharm. 2015; 41, (6): 978-988.

[48] Hou, Q.; Fan, R. H.; Zhang, Z. D.; Yan, K. L.; Cheng, C. B.; Chen, M.; Sun, K.; Liu, G. F.; Xie, P. T., Graphene epoxy composites with high dielectric constant prepared by cryomilling. Mater. Sci. Forum 2015; 815: 611-615.

[49] Ullah, M.; Ali, M. E.; Hamid, S. B. A., Structure-controlled nanomaterial synthesis using surfactant-assisted ball milling-a review. Current Nanoscience 2014; 10, (3): 344-354.

[50] Nigam, P.; Grewal, P.; Singh, V. P.; Prasad, K.; Tak, J.; Sinha, A., Cryogenic Grinding: An Insight into The New Era Int J Dent Med Res 2014; 1, (4): 3.

[51] Zhu, Y. G.; Li, Z. Q.; Gu, J. J.; Zhang, D.; Tanimoto, T., Polyaniline/iron nanocomposites prepared by cryomilling. J. Polym. Sci., Part B: Polym. Phys. 2006; 44, (21): 3157-3164.

[52] Balcı, Ö.; Ağaoğulları, D.; Gökçe, H.; Öveçoğlu, M. L.; Somer, M., Effect of cryomilling on matrix/reinforcement interfaces and properties of $\mathrm{Al}^{-\mathrm{TiB}_{2}}$ composites. J. Alloys Compd. 2018; 757: 393-402.

[53] Biswas, K.; Phanikumar, G.; Chattopadhyay, K.; Volkmann, T.; Funke, O.; Holland-Moritz, D.; Herlach, D. M., Rapid solidification behaviour of undercooled levitated Fe-Ge alloy droplets. Mater. Sci. Eng. A. 2004; 375-377, (Supplement C): 464-467. 
[54] Smith, A. P. Solid state blending and compatibilization of polymers by cryogenic mechanical alloying. Ph. D Thesis, North Carolina State University, 1999.

[55] Smith, A. P.; Spontak, R. J.; Ade, H.; Smith, S. D.; Koch, C. C., High-energy cryogenic blending and compatibilizing of immiscible polymers. Adv. Mater. 1999; 11, (15): 1277-1281.

[56] Jeeva Jothi, K.; Santhoskumar, A. U.; Amanulla, S.; Palanivelu, K., Thermally Sprayable Anticorrosion Marine Coatings Based on MAH-g-LDPE/UHMWPE Nanocomposites. J. Therm. Spray Technol 2014; 23, (8): 1413-1424.

[57] Tiwary, C. S.; Kishore, S.; Vasireddi, R.; Mahapatra, D. R.; Ajayan, P. M.; Chattopadhyay, K., Electronic waste recycling via cryo-milling and nanoparticle beneficiation. Mater. Today 2017; 20, (2): 67-73.

[58] Bruyère, D.; Simon, S.; Haas, H.; Conte, T.; Menad, N.-E., Cryogenic ball milling: A key for elemental analysis of plastic-rich automotive shedder residue. Powder Technol. 2016; 294: 454-462.

[59] Wu, J. Y.; Liu, Q.; Wang, Z. H.; Wang, Z., Cryomilling and characterization of $\mathrm{Ti} / \mathrm{Al}_{2} \mathrm{O}_{3}$ powders. Solid State Phenom. 2018; 281: 285-290.

[60] Back, S. H.; Lee, G. H.; Kang, S., Effect of cryomilling on particle size and microstrain in a WCCo alloy. Mater. Trans. 2005; 46, (1): 105-110.

[61] Ye, J.; Lee, Z.; Ahn, B.; Nutt, S. R.; He, J.; Schoenung, J. M., Cryomilling for the fabrication of a particulate $\mathrm{B} 4 \mathrm{C}$ reinforced Al nanocomposite: Part II. Mechanisms for microstructural evolution. Metall and Mat Trans A 2006; 37, (10): 3111-3117.

[62] Hou, Q.; Shi, Z. C.; Fan, R. H.; Ju, L. C., Cryomilling and characterization of metal/ceramic powders. Key Eng. Mater. 2012; 512-515: 127-131.

[63] Sharma, P.; Biswas, K.; Mondal, A. K.; Chattopadhyay, K., Size effect on the lattice parameter of $\mathrm{KCl}$ during mechanical milling. Scripta Materialia 2009; 61, (6): 600-603.

[64] Verma, A.; Biswas, K.; Tiwary, C.; Mondal, A.; Chattopadhyay, K., Combined Cryo and RoomTemperature Ball Milling to Produce Ultrafine Halide Crystallites. Metall and Mat Trans A 2011; 42, (4): 1127-1137.

[65] Tiwary, C. S.; Verma, A.; Biswas, K.; Mondal, A. K.; Chattopadhyay, K., Preparation of ultrafine $\mathrm{CsCl}$ crystallites by combined cryogenic and room temperature ball milling. Ceramics International 2011; 37, (8): 3677-3686.

[66] Murdande, S. B.; Pikal, M. J.; Shanker, R. M.; Bogner, R. H., Solubility Advantage of Amorphous Pharmaceuticals: II. Application of Quantitative Thermodynamic Relationships for 
Prediction of Solubility Enhancement in Structurally Diverse Insoluble Pharmaceuticals. Pharm. Res. 2010; 27, (12): 2704-2714.

[67] Sugimoto, S.; Niwa, T.; Nakanishi, Y.; Danjo, K., Novel Ultra-Cryo Milling and Co-grinding Technique in Liquid Nitrogen to Produce Dissolution-Enhanced Nanoparticles for Poorly WaterSoluble Drugs. Chem. Pharm. Bull. 2012; 60, (3): 325-333.

[68] Sugimoto, S.; Niwa, T.; Nakanishi, Y.; Danjo, K., Development of a novel ultra cryo-milling technique for a poorly water-soluble drug using dry ice beads and liquid nitrogen. Int. J. Pharm 2012; 426, (1): 162-169.

[69] Macfhionnghaile, P.; Hu, Y.; Gniado, K.; Curran, S.; McArdle, P.; Erxleben, A., Effects of BallMilling and Cryomilling on Sulfamerazine Polymorphs: A Quantitative Study. J. Pharm. Sci. 2014; 103, (6): 1766-1778.

[70] Liu, H.; Zheng, J.; Liu, P.; Zeng, F., Pulverizing processes affect the chemical quality and thermal property of black, white, and green pepper (Piper nigrum L.). J. Food Sci. Technol. 2018; 55, (6): 2130-2142.

[71] Ahmed, M. J.; Murtaza, G.; Mehmood, A.; Bhatti, T. M., Green synthesis of silver nanoparticles using leaves extract of Skimmia laureola: Characterization and antibacterial activity. Materials Letters 2015; 153: 10-13.

[72] Baghizadeh, A.; Ranjbar, S.; Gupta, V. K.; Asif, M.; Pourseyedi, S.; Karimi, M. J.; Mohammadinejad, R., Green synthesis of silver nanoparticles using seed extract of Calendula officinalis in liquid phase. J. Mol. Liq. 2015; 207: 159-163.

[73] Dhand, V.; Soumya, L.; Bharadwaj, S.; Chakra, S.; Bhatt, D.; Sreedhar, B., Green synthesis of silver nanoparticles using Coffea arabica seed extract and its antibacterial activity. Mater. Sci. Eng., $C$ 2016; 58: 36-43.

[74] Patra, S.; Mukherjee, S.; Barui, A. K.; Ganguly, A.; Sreedhar, B.; Patra, C. R., Green synthesis, characterization of gold and silver nanoparticles and their potential application for cancer therapeutics. Mater. Sci. Eng., C 2015; 53: 298-309.

[75] Sharma, V. K.; Yngard, R. A.; Lin, Y., Silver nanoparticles: Green synthesis and their antimicrobial activities. Adv. Colloid Interface Sci. 2009; 145, (1-2): 83-96.

[76] Vijayaraghavan, K.; Nalini, S. P. K.; Prakash, N. U.; Madhankumar, D., One step green synthesis of silver nano/microparticles using extracts of Trachyspermum ammi and Papaver somniferum. Colloids Surf., B 2012; 94: 114-117.

[77] Wasserscheid, P., Handbook of Green Chemistry: Ionic liquids / ed. by Peter Wasserscheid and Annegret Stark. Vol. 6 : Green solvents. Wiley-VCH-Verlag: 2010. 
[78] Li, S.; Shen, Y.; Xie, A.; Yu, X.; Qiu, L.; Zhang, L.; Zhang, Q., Green synthesis of silver nanoparticles using Capsicum annuum L. extract. Green Chemistry 2007; 9, (8): 852-858.

[79] Witkin, D. B.; Lavernia, E. J., Synthesis and mechanical behavior of nanostructured materials via cryomilling. Prog. Mater Sci. 2006; 51, (1): 1-60.

[80] Mechanical Behavior of Nanostructured Materials. MRS Bulletin 1999; 24, (2): 14-19.

[81] Koch, C. C., The synthesis and structure of nanocrystalline materials produced by mechanical attrition: A review. Nanostruct. Mater. 1993; 2, (2): 109-129.

[82] Huang, B.; Vallone, J.; Luton, M. J., The effect of nitrogen and oxygen on the synthesis of B2 NiAl by cryomilling. Nanostruct. Mater. 1995; 5, (6): 631-642.

[83] Kozlík, J.; Stráský, J.; Harcuba, P.; Ibragimov, I.; Chráska, T.; Janeček, M., Cryogenic milling of titanium powder. Metals 2018; 8, (1).

[84] Saxena, S. N.; Barnwal, P.; Balasubramanian, S.; Yadav, D. N.; Lal, G.; Singh, K. K., Cryogenic grinding for better aroma retention and improved quality of Indian spices and herbs: A review. J. Food Process Eng. 2018; 41, (6): e12826.

[85] http://www.unionprocess.com/laboratory-grinding-attritors.html http://www.unionprocess.com/laboratory-grinding-attritors.html

[86] http://www.retsch.com/products/milling/ball-mills/mixer-mill-cryomill.

[87] https://www.spexsampleprep.com/freezermill-for-cryogenic-grinding, SPEX CentriPrep Freezer mill.

[88] http://tauinstrument.com/cryo-ball-mill-pictures/.

[89] http://www.fritsch-milling.com/products/milling/ball-mills/pulverisette-0/description/ http://www.fritsch-milling.com/products/milling/ball-mills/pulverisette-0/description/

[90] He, Y.; Ho, C., Amorphous Solid Dispersions: Utilization and Challenges in Drug Discovery and Development. J. Pharm. Sci. 2015; 104, (10): 3237-3258.

[91] Benjamin, J. S.; Volin, T. E., Mechanism of mechanical alloying. Metall Trans 1974; 5, (8): 1929-1934.

[92] Gilman, P. S.; Benjamin, J. S., Mechanical Alloying. Annu. Rev. Mater. Sci. 1983; 13, (1): 279300. 
[93] Benjamin, J. S., Mechanical alloying - A perspective. Met. Powder Rep. 1990; 45, (2): $122-$ 127.

[94] Lala, S.; Maity, T. N.; Singha, M.; Biswas, K.; Pradhan, S. K., Effect of doping (Mg,Mn,Zn) on the microstructure and mechanical properties of spark plasma sintered hydroxyapatites synthesized by mechanical alloying. Ceramics International 2017; 43, (2): 2389-2397.

[95] Murty, B.; Ranganathan, S., Novel materials synthesis by mechanical alloying/milling. Int. Mater. Rev. 1998; 43, (3): 101-141.

[96] Koch, C. C.; Whittenberger, J. D., Mechanical milling/alloying of intermetallics. Intermetallics 1996; 4, (5): 339-355.

[97] Takacs, L.; McHenry, J. S., Temperature of the milling balls in shaker and planetary mills. J. mater. Sci. 2006; 41, (16): 5246-5249.

[98] Maurice, D. R.; Courtney, T. H., The physics of mechanical alloying: A first report. Metall and Mat Trans A 1990; 21, (1): 289-303.

[99] Han, B. Q.; Ye, J.; Tang, F.; Schoenung, J.; Lavernia, E. J., Processing and behavior of nanostructured metallic alloys and composites by cryomilling. J. mater. Sci. 2007; 42, (5): 1660-1672.

[100] Mohamed, F. A., A dislocation model for the minimum grain size obtainable by milling. Acta Materialia 2003; 51, (14): 4107-4119.

[101] Alymov, M. I.; Maltina, E. I.; Stepanov, Y. N., Model of initial stage of ultrafine metal powder sintering. Nanostruct. Mater. 1994; 4, (6): 737-742.

[102] Tiwary, C.; Verma, A.; Kashyp, S.; Biswas, K.; Chattopadhyay, K., Preparation of Freestanding Zn Nanocrystallites by Combined Milling at Cryogenic and Room Temperatures. Metall and Mat Trans A 2013; 44, (4): 1917-1924.

[103] Katiyar, N. K.; Biswas, K.; Tiwary, C. S.; Machado, L. D.; Gupta, R. K., Stabilization of a Highly Concentrated Colloidal Suspension of Pristine Metallic Nanoparticles (Supporting Information). Langmuir 2019; 35, (7): 2668-2673.

[104] Cahn, R. W.; Haasen, P., Physical Metallurgy. Elsevier Science: 1996.

[105] Hallén, H., A theory of dynamic recovery in F.C.C. metals. Mater. Sci. Engg. 1985; 72, (2): 119-123.

[106] Sattler, K. D., Handbook of Nanophysics: Nanotubes and Nanowires. CRC Press: 2010. 
[107] Hofmeister, C.; Klimov, M.; Deleghanty, T.; Cho, K.; Sohn, Y., Quantification of nitrogen impurity and estimated Orowan strengthening through secondary ion mass spectroscopy in aluminum cryomilled for extended durations. Mater. Sci. Eng. A. 2015; 648: 412-417.

[108] https://www.ciphet.in/saifinstruments.php?id=Cryogenic\%20grinder.

[109] Swift, H. F.; Hirst, G. K., An Apparatus for Grinding Bacteria at Low Temperatures. SEBM 1937; 37, (1): 162-166.

[110] Schaub, R., Cryogen - Low Temperature Grinding of Brittle Materials. Plastverarbeiter 1973; 24, (11): 694-696.

[111] El-Eskandarany, M. S., Mechanical Alloying: Nanotechnology, Materials Science and Powder Metallurgy. Elsevier Science: 2015.

[112] Salah, N.; Habib, S. S.; Khan, Z. H.; Memic, A.; Azam, A.; Alarfaj, E.; Zahed, N.; Al-Hamedi, S., High-energy ball milling technique for $\mathrm{ZnO}$ nanoparticles as antibacterial material. Int. J. Nanomed. 2011; 6: 863-869.

[113] Wang, F.; Wang, X., Mechanisms in the solution growth of free-standing two-dimensional inorganic nanomaterials. Nanoscale 2014; 6, (12): 6398-6414.

[114] Spiegelberg, S., Chapter 24 - Characterization of Physical, Chemical, and Mechanical Properties of UHMWPE. In UHMWPE Biomaterials Handbook (Second Edition), Kurtz, S. M., Ed. Academic Press: Boston, 2009; pp 355-368.

[115] Santhanam, P. R.; Ermoline, A.; Dreizin, E. L., Discrete element model for an attritor mill with impeller responding to interactions with milling balls. Chem. Eng. Sci. 2013; 101: 366-373.

[116] http://www.retsch.com/products/sieving/sieve-shakers/as-200-basic/function-features/ http://www.retsch.com/products/sieving/sieve-shakers/as-200-basic/function-features/

[117] Harish, N.; Anil Kumar, K.; Sirnivas, D.; Kumar, S., Advanced Technology for Spices Grinding-A Review. IJASR 2017; 7, (4): 529-536.

[118] Zhang, X.; Wang, H.; Narayan, J.; Koch, C. C., Evidence for the formation mechanism of nanoscale microstructures in cryomilled Zn powder. Acta Materialia 2001; 49, (8): 1319-1326.

[119] Zhang, X.; Wang, H.; Scattergood, R. O.; Narayan, J.; Koch, C. C., Modulated oscillatory hardening and dynamic recrystallization in cryomilled nanocrystalline Zn. Acta Materialia 2002; 50, (16): 3995-4004. 
[120] Tiwary, C. S.; Kashyap, S.; Biswas, K.; Chattopadhyay, K., Synthesis of pure iron magnetic nanoparticles in large quantity. J. Phys. D 2013; 46, (38): 385001-385005.

[121] Bagus, P. S.; Brundle, C. R.; Illas, F.; Parmigiani, F.; Polzonetti, G., Evidence for oxygen-island formation on $\mathrm{Al}(111)$ : Cluster-model theory and x-ray photoelectron spectroscopy. Phys. Rev. B 1991; 44, (16): 9025-9034.

[122] Cordier, F.; Ollivier, E., X-ray photoelectron spectroscopy study of aluminium surfaces prepared by anodizing processes. Surf. Interface Anal. 1995; 23, (9): 601-608.

[123] Hess, A.; Kemnitz, E.; Lippitz, A.; Unger, W. E. S.; Menz, D. H., ESCA, XRD, and IR Characterization of Aluminum Oxide, Hydroxyfluoride, and Fluoride Surfaces in Correlation with Their Catalytic Activity in Heterogeneous Halogen Exchange Reactions. J. Catal. 1994; 148, (1): 270280.

[124] Kovacich, J. A.; Lichtman, D., A qualitative and quantitative study of the oxides of aluminum and silicon using AES and XPS. J Electron Spectros Relat Phenomena 1985; 35, (1): 7-18.

[125] Kaplin, C.; Ivanov, R.; Paliwal, M.; Jung, I.-H.; Brochu, M., The effect of nanostructure on the oxidation of NiAl. Intermetallics 2014; 54: 209-217.

[126] Ma, K.; Schoenung, J. M., Influence of cryomilling on the microstructural features in HVOFsprayed NiCrAlY bond coats for thermal barrier coatings: Creation of a homogeneous distribution of nanoscale dispersoids. Philos. Mag. Lett. 2010; 90, (10): 739-751.

[127] Ajdelsztajn, L.; Hulbert, D.; Mukherjee, A.; Schoenung, J. M., Creep deformation mechanism of cryomilled NiCrAlY bond coat material. Surf. Coat. Technol. 2007; 201, (24): 9462-9467.

[128] Ma, K.; Schoenung, J. M., Isothermal oxidation behavior of cryomilled NiCrAlY bond coat: Homogeneity and growth rate of TGO. Surf. Coat. Technol. 2011; 205, (21): 5178-5185.

[129] Todde, S.; Licheri, R.; Orrù, R.; Cao, G., Spark plasma sintering processing for the evaluation of cryomilled CoNiCrAIY alloys for high temperature applications in oxidizing environment. Chem. Engg. J. 2012; 200-202: 68-80.

[130] Feng, B.; Tariq, N. u. H.; Wang, J.; Du, H.; Zang, X.; Xiong, T., Modification of cryomilling process to tailor geometrical characteristics of nanostructured Al powder for cold spraying. Powder Technol. 2018; 338: 173-179.

[131] Sun, Y.; Luo, G.; Zhang, J.; Chen, J.; Wang, G.; Shen, Q.; Zhang, L., Microstructure, mechanical properties and reinforcement mechanism of dual-scale TC4 titanium alloy prepared by cryomilling and plasma activated sintering. Mater. Sci. Eng. A. 2018; 736: 120-129. 
[132] Kim, J. H.; Lee, J. H.; Min, J. Y.; Kim, S. W.; Park, C. H.; Yeom, J. T.; Byun, T. S., Cryomilling effect on the mechanical alloying behaviour of ferritic oxide dispersion strengthened powder with Y2O3. J. Alloys Compd. 2013; 580: 125-130.

[133] Ertorer, O.; Topping, T.; Li, Y.; Moss, W.; Lavernia, E. J., Enhanced tensile strength and high ductility in cryomilled commercially pure titanium. Scripta Materialia 2009; 60, (7): 586-589.

[134] Wen, H.; Lavernia, E. J., Twins in cryomilled and spark plasma sintered Cu-Zn-Al. Scripta Materialia 2012; 67, (3): 245-248.

[135] Tjong, S. C., Novel Nanoparticle-Reinforced Metal Matrix Composites with Enhanced Mechanical Properties. Adv. Eng. Mater. 2007; 9, (8): 639-652.

[136] Dheda, S. S.; Melnyk, C.; Mohamed, F. A., Effect of titanium nitride nanoparticles on grain size stabilization and consolidation of cryomilled titanium. Mater. Sci. Eng. A. 2013; 584: 88-96.

[137] Maung, K.; Mishra, R. K.; Roy, I.; Lai, L. C.; Mohamed, F. A.; Earthman, J. C., Thermal stability of cryomilled nanocrystalline aluminum containing diamantane nanoparticles. J. mater. Sci. 2011; 46, (21): 6932-6940.

[138] Tang, F.; Hagiwara, M.; Schoenung, J. M., Microstructure and tensile properties of bulk nanostructured Al-5083/SiCp composites prepared by cryomilling. Mater. Sci. Eng. A. 2005; 407, (1): 306-314.

[139] Vogt, R. G.; Zhang, Z.; Topping, T. D.; Lavernia, E. J.; Schoenung, J. M., Cryomilled aluminum alloy and boron carbide nano-composite plate. J. Mater. Process. Technol. 2009; 209, (11): 50465053.

[140] Chung, K. H.; He, J.; Shin, D. H.; Schoenung, J. M., Mechanisms of microstructure evolution during cryomilling in the presence of hard particles. Mater. Sci. Eng. A. 2003; 356, (1): 23-31.

[141] Thornton, J. J.; Han, B. Q.; Lavernia, E. J., Grain growth in cryomilled Ni powder during degassing. Metall. Mater. Trans. A 2007; 38, (6): 1343-1350.

[142] Zhou, F.; Rodriguez, R.; Lavernia, E. J., Thermally stable nanocrystalline Al-Mg alloy powders produced by cryomilling. In Mater. Sci. Forum, 2002; Vol. 386-388, pp 409-414.

[143] Han, B. Q.; Lavernia, E. J., High-temperature behavior of a cryomilled ultrafine-grained Al7.5\% Mg alloy. Mater. Sci. Eng. A. 2005; 410-411: 417-421.

[144] Han, B. Q.; Mohamed, F. A.; Bampton, C. C.; Lavernia, E. J., Improvement of toughness and ductility of a cryomilled Al-Mg alloy via microstructural modification. Metall. Mater. Trans. A 2005; 36, (8): 2081-2091. 
[145] Han, B. Q.; Zhang, Z.; Lavernia, E. J., Creep behaviour and thermal stability of cryomilled Al alloy. Philos. Mag. Lett. 2005; 85, (2): 97-108.

[146] Han, B. Q.; Huang, J. Y.; Zhu, Y. T.; Lavernia, E. J., Effect of strain rate on the ductility of a nanostructured aluminum alloy. Scripta Materialia 2006; 54, (6): 1175-1180.

[147] Han, B. Q.; Lavernia, E. J., Deformation mechanisms of nanostructured Al alloys. Adv. Eng. Mater. 2005; 7, (6): 457-465.

[148] Witkin, D.; Han, B. Q.; Lavernia, E. J., Mechanical behavior of ultrafine-grained cryomilled Al 5083 at elevated temperature. J. Mater. Eng. Perform. 2005; 14, (4): 519-527.

[149] Han, B. Q.; Lavernia, E. J.; Mohamed, F. A., Mechanical properties of nanostructured materials. Rev. Adv. Mater. Sci. 2005; 9, (1): 1-16.

[150] Cao, B.; Joshi, S. P.; Ramesh, K. T., Strengthening mechanisms in cryomilled ultrafine-grained aluminum alloy at quasi-static and dynamic rates of loading. Scripta Materialia 2009; 60, (8): 619622.

[151] Hanna, W.; Maung, K.; Enayati, M.; Earthman, J. C.; Mohamed, F. A., Grain size stability in a cryomilled nanocrystalline Al alloy powders containing diamantane nanoparticles. Mater. Sci. Eng. A. 2019; 746: 290-299.

[152] Kim, J. H.; Park, C. H., Effect of milling temperature on nanoclusters and ultra fine grained microstructure of oxide dispersion strengthened steel. J. Alloys Compd. 2014; 585: 69-74.

[153] Kim, J. H.; Byun, T. S.; Shin, E.; Seol, J.-B.; Young, S.; Reddy, N. S., Small angle neutron scattering analyses and high temperature mechanical properties of nano-structured oxide dispersion-strengthened steels produced via cryomilling. J. Alloys Compd. 2015; 651: 363-374.

[154] Dai, C.; Schade, C.; Apelian, D.; Lavernia, E. J., Processing Techniques for ODS Stainless Steels. Metall. Mater. Trans. B 2018; 49, (6): 3043-3055.

[155] Lv, P.; Guzik, M. N.; Sartori, S.; Huot, J., Effect of ball milling and cryomilling on the microstructure and first hydrogenation properties of TiFe+4wt.\% $\mathrm{Zr}$ alloy. J. Mater. Res. Technol. 2019; 8, (2): 1828-1834.

[156] Lee, Z.; Witkin, D. B.; Radmilovic, V.; Lavernia, E. J.; Nutt, S. R., Bimodal microstructure and deformation of cryomilled bulk nanocrystalline Al-7.5Mg alloy. Mater. Sci. Eng. A. 2005; 410-411: 462-467.

[157] Park, Y. S.; Chung, K. H.; Kim, N. J.; Lavernia, E. J., Microstructural investigation of nanocrystalline bulk Al-Mg alloy fabricated by cryomilling and extrusion. Mater. Sci. Eng. A. 2004; 374, (1): 211-216. 
[158] Ye, J.; Ajdelsztajn, L.; Schoenung, J. M., Bulk nanocrystalline aluminum 5083 alloy fabricated by a novel technique: Cryomilling and spark plasma sintering. Metall and Mat Trans A 2006; 37, (8): 2569-2579.

[159] Deng, H.; Chen, A.; Chen, L.; Wei, Y.; Xia, Z.; Tang, J., Bulk nanostructured Ti-45Al-8Nb alloy fabricated by cryomilling and Spark Plasma Sintering. J. Alloys Compd. 2019; 772: 140-149.

[160] Sikdar, K.; Mahata, A.; Chakravarty, S.; Atwater, M. A.; Roy, D.; Koch, C. C., Effect of B on the thermal stabilization of cryomilled nanocrystalline Cu-Al alloy. Materialia 2019; 5: 100253.

[161] Chen, H.-b.; Cheng, J.-S.; Yang, B.; Zhang, J.-s.; Tian, X.-f.; Fan, J.-z., Deformation twins and twinning at ambient temperature in cryomilled Al-Zn-Mg-Cu alloy powders. Trans. Nonferrous Met. Soc. China 2007; 17, (5): 898-901.

[162] Gwon, J.-H.; Kim, J.-H.; Lee, K.-A., Effects of cryomilling on the microstructures and high temperature mechanical properties of oxide dispersion strengthened steel. J. Nucl. Mater. 2015; 459: 205-216.

[163] Kaplin, C.; Brochu, M., Effects of water vapor on high temperature oxidation of cryomilled NiCoCrAlY coatings in air and low-SO2 environments. Surf. Coat. Technol. 2011; 205, (17): 42214227.

[164] Whittenberger, J. D.; Grahle, P.; Behr, R.; Arzt, E.; Hebsur, M. G., Elevated temperature compressive strength properties of oxide dispersion strengthened NiAl after cryomilling and roasting in nitrogen. Mater. Sci. Eng. A. 2000; 291, (1): 173-185.

[165] Susegg, O.; Hellum, E.; Olsen, A.; Luton, M. J., HREM study of dispersoids in cryomilled oxide dispersion strengthened materials. Philosophical Magazine A 1993; 68, (2): 367-380.

[166] Huang, B.; Perez, R. J.; Lavernia, E. J., Grain growth of nanocrystalline Fe-Al alloys produced by cryomilling in liquid argon and nitrogen. Mater. Sci. Eng. A. 1998; 255, (1): 124-132.

[167] Perez, R. J.; Jiang, H. G.; Lavernia, E. J.; Dogan, C. P., Grain growth of nanocrystalline cryomilled Fe-Al powders. Metall and Mat Trans A 1998; 29, (10): 2469-2475.

[168] Li, Y.; Liu, W.; Ortalan, V.; Li, W. F.; Zhang, Z.; Vogt, R.; Browning, N. D.; Lavernia, E. J.; Schoenung, J. M., HRTEM and EELS study of aluminum nitride in nanostructured AI 5083/B4C processed via cryomilling. Acta Materialia 2010; 58, (5): 1732-1740.

[169] Sikdar, K.; Mahata, A.; Roy, B.; Roy, D., Hybrid thermal stabilization of Zr doped nanocrystalline Cu. Materials \& Design 2019; 164: 107564. 
[170] Chakravarty, S.; Sikdar, K.; Singh, S. S.; Roy, D.; Koch, C. C., Grain size stabilization and strengthening of cryomilled nanostructured Cu 12 at\% Al alloy. J. Alloys Compd. 2017; 716: 197-203.

[171] Wu, C.; Luo, G.; Zhang, J.; Shen, Q.; Gan, Z.; Liu, J.; Zhang, L., Influence of length-scale on stabilization of boron carbide in Al-based metal matrix composites during plasma activated sintering. Powder Technol. 2018; 339: 809-816.

[172] Liu, R.; Wu, C.; Zhang, J.; Luo, G.; Shen, Q.; Zhang, L., Microstructure and mechanical behaviors of the ultrafine grained AA7075/B4C composites synthesized via one-step consolidation. J. Alloys Compd. 2018; 748: 737-744.

[173] Wu, C.; Zhang, J.; Luo, G.; Shen, Q.; Gan, Z.; Liu, J.; Zhang, L., Interfacial segregation and precipitates behavior in the ultrafine grained Al-based metal matrix composites. J. Alloys Compd. 2019; 770: 625-630.

[174] Maung, K.; Earthman, J. C.; Mohamed, F. A., Inverse Hall-Petch behavior in diamantane stabilized bulk nanocrystalline aluminum. Acta Materialia 2012; 60, (16): 5850-5857.

[175] Zhang, Z.; Topping, T.; Li, Y.; Vogt, R.; Zhou, Y.; Haines, C.; Paras, J.; Kapoor, D.; Schoenung, J. M.; Lavernia, E. J., Mechanical behavior of ultrafine-grained Al composites reinforced with B4C nanoparticles. Scripta Materialia 2011; 65, (8): 652-655.

[176] Lee, Z.; Zhou, F.; Valiev, R. Z.; Lavernia, E. J.; Nutt, S. R., Microstructure and microhardness of cryomilled bulk nanocrystalline $\mathrm{Al}-7.5 \% \mathrm{Mg}$ alloy consolidated by high pressure torsion. Scripta Materialia 2004; 51, (3): 209-214.

[177] Kudashov, D. V.; Baum, H.; Martin, U.; Heilmaier, M.; Oettel, H., Microstructure and room temperature hardening of ultra-fine-grained oxide-dispersion strengthened copper prepared by cryomilling. Mater. Sci. Eng. A. 2004; 387-389: 768-771.

[178] Kozlík, J.; Harcuba, P.; Stráský, J.; Becker, H.; Šmilauerová, J.; Janeček, M., Microstructure and texture formation in commercially pure titanium prepared by cryogenic milling and spark plasma sintering. Mater. Charact. 2019; 151: 1-5.

[179] Lucadamo, G.; Yang, N. Y. C.; Marchi, C. S.; Lavernia, E. J., Microstructure characterization in cryomilled Al 5083. Mater. Sci. Eng. A. 2006; 430, (1): 230-241.

[180] Chen, H.-b.; Tao, K.; Yang, B.; Zhang, J.-S., Nanostructured Al-Zn-Mg-Cu alloy synthesized by cryomilling and spark plasma sintering. Trans. Nonferrous Met. Soc. China 2009; 19, (5): 1110-1115.

[181] Saessi, M.; Alizadeh, A., Comparative studies on microstructural evolution, mechanical properties and room temperature dry sliding tribological behavior of nano-crystalline Al5083 alloy produced by the cryobox technique. Mater. Res. Express 2019; 6, (9): 0965a2. 
[182] Chauhan, M.; Roy, I.; Mohamed, F. A., High-strain-rate superplasticity in bulk cryomilled ultra-fine-grained 5083 Al. Metall and Mat Trans A 2006; 37, (9): 2715-2725.

[183] Shanmugasundaram, T.; Guyon, J.; Monchoux, J. P.; Hazotte, A.; Bouzy, E., On grain refinement of a $\gamma$-TiAl alloy using cryo-milling followed by spark plasma sintering. Intermetallics 2015; 66: 141-148.

[184] Huang, B.; Perez, R. J.; Crawford, P. J.; Sharif, A. A.; Nutt, S. R.; Lavernia, E. J., Mechanically induced crystallization of metglas Fe78B13Si9 during cryogenic high energy ball milling. Nanostruct. Mater. 1995; 5, (5): 545-553.

[185] Perez, R. J.; Huang, B.; Lavernia, E. J., Thermal stability of nanocrystalline Fe-10 wt.\% Al produced by cryogenic mechanical alloying. Nanostruct. Mater. 1996; 7, (5): 565-572.

[186] Yang, N.; Yee, J. K.; Zhang, Z.; Kurmanaeva, L.; Cappillino, P.; Stavila, V.; Lavernia, E. J.; San Marchi, C., Hydrogen sorption characteristics of nanostructured $\mathrm{Pd}-10 \mathrm{Rh}$ processed by cryomilling. Acta Materialia 2015; 82: 41-50.

[187] Lee, J. H.; Rhee, K. Y.; Park, S. J., Effects of cryomilling on the structures and hydrogen storage characteristics of multi-walled carbon nanotubes. Int. J. Hydrogen Energ. 2010; 35, (15): 7850-7857.

[188] Azeez, A. A.; Rhee, K. Y.; Park, S. J.; Kim, H. J.; Jung, D. H., Application of cryomilling to enhance material properties of carbon nanotube reinforced chitosan nanocomposites. Compos. Part B-Eng. 2013; 50: 127-134.

[189] Huot, J.; Cuevas, F.; Deledda, S.; Edalati, K.; Filinchuk, Y.; Grosdidier, T.; Hauback, B. C.; Heere, M.; Jensen, T. R.; Latroche, M.; Sartori, S., Mechanochemistry of metal hydrides: Recent advances. Materials 2019; 12, (7).

[190] Pommerin, A.; Weidenthaler, C.; Schüth, F.; Felderhoff, M., Direct synthesis of pure complex aluminium hydrides by cryomilling. Scripta Materialia 2010; 62, (8): 576-578.

[191] Cai, X.; Xin, S.; Sun, B.; Cui, H.; Yu, H.; Peng, Q.; Shen, T., Thermally stable and strong bulk $\mathrm{Mg}-\mathrm{MgO}$ in situ nanocomposites by reactive cryomilling and high-pressure consolidation. J. mater. Sci. 2018; 53, (9): 6613-6625.

[192] Pu, K.; Qu, X.; Zhang, X.; Hu, J.; Gu, C.; Wu, Y.; Gao, M.; Pan, H.; Liu, Y., Nanoscaled Lithium Powders with Protection of Ionic Liquid for Highly Stable Rechargeable Lithium Metal Batteries. Advanced Science 0, (0): 1901776.

[193] Trasi, N. S.; Byrn, S. R., Mechanically Induced Amorphization of Drugs: A Study of the Thermal Behavior of Cryomilled Compounds. AAPS PharmSciTech 2012; 13, (3): 772-784. 
[194] Qi, S.; Weuts, I.; De Cort, S.; Stokbroekx, S.; Leemans, R.; Reading, M.; Belton, P.; Craig, D. Q. M., An investigation into the crystallisation behaviour of an amorphous cryomilled pharmaceutical material above and below the glass transition temperature. J. Pharm. Sci. 2010; 99, (1): 196-208.

[195] Graeser, K. A.; Strachan, C. J.; Patterson, J. E.; Gordon, K. C.; Rades, T., Physicochemical Properties and Stability of Two Differently Prepared Amorphous Forms of Simvastatin. Crystal Growth \& Design 2008; 8, (1): 128-135.

[196] Crowley, K. J.; Zografi, G., Cryogenic grinding of indomethacin polymorphs and solvates: Assessment of amorphous phase formation and amorphous phase physical stability. J. Pharm. Sci. 2002; 91, (2): 492-507.

[197] Chieng, N.; Rades, T.; Saville, D., Formation and physical stability of the amorphous phase of ranitidine hydrochloride polymorphs prepared by cryo-milling. Eur. J. Pharm. Biopharm. 2008; 68, (3): 771-780.

[198] Hu, Y.; Macfhionnghaile, P.; Caron, V.; Tajber, L.; Healy, A. M.; Erxleben, A.; McArdle, P., Formation, Physical Stability, and Quantification of Process-Induced Disorder in Cryomilled Samples of a Model Polymorphic Drug. J. Pharm. Sci. 2013; 102, (1): 93-103.

[199] Aljohani, M.; MacFhionnghaile, P.; McArdle, P.; Erxleben, A., Investigation of the formation of drug-drug cocrystals and coamorphous systems of the antidiabetic drug gliclazide. Int. J. Pharm 2019; 561: 35-42.

[200] Sheth, A. R.; Lubach, J. W.; Munson, E. J.; Muller, F. X.; Grant, D. J. W., Mechanochromism of Piroxicam Accompanied by Intermolecular Proton Transfer Probed by Spectroscopic Methods and Solid-Phase Changes. J. Am. Chem. Soc. 2005; 127, (18): 6641-6651.

[201] Kaminski, K.; Adrjanowicz, K.; Wojnarowska, Z.; Grzybowska, K.; Hawelek, L.; Paluch, M.; Zakowiecki, D.; Mazgalski, J., Molecular Dynamics of the Cryomilled Base and Hydrochloride Ziprasidones by Means of Dielectric Spectroscopy. J. Pharm. Sci. 2011; 100, (7): 2642-2657.

[202] Kaminska, E.; Adrjanowicz, K.; Kaminski, K.; Wlodarczyk, P.; Hawelek, L.; Kolodziejczyk, K.; Tarnacka, M.; Zakowiecki, D.; Kaczmarczyk-Sedlak, I.; Pilch, J.; Paluch, M., A New Way of Stabilization of Furosemide upon Cryogenic Grinding by Using Acylated Saccharides Matrices. The Role of Hydrogen Bonds in Decomposition Mechanism. Molecular Pharmaceutics 2013; 10, (5): 1824-1835.

[203] Adrjanowicz, K.; Kaminski, K.; Grzybowska, K.; Hawelek, L.; Paluch, M.; Gruszka, I.; Zakowiecki, D.; Sawicki, W.; Lepek, P.; Kamysz, W.; Guzik, L., Effect of Cryogrinding on Chemical Stability of the Sparingly Water-Soluble Drug Furosemide. Pharm. Res. 2011; 28, (12): 3220-3236.

[204] Modhave, D.; Laggner, P.; Brunsteiner, M.; Paudel, A., Solid-State Reactivity of MechanoActivated Simvastatin: Atypical Relation to Powder Crystallinity. J. Pharm. Sci. 2019; 108, (10): 32723280. 
[205] Ali, J.; Zgair, A.; Hameed, G. S.; Garnett, M. C.; Roberts, C. J.; Burley, J. C.; Gershkovich, P., Application of biorelevant saliva-based dissolution for optimisation of orally disintegrating formulations of felodipine. Int. J. Pharm 2019; 555: 228-236.

[206] Kaur, N.; Duggirala, N. K.; Thakral, S.; Suryanarayanan, R., Role of Lattice Disorder in WaterMediated Dissociation of Pharmaceutical Cocrystal Systems. Molecular Pharmaceutics 2019; 16, (7): 3167-3177.

[207] Feng, T.; Bates, S.; Carvajal, M. T., Toward understanding the evolution of griseofulvin crystal structure to a mesophase after cryogenic milling. Int. J. Pharm 2009; 367, (1): 16-19.

[208] Haward, M., Plastic pollution of the world's seas and oceans as a contemporary challenge in ocean governance. Nat. Commun. 2018; 9, (1): 667.

[209] Trotter, B.; Ramsperger, A. F. R. M.; Raab, P.; Haberstroh, J.; Laforsch, C., Plastic waste interferes with chemical communication in aquatic ecosystems. Sci. Rep. 2019; 9, (1): 5889.

[210] Thompson, R. C.; Moore, C. J.; vom Saal, F. S.; Swan, S. H., Plastics, the environment and human health: current consensus and future trends. Philosophical Transactions of the Royal Society B: Biological Sciences 2009; 364, (1526): 2153-2166.

[211] Smith, A. P.; Ade, H.; Koch, C. C.; Spontak, R. J., Cryogenic mechanical alloying as an alternative strategy for the recycling of tires. Polymer 2001; 42, (9): 4453-4457.

[212] Gente, V.; La Marca, F.; Lucci, F.; Massacci, P.; Pani, E., Cryo-comminution of plastic waste. Waste Management 2004; 24, (7): 663-672.

[213] Jonna, S.; Lyons, J., Processing and properties of cryogenically milled post-consumer mixed plastic waste. Polymer Testing 2005; 24, (4): 428-434.

[214] Nekouei, R. K.; Pahlevani, F.; Rajarao, R.; Golmohammadzadeh, R.; Sahajwalla, V., Direct transformation of waste printed circuit boards to nano-structured powders through mechanical alloying. Materials \& Design 2018; 141: 26-36.

[215] Fabián, M.; Tyuliev, G.; Feldhoff, A.; Kostova, N.; Kollár, P.; Suzuki, S.; Saito, F.; Šepelák, V., One-step synthesis of nanocrystalline ZnO via cryomilling. Powder Technol. 2013; 235, (0): 395-399.

[216] Floriano, R.; Deledda, S.; Hauback, B. C.; Leiva, D. R.; Botta, W. J., Iron and niobium based additives in magnesium hydride: Microstructure and hydrogen storage properties. Int. J. Hydrogen Energ. 2017; 42, (10): 6810-6819.

[217] Kanakkillam, S. S.; Shaji, S.; Krishnan, B.; Vazquez-Rodriguez, S.; Martinez, J. A. A.; Palma, M. I. M.; Avellaneda, D. A., Nanoflakes of zinc oxide:cobalt oxide composites by pulsed laser fragmentation for visible light photocatalysis. Appl. Surf. Sci. 2020; 501: 144223. 
[218] Sormunen, H.; Ruponen, M.; Laitinen, R., The effect of co-amorphization of glibenclamide on its dissolution properties and permeability through an MDCKII-MDR1 cell layer. Int. J. Pharm 2019; 570: 118653.

[219] Wojnarowska, Z.; Grzybowska, K.; Adrjanowicz, K.; Kaminski, K.; Paluch, M.; Hawelek, L.; Wrzalik, R.; Dulski, M.; Sawicki, W.; Mazgalski, J.; Tukalska, A.; Bieg, T., Study of the Amorphous Glibenclamide Drug: Analysis of the Molecular Dynamics of Quenched and Cryomilled Material. Molecular Pharmaceutics 2010; 7, (5): 1692-1707.

[220] Adrjanowicz, K.; Grzybowska, K.; Kaminski, K.; Hawelek, L.; Paluch, M.; Zakowiecki, D., Comprehensive studies on physical and chemical stability in liquid and glassy states of telmisartan (TEL): solubility advantages given by cryomilled and quenched material. Philosophical Magazine 2011; 91, (13-15): 1926-1948.

[221] Romanini, M.; Lorente, M.; Schammé, B.; Delbreilh, L.; Dupray, V.; Coquerel, G.; Tamarit, J. L.; Macovez, R., Enhancement of the Physical and Chemical Stability of Amorphous Drug-Polymer Mixtures via Cryogenic Comilling. Macromolecules 2018; 51, (22): 9382-9392.

[222] Stranz, M.; Köster, U., Irreversible structural changes in cryogenic mechanically milled isotactic polypropylene. Colloid Polym Sci 2004; 282, (4): 381-386.

[223] Liang, S. B.; Hu, D. P.; Zhu, C.; Yu, A. B., Production of Fine Polymer Powder under Cryogenic Conditions. Chemical Engineering \& Technology 2002; 25, (4): 401-405.

[224] Smith, A. P.; Spontak, R. J.; Koch, C. C.; Smith, S. D.; Ade, H., Temperature-induced morphological evolution in polymer blends produced by cryogenic mechanical alloying. Macromolecular Materials and Engineering 2000; 274, (1): 1-12.

[225] Ramesh, S.; Lungaro, L.; Tsikritsis, D.; Weflen, E.; Rivero, I. V.; Elfick, A. P. D., Fabrication and evaluation of poly(lactic acid), chitosan, and tricalcium phosphate biocomposites for guided bone regeneration. J. Appl. Polym. Sci. 2018; 135, (39): 46692.

[226] Shakhtshneider, T. P.; Danède, F.; Capet, F.; Willart, J. F.; Descamps, M.; Myz, S. A.; Boldyreva, E. V.; Boldyrev, V. V., Grinding of drugs with pharmaceutical excipients at cryogenic temperatures. J. Therm. Anal. Calorim. 2007; 89, (3): 699-707.

[227] Shakhtshneider, T. P.; Danède, F.; Capet, F.; Willart, J. F.; Descamps, M.; Paccou, L.; Surov, E. V.; Boldyreva, E. V.; Boldyrev, V. V., Grinding of drugs with pharmaceutical excipients at cryogenic temperatures. J. Therm. Anal. Calorim. 2007; 89, (3): 709-715.

[228] Smith, A. P.; Harald, A.; Koch, C. C.; Smith, S. D.; Spontak, R. J., Addition of a block copolymer to polymer blends produced by cryogenic mechanical alloying. Macromolecules 2000; 33, (4): 11631172. 
[229] Allaf, R. M.; Albarahmieh, E. a.; AlHamarneh, B. M., Solid-state compounding of immiscible PCL-PEO blend powders for molding processes. J. Mech. Behav. Biomed. Mater. 2019; 97: 198-211.

[230] Laçin, Ö.; Kwiczak-Yiğitbaşı, J.; Erkan, M.; Cevher, Ş. C.; Baytekin, B., The morphological changes upon cryomilling of cellulose and concurrent generation of mechanoradicals. Polym. Degrad. Stabil. 2019; 168: 108945.

[231] Bas, O.; Hanßke, F.; Lim, J.; Ravichandran, A.; Kemnitz, E.; Teoh, S.-H.; Hutmacher, D. W.; Börner, H. G., Tuning mechanical reinforcement and bioactivity of 3D printed ternary nanocomposites by interfacial peptide-polymer conjugates. Biofabrication 2019; 11, (3): 035028.

[232] Lim, J.; Chong, M. S. K.; Chan, J. K. Y.; Teoh, S.-H., Polymer Powder Processing of Cryomilled Polycaprolactone for Solvent-Free Generation of Homogeneous Bioactive Tissue Engineering Scaffolds. Small 2014; 10, (12): 2495-2502.

[233] Dedroog, S.; Huygens, C.; Van den Mooter, G., Chemically identical but physically different: A comparison of spray drying, hot melt extrusion and cryo-milling for the formulation of high drug loaded amorphous solid dispersions of naproxen. Eur. J. Pharm. Biopharm. 2019; 135: 1-12.

[234] Stranz, M.; Köster, U., Structural changes during cryogenic mechanical milling of iPP/sPS blends. J. mater. Sci. 2004; 39, (16): 5275-5277.

[235] Smith, A. P.; Ade, H.; Smith, S. D.; Koch, C. C.; Spontak, R. J., Anomalous phase inversion in polymer blends prepared by cryogenic mechanical alloying [2]. Macromolecules 2001; 34, (6): 15361538.

[236] Smith, A. P.; Spontak, R. J.; Koch, C. C.; Ade, H., X-ray microscopy of rubber modified poly(methyl methacrylate) blends produced by cryogenic mechanical alloying. AIP Conf. Proc. 2000; 507, (1): 60-65.

[237] Smith, A. P.; Ade, H.; Balik, C. M.; Koch, C. C.; Smith, S. D.; Spontak, R. J., Cryogenic Mechanical Alloying of Poly(methyl methacrylate) with Polyisoprene and Poly(ethylene-altpropylene). Macromolecules 2000; 33, (7): 2595-2604.

[238] Jonnalagadda, J. B.; Rivero, I. V., Effect of cryomilling times on the resultant properties of porous biodegradable poly(e-caprolactone)/poly(glycolic acid) scaffolds for articular cartilage tissue engineering. J. Mech. Behav. Biomed. Mater. 2014; 40: 33-41.

[239] Zhu, Y. G.; Li, Z. Q.; Zhang, D.; Tanimoto, T., Effect of cryomilling on the thermal behaviors of poly(ethylene terephthalate). J. Appl. Polym. Sci. 2006; 99, (6): 2868-2873.

[240] Zhu, Y. G.; Li, Z. Q.; Zhang, D.; Tanimoto, T., Abs/iron nanocomposites prepared by cryomilling. J. Appl. Polym. Sci. 2006; 99, (2): 501-505. 
[241] Zhu, Y. G.; Li, Z. Q.; Zhang, D.; Tanimoto, T., PET/SiO2 nanocomposites prepared by cryomilling. J. Polym. Sci., Part B: Polym. Phys. 2006; 44, (8): 1161-1167.

[242] Zhu, Y.-G.; Li, Z.-Q.; Zhang, D.; Tanimoto, T., Thermal behaviors of poly(ethylene terephthalate)/SiO2 nanocomposites prepared by cryomilling. J. Polym. Sci., Part B: Polym. Phys. 2006; 44, (9): 1351-1356.

[243] Pietrzykowska, E.; Mukhovskyi, R.; Chodara, A.; Wojnarowicz, J.; Koltsov, I.; Chudoba, T.; Łojkowski, W., Composites of polylactide and nano-hydroxyapatite created by cryomilling and warm isostatic pressing for bone implants applications. Materials Letters 2019; 236: 625-628.

[244] Anesh, M. P.; Gulrez, S. K. H.; Anis, A.; Shaikh, H.; Ali Mohsin, M. E.; AL-Zahrani, S. M., Developments in Eu+2-Doped Strontium Aluminate and Polymer/Strontium Aluminate Composite. Polym. Adv. Technol. 2014; 33, (S1).

[245] Woo, D. J.; Hooper, J. P.; Osswald, S.; Bottolfson, B. A.; Brewer, L. N., Low temperature synthesis of carbon nanotube-reinforced aluminum metal composite powders using cryogenic milling. J. Mater. Res. 2014; 29, (22): 2644-2656.

[246] Tang, F.; Liao, C. P.; Ahn, B.; Nutt, S. R.; Schoenung, J. M., Thermal stability in nanostructured Al-5083/SiCp composites fabricated by cryomilling. Powder Metallurgy 2007; 50, (4): 307-312.

[247] An, Y.; Yang, S.; Zhao, E.; Wang, Z.; Wu, H., Fabrication of aluminum foam reinforced by graphene nanoflakes. Materials Letters 2018; 212: 4-7.

[248] Li, J. L.; Xiong, Y. C.; Wang, X. D.; Yan, S. J.; Yang, C.; He, W. W.; Chen, J. Z.; Wang, S. Q.; Zhang, X. Y.; Dai, S. L., Microstructure and tensile properties of bulk nanostructured aluminum/graphene composites prepared via cryomilling. Mater. Sci. Eng. A. 2015; 626: 400-405.

[249] Gandha, K.; Ouyang, G.; Gupta, S.; Kunc, V.; Parans Paranthaman, M.; Nlebedim, I. C., Recycling of additively printed rare-earth bonded magnets. Waste Management 2019; 90: 94-99.

[250] Zhu, Y.; Li, Z.; Zhang, D., Electromagnetic nanocomposites prepared by cryomilling of polyaniline and Fe nanoparticles. J. Polym. Sci., Part B: Polym. Phys. 2008; 46, (15): 1571-1576.

[251] Zhang, F.; Liu, Y.; Li, J.; Wang, R., Ultrafine nanocrystalline NdFeB prepared by cryomilling with HDDR process. J. Alloys Compd. 2018; 750: 401-408.

[252] An, X.; Jin, K.; Abbas, N.; Fang, Q.; Wang, F.; Du, J.; Xia, W.; Yan, A.; Liu, J. P.; Zhang, J., High anisotropic NdFeB submicro/nanoflakes prepared by surfactant-assisted ball milling at low temperature. J. Magn. Magn. Mater. 2017; 442: 279-287.

[253] Picas, J. A.; Forn, A.; Ajdelsztajn, L.; Schoenung, J., Nanocrystalline NiCrAlY powder synthesis by mechanical cryomilling. Powder Technol. 2004; 148, (1): 20-23. 
[254] Khodsiani, Z.; Mansuri, H.; Mirian, T., The effect of cryomilling on the morphology and particle size distribution of the NiCoCrAlYSi powders with and without nano-sized alumina. Powder Technol. 2013; 245: 7-12.

[255] Rama Rao, N. V.; Gabay, A. M.; Li, W. F.; Hadjipanayis, G. C., Nanostructured bulk MnBi magnets fabricated by hot compaction of cryomilled powders. J. Phys. D 2013; 46, (26): 265001.

[256] Øygarden, V.; Rial, J.; Bollero, A.; Deledda, S., Phase-pure t-MnAIC produced by mechanical alloying and a one-step annealing route. J. Alloys Compd. 2019; 779: 776-783.

[257] Marshall, L. G.; McDonald, I. J.; Lewis, L. H., Quantification of the strain-induced promotion of t-MnAl via cryogenic milling. J. Magn. Magn. Mater. 2016; 404: 215-220.

[258] Hernandez, J. S. T.; Maccari, F.; Marshall, L. G.; Tabares, J. A.; Alcázar, G. A. P., Exchange Coupling in MnAIC/ $\alpha-F e$ Nanocomposite Magnets. J. Supercond. Nov. Magn. 2018; 31, (12): 39413947.

[259] Fang, H.; Cedervall, J.; Hedlund, D.; Shafeie, S.; Deledda, S.; Olsson, F.; Von Fieandt, L.; Bednarcik, J.; Svedlindh, P.; Gunnarsson, K.; Sahlberg, M., Structural, microstructural and magnetic evolution in cryo milled carbon doped MnAl. Sci. Rep. 2018; 8, (1).

[260] Guzik, M. N.; Golasiński, K. M.; Pedrosa, F. J.; Jenuš, P.; Bollero, A.; Hauback, B. C.; Deledda, $\mathrm{S}$., Influence of ultra-short cryomilling on the microstructural and magnetic properties of cobalt ferrite. J. Alloys Compd. 2017; 721: 440-448.

[261] Jiang, Y.; Jiang, L., Synthesis of $\gamma^{\prime}-F e 4 N$ powder in liquid nitrogen. AlP Advances 2019; 9, (3): 035215.

[262] Dias, G. S.; Volnistem, E. A.; Leonardo, J. M. P.; Silva, D. M.; Cótica, L. F.; Santos, I. A.; Garcia, D., On the unusual magnetic response of cryomilled BiFeO3 polycrystals. Ferroelectrics 2018; 534, (1): 146-151.

[263] Bednarcik, J.; Saksl, K.; Nicula, R.; Roth, S.; Franz, H., Influence of cryomilling on structure of CoFeZrB alloy. J. Non-Cryst. Solids 2008; 354, (47): 5117-5119.

[264] Ghobrial, S.; Kirk, D. W.; Thorpe, S. J., Amorphous Ni-Nb-Y Alloys as Hydrogen Evolution Electrocatalysts. Electrocatalysis 2019; 10, (3): 243-252.

[265] Balasubramanian, S.; Gupta, M. K.; Singh, K. K., Cryogenics and its Application with Reference to Spice Grinding: A Review. Crit. Rev. Food Sci. 2012; 52, (9): 781-794.

[266] Russo, J. R., Cryogenic grinding 'carousel' material handling. Food Eng. Int. 1976; 1, (8): 3335. 
[267] Wolf, T.; Pahl, M. H., Cold grinding of caraway seeds in impact mill. ZFL 1990; 41, (10): 596604.

[268] Li, S.; Ge, S.; Huang, Z.; Wang, Q.; Zhao, H.; Pan, H., Cryogenic grinding technology for traditional Chinese herbal medicine. Cryogenics 1991; 31, (2): 136-137.

[269] Singh, K. K.; Goswami, T. K., Design of a cryogenic grinding system for spices. J. Food Eng. 1999; 39, (4): 359-368.

[270] Singh, S. S.; Ghodki, B. M.; Goswami, T. K., Effect of grinding methods on powder quality of king chilli. J. Food Meas. Charat. 2018; 12, (3): 1686-1694.

[271] PESEK, C. A.; WILSON, L. A., Spice Quality: Effect of Cryogenic and Ambient Grinding on Color. Journal of Food Science 1986; 51, (5): 1386-1386.

[272] Singh, K. K.; Goswami, T. K., Studies on cryogenic grinding of cumin seed. J. Food Process Eng. 1999; 22, (3): 175-190.

[273] Sharma, L. K.; Agarwal, D.; Rathore, S. S.; Malhotra, S. K.; Saxena, S. N., Effect of cryogenic grinding on volatile and fatty oil constituents of cumin (Cuminum cyminum L.) genotypes. J. Food Sci. Technol. 2016; 53, (6): 2827-2834.

[274] Manohar, B.; Sridhar, B. S., Size and shape characterization of conventionally and cryogenically ground turmeric (Curcuma domestica) particles. Powder Technol. 2001; 120, (3): 292297.

[275] Sridhar, B. S.; Sommer, K., Fracture Behavior of Turmeric (Curcuma Longa) under Ambient and Cryogenic Conditions. J. Food Process Eng. 2013; 36, (5): 645-655.

[276] Singh, K. K.; Goswami, T. K., CRYOGENIC GRINDING of CLOVES. J. Food Process. Preserv. 2000; 24, (1): 57-71.

[277] Murthy, C. T.; Bhattacharya, S., Cryogenic grinding of black pepper. J. Food Eng. 2008; 85, (1): 18-28.

[278] Meghwal, M.; Goswami, T. K., Ambient and Cryogenic Grinding of Fenugreek and Flow Characterization of Its Powder. J. Food Process Eng. 2013; 36, (4): 548-557.

[279] Meghwal, M.; Goswami, T. K., Evaluation of size reduction and power requirement in ambient and cryogenically ground fenugreek powder. Adv. Powder Technol. 2013; 24, (1): 427-435. 
[280] Barnwal, P.; Singh, K. K.; Mohite, A.; Sharma, A.; Saxena, S. N., Influence of Cryogenic and Ambient Grinding on Grinding Characteristics of Fenugreek Powder: A Comparative Study. J. Food Process. Preserv. 2015; 39, (6): 1243-1250.

[281] Meghwal, M.; Goswami, T. K., Comparative study on ambient and cryogenic grinding of fenugreek and black pepper seeds using rotor, ball, hammer and Pin mill. Powder Technol. 2014; 267: 245-255.

[282] Saxena, S. N.; Sharma, Y. K.; Rathore, S. S.; Singh, K. K.; Barnwal, P.; Saxena, R.; Upadhyaya, P.; Anwer, M. M., Effect of cryogenic grinding on volatile oil, oleoresin content and anti-oxidant properties of coriander (Coriandrum sativum L.) genotypes. J. Food Sci. Technol. 2015; 52, (1): 568573.

[283] Ghodki, B. M.; Goswami, T. K., Optimization of Cryogenic Grinding Process for Cassia (Cinnamomum loureirii Nees L.). J. Food Process Eng. 2016; 39, (6): 659-675.

[284] Ghodki, B. M.; Goswami, T. K., Thermal and Mechanical Properties of Black Pepper at Different Temperatures. J. Food Process Eng. 2017; 40, (1): e12342.

[285] Ghodki, B. M.; Goswami, T. K., DEM simulation of flow of black pepper seeds in cryogenic grinding system. J. Food Eng. 2017; 196: 36-51.

[286] Ghodki, B. M.; Charith Kumar, K.; Goswami, T. K., Modeling breakage and motion of black pepper seeds in cryogenic mill. Adv. Powder Technol. 2018; 29, (Powder Technol. 267 2014): 10551071.

[287] Saxena, V.; Patel, B. B.; Sutar, R. F.; Joshi, D. C., Improving quality of cumin powder through cryogenic grinding technology. J. Food Process. Preserv. 2018; 42, (1): e13371.

[288] Kaur, B.; Srivastav, P. P., Effect of Cryogenic grinding on chemical and morphological characteristics of mango (Mangifera indica L.) peel powder. J. Food Process. Preserv. 2018; 42, (4).

[289] Salieri, B.; Turner, D. A.; Nowack, B.; Hischier, R., Life cycle assessment of manufactured nanomaterials: Where are we? Nanolmpact 2018; 10: 108-120.

[290] Arvidsson, R., Life Cycle Assessment and Risk Assessment of Manufactured Nanomaterials. In Nanoengineering: Global Approaches to Health and Safety Issues, 2015; pp 225-256.

[291] Kerdsuwan, S.; Laohalidanond, K.; Jangsawang, W., Sustainable Development and Ecofriendly Waste Disposal Technology for the Local Community. Energy Procedia 2015; 79: 119-124.

[292] Ajitha, B.; Reddy, Y. A. K.; Reddy, P. S., Biosynthesis of silver nanoparticles using Momordica charantia leaf broth: Evaluation of their innate antimicrobial and catalytic activities. J. Photoch.

Photobio. B 2015; 146: 1-9. 
[293] Haase, A.; Tentschert, J.; Jungnickel, H.; Graf, P.; Mantion, A.; Draude, F.; Plendl, J.; Goetz, M. E.; Galla, S.; Mašić, A.; Thuenemann, A. F.; Taubert, A.; Arlinghaus, H. F.; Luch, A., Toxicity of silver nanoparticles in human macrophages: uptake, intracellular distribution and cellular responses. J. Phys. Conf. 2011; 304: 012030.

[294] Ashby, M. F.; Ferreira, P. J.; Schodek, D. L., Chapter 1 - Nanomaterials and Nanotechnologies: An Overview. In Nanomaterials, Nanotechnologies and Design, Ashby, M. F.; Ferreira, P. J.; Schodek, D. L., Eds. Butterworth-Heinemann: Boston, 2009; pp 1-16.

[295] Carabineiro, S. A. C., Applications of gold nanoparticles in nanomedicine: Recent advances in vaccines. Molecules 2017; 22, (5).

[296] Ghasemzadeh, G.; Momenpour, M.; Omidi, F.; Hosseini, M. R.; Ahani, M.; Barzegari, A., Applications of nanomaterials in water treatment and environmental remediation. Frontiers of Environmental Science \& Engineering 2014; 8, (4): 471-482. 